\title{
Gender as a Factor in the Response of the Law- Enforcement System to Violence Against Partners ${ }^{1}$
}

\author{
by Grant A. Brown, D.Phil. (Oxon), LL.B. \\ ....it is the worst oppression, that is done by colour of justice \\ - Sir Edward Coke ${ }^{2}$ \\ A sign that says "men only" looks very different \\ on a bathroom door than on a courthouse door. \\ - U.S. Supreme Court Justice Thurgood Marshall ${ }^{3}$

\begin{abstract}
"Is Parkinson's the toughest opponent you've ever faced, Muhammed?" someone asked. "Toughest was my first wife," he said.

- Former World Heavyweight Boxing Champion Muhammed Ali ${ }^{4}$
\end{abstract}

\begin{abstract}
A great deal of sociological evidence has been collected in the past three decades on the prevalence of abuse among adult heterosexual partners in domestic relationships of some degree of permanence. Partly as a result of this information, partner abuse has been identified as an important social ill that must be addressed aggressively through public-awareness campaigns, the funding of a broad range of support services, and the re-training of law-enforcement authorities including police, prosecutors, and judges. However, in at least one important respect, these manifestations of public concern diverge substantially from what the sociological data which ostensibly motivates public policy in this area would indicate: they have been, to date, overwhelmingly gender specific. That is, partner abuse is routinely portrayed and acted upon as though it were almost exclusively about men abusing and victimizing innocent women and, by extention, their children - despite the overwhelming sociological evidence that a significant amount of abuse is also suffered by male partners. The prevailing orientation to the problem is typically supported by little more than speculative, ideological rationalizations of the sociological evidence, if not outright suppression or denial of that evidence. Genuinely genderinclusive research is needed to test the validity of this orientation, and to determine whether it has had a beneficial or detrimental effect on the administration of justice.
\end{abstract}

\footnotetext{
${ }^{1}$ This report is written for a general audience and does not presume any specialized training in sociology, statistics, or Canadian law. Technical terms will be explained in the footnotes when they are first used; however, a few nonstandard terms of art must be explained at the start. The focus of this study is on how the law-enforcement system deals with putatively criminal acts between adults in heterosexual relationships of some degree of permanence. Thus the term 'partner' includes married and common-law spouses, as well as some couples who might not meet the legal definition of a spouse; but it excludes persons in dating or homosexual relationships. Because of the focus on criminal behaviour, as opposed to abuse more generally, the terms 'partner violence' or 'violence against partners' is meant to capture any act which could be classified as criminal, whether or not charges were laid and even if the act is not inherently violent (e.g. a non-violent breach of a restraining order). 'Partner abuse' is a broader term which includes partner violence as well as non-criminal abusive behaviour between partners. ('Domestic abuse' is broader still, and includes abuse of children, elders, and siblings. This is beyond the scope of the present study.)

${ }^{2}$ The Institutes of the Laws of England, vol. 2, 1628-1641.

${ }^{3}$ City of Cleburne v. Cleburne Living Center, Inc. (1985), 473 U.S. 432, 468-69.

${ }^{4}$ Cam Cole, "Boxing has a funny way of making friends," National Post, 21 October 2002, A10.
} 
Most previous research on gender differences in the way men and women are treated by the law-enforcement system are limited in one of two respects: Either it relies upon public sources of data which are incomplete and impossible to analyse adequately; or else it focuses on only the police or judges, omitting consideration of the role of prosecutors in the disposition of cases. The present study is unique in that it attempts to shed light on the pivotal role of the prosecutor in partner violence cases, while at the same time subjecting the decisions of local police and judges to further examination based on data not so readily available from public sources. Original data for this study were obtained from two previously untapped sources: from databases for the years 1999 and 2000 compiled by the Edmonton Police Service pursuant to provincial legislation aimed at tracking the police response to partner abuse; and from the "spousal abuse" files in the Edmonton Crown Prosecutor's Office for the first half of 2001.

This study tends to confirm that men who are accused of partner violence are treated significantly more harshly than women at every step of the law-enforcement system. Men are found to have been charged much more frequently than women, especially in the minor-injury and no-injury categories, compared to what the sociological evidence would indicate is appropriate - and even compared to what the data collected by the police themselves would indicate is appropriate. This is explained in large part by the fact that police are significantly more likely to find a reason not to lay a charge when only the male partner is injured as opposed to when only the female partner is injured. Consequently, among those who were charged with an offence in a dispute between partners, a higher proportion of women than of men were charged with offences involving injury, and with offences involving the use of a weapon. Yet, despite the fact that the men who were charged caused less injury and were less likely to use a weapon, they were nevertheless charged with more offences per incident, and were more likely to have been taken into custody at the time of the incident, compared to female suspects.

Of those charged, men were more likely than women to have been found guilty, at least in part because the charges against women were more likely to have been withdrawn by the prosecutors. And while men and women were equally likely to have received plea bargains, men were significantly more likely than women to have received a term of jail, a conditional sentence, or probation - i.e. the more serious sentencing options - as a result of their plea bargains. Among those found guilty, women were more likely than men to have been intoxicated, to have used a major weapon, to have inflicted a serious injury, to have been separated from their partners at the time of the incident, and to have committed their offence while children were present - all factors supposedly tending to lead to harsher sentences. Guilty men, on the other hand, had longer prior criminal records than guilty women; but they were also more likely to have served time in custody prior to trial. Yet, despite all of this, guilty men were significantly more likely than guilty women to have received a term of jail, a conditional sentence, or probation. Regression analyses reveal that harsher sentencing outcomes were generally more highly associated with being male than with any other factor. The disparities found in this study are cumulative: despite having been treated more harshly at all earlier stages, men on average continued to be treated more harshly at all later stages. 


\section{Introduction and Background}

\section{General Introduction}

While most of the findings of this study are capable of standing on their own, it is nevertheless worthwhile to place them within a broader context of surveys of partner abuse for three reasons. First, to the degree that the profile of the data for the present study matches the profile of nationally or internationally representative data, one can be confident in the validity of the data on which this study is based. Second, one can likewise be confident in extrapolating the results of this study to other jurisdictions where similar data-profiles and similar laws exist - i.e. to other large urban centres in Canada, and possibly in the United States and in Britain as well. Third, comparing the data of the present study with external data can help to put a better estimate on the magnitude of some of the findings in this study. The multitude of different methodologies used to measure various aspects of partner abuse means that comparisons between one set of data and others is fraught with complications (Archer 2000). For this reason, even the context for the present study must be contextualized: the external Canadian data on partner abuse must be interpreted in some cases in light of a broad range of international studies.

Two fundamental distinctions must be borne in mind with respect to survey methodology in this area of research. The first distinction is between "all-act" and "criminal-act" surveys. Allact surveys attempt to measure partner abuse generally, whereas criminal-act surveys attempt to measure the narrower and typically more serious category of partner violence (see footnote 1). The second distinction is between surveys whose data is derived from peoples' experiences of partner abuse as reported to research interviewers, and surveys whose data is derived from incidents reported to police (or other social agencies). Interview-derived data typically reveal the numbers and proportions of male and female persons who report having experienced abuse by a partner, while social-agency-derived data reveal the numbers and proportions of incidents of partner abuse that are reported to the agency by men and women. The victimization rates will diverge between these two reporting methods whenever the frequency of victimization is significantly associated with gender. For example, if the same number of men and women report having been the victim of partner abuse, but women report having been victimized twice as frequently, on average, then women will comprise two-thirds rather than one-half of the incidents of partner abuse. Failure to attend to the method of reporting data can lead to significant misinterpretations. Still, each survey method and each data-reporting method reveals important information which is valid for different purposes (Straus 1999).

The strength of interviewer-based surveys is that they are capable of identifying abuse which has not been reported to police or other social agencies. They therefore tend to avoid the selection biases inherent in data from those sources. On the other hand, these surveys are more prone to both sampling and non-sampling error (Ogrodnik and Trainor 1997: 8). Sampling error arises mainly due to the limited number of persons interviewed as compared to the volume of incidents reported to police. Non-sampling error arises from the effects of memory and other individual reactions to the interviewers' questioning. That is why interviewer-based surveys tend to be more sensitive to the wording of the questions that are asked, and even to interviewer technique (Pottie Bunge and Locke 2000: 9). 
It is important to appreciate the potential significance of non-sampling error with interview-derived data. One measure of the extent of non-sampling error is obtained from studies which ask both partners in a relationship about their experiences with partner abuse, both as victims and as perpetrators. Browning and Dutton (1986), working with a sample of couples from Vancouver, and Brinkerhoff and Lupri (1998), working with a random sample of 562 couples from Calgary, found significant differences in the reports of men and women as to the number and types of acts of abuse that had taken place in the relationship. Sommer (1994), in a follow-up to a previous study on a random sample of 1,257 Winnipeg couples (Sommer, Barnes and Murray 1992), found that $18 \%$ of the men and $25 \%$ of the women denied committing aggressive acts which they had admitting to previously. Not surprisingly, both men and women tend to under-report their own perpetration of partner abuse, though men tend to under-report this to a greater degree than women.

Perhaps more surprisingly, however, men and women also tend to significantly underreport their own victimization. Szinovacz and Egley (1995: 1002) found that women underreport their own injuries by $43 \%$, while men under-report their own injuries by fully $93 \%$. (This finding is consistent with the finding, presented below, that men are only half as likely as women to report their victimization to the police, too.) Since self-reports of victimization tend to be more reliable than self-reports of perpetration, and since most studies of partner abuse rely upon the self-reports of victimization, the fact that men may be as much as twice as likely to under-report their own victimization as compared to women may be significant.

There are a number of reasons why men might tend to under-report their own victimization relative to women. The first is that much of the partner abuse men suffer is unlikely to be conceptualized by them as abuse in the first instance. Terms like 'battered husband' or 'husband abuse' are not so readily available to men who are its victims as the parallel terms 'battered wife' and 'abused wife' are to women. (By comparison, being hit in the genitals is not conceptualized by most people as sexual assault when it happens to men; indeed, this is regularly played for laughs on prime-time television.) Second, men may be much less self-aware of the injuries they suffer at the hands of their partners, because men are intensely socialized from a very young age to suppress their fears, their pain, and their suffering. Third, men's memories of their victimization are less likely to be as vivid as women's. This is in part because of the preceding two points, but it is also because men tend to be less seriously injured by and less fearful of their partners (Straus 1999). Finally, a greater social stigma attaches to men who are abused by their partners than to women who are abused by their partners, which would lead men to be more circumspect in admitting their victimization or making much out of it.

The most comprehensive list of publications on the sociological surveys of partner abuse is Fiebert's (1997) annotated bibliography. ${ }^{5}$ The majority of the studies listed in this source are interview-derived, all-act surveys, which fairly consistently get the result that as many women as men commit acts of abuse toward their partners. More specifically: in about a quarter of the cases, the abuse is committed by the woman only; in another quarter of the cases, the abuse is committed by the man only; and in the remaining half of the cases the abuse is mutual. Brinkerhoff and Lupri (1998), a typical Canadian study, found that $37.5 \%$ of partner abuse was mutual, $27.3 \%$ was committed by the man only, and $35.0 \%$ was committed by the woman only.

\footnotetext{
A frequently up-dated version of this important resource is available on the World Wide Web at
} http://www.csulb.edu/ mfiebert/assault.htm and now references over 100 such studies. 
Two Alberta studies in the 1980s broadly replicated this result (see the All-Alberta Survey referenced in footnote 11 below; and Bland and Orn 1986). ${ }^{6}$ This is the basis on which claims are sometimes made about the "equal perpetration" rates of partner abuse between men and women. However, these overall, person-based results fail to take into account two significant factors which tend to minimize the extent of female victimization. First, since they use the person-based method of reporting results, they fail to take into account differences in the frequency of victimization of women and men. Second, because they are all-act survey results, they fail to take into account differences in the severity of abuse suffered by women and men. The "equal perpetration" rates found are therefore importantly misleading.

Some of the surveys listed in Fiebert's (1997) bibliography take the frequency and seriousness of victimization into account. These studies tend to show that women suffer abuse more frequently than men do, especially of the more-serious kinds of violence that leads to injuries. A small minority of these representative surveys, notably surveys of criminal acts, filter out to one degree or another abusive acts that tend to produce less physical injury. The latter find both lower victimization rates overall, and also lower percentages of male victims, than the allact surveys. Sommer (1994) found that $60 \%$ of those injured in her Winnipeg sample were women. The lone meta-analysis of international partner-abuse surveys published to date found that, overall, women were injured in $65 \%$ of those incidents of partner violence that produce injuries (Archer 2000). It is bears repeating, however, that the vast majority of partnerships featuring violence do not produce injuries and do not escalate. Johnson (1995) states that " $94 \%$ of perpetrators of minor violence do not go on to severe violence."

When statistics on partner abuse began to be gathered in the 1970s, it was thought that most of the abusive acts by women might be in self defence. ${ }^{7}$ Even then, however, in fully a quarter of the cases, only the woman had committed the actions. Since at least some cases of mutual abuse would also have been initiated by the woman, it was already clear that female-only abuse and female-instigated mutual abuse might constitute at least a considerable minority of the total incidents. Since 1985, many surveys have asked respondents reporting mutual abuse which partner was the initiator of the abuse, and they consistently report that about half the time it is the woman (Straus 1993; Bland and Orn 1986). Further, some studies have directly asked about selfdefence, with the typical result that (a) $20 \%$ or less of the abuse was committed for that reason, and (b) roughly equal proportions of men's and women's abuse is committed in self-defence (Follingstad et al 1991; Sommer 1994; and DeKeseredy et al 1997, who refrained from reporting on self-defence by males).

One deficiency in all of the surveys of partner abuse is that self-inflicted violence is not considered. Persons who are driven to suicide or some lesser form of self-destructive behaviour as a result of abusive partners are therefore not captured by these data. It is known, however, that men are much more likely to commit suicide and other self-destructive acts in general.

\footnotetext{
${ }^{6}$ Tutty (1999: 8) claims that these results might be a product of the fact that men under-report their aggressiveness. However, most of these studies ask about victimization as well as perpetration of violence. Consequently, one can make comparisons regarding rates of initiation and overall abuse between the genders by looking solely at women's answers on the surveys. And when that is done, as Straus $(1993,1999)$ and others have been reporting for the past 13 years, it is still found that roughly the same number of men and women initiate abuse in their relationships.

${ }^{7}$ In fact, this argument is still being urged by some researchers. See, e.g., Tutty (1999: 10).
} 


\section{Canadian Sources of Data - The 1999 GSS}

Criminal victimization surveys are undertaken by Statistics Canada on a cyclical basis. The 1999 General Social Survey (GSS) included a special module to measure partner violence. Its results have been analysed and reported in a variety of publications by the Canadian Centre for Justice Statistics (CCJS). In particular, CCJS publishes an annual volume titled Family Violence in Canada: A Statistical Profile, with a slightly different focus each year. The present study draws upon the three volumes which have been published since the GSS was conducted: Pottie Bunge and Locke (2000), Trainor and Mihorean (2001), and Trainor (2002).

The GSS is an interview-derived, criminal-act survey, with two important peculiarities that should be noted. First, the raw numbers from the survey are never reported by CCJS; instead, results of the survey are reported in the form of projections to the entire Canadian population. While this reporting method helps to give perspective to the extent of the problem of partner violence in Canada, it also makes it difficult to analyse the data in ways not explicitly reported in CCJS publications. Second, the GSS is perhaps unique in asking respondents about their experiences of victimization by over the most recent 5-year period (i.e. from 1995 to 1999), as well as in the most-recent 12-month period. The advantage of asking respondents about their experiences with partner violence in a relatively short, immediate period such as 12 months is that it reduces the scope for non-sampling error to arise by asking about events that are still relatively fresh in the respondents' minds. The disadvantage of this survey method is that it requires a larger sample size in order to obtain enough observations to produce statistically significant results. Although the GSS is based on a nationally representative sample of 25,876 persons aged 15 years and older, even a survey of this size is apparently insufficient to produce statistically significant results for a fine-grained analysis of the 12-month data. In any case, very little reporting and analysis of the 12-month data is provided in CCJS publications.

The rationale behind limiting respondents to their experience of partner violence in the immediately preceding 5-year period is presumably to reduce non-sampling error in the survey, while still obtaining enough observations to produce statistically significant results. In particular, the effect of forgetting or misremembering events should be less pronounced in a survey restricted to the most recent 5 -year period than in a survey that asks respondents about their lifelong experiences with partner violence. Nevertheless, as will be shown, a fair amount of nonsampling error still arises in the 5-year data from the GSS. In addition, the results of the 1999 GSS are more difficult to compare with the results of most other surveys, which are open-ended, because of the peculiarity of limiting respondents to the most recent 5-year period.

The results of the GSS are broadly consistent with the results of the studies compiled by Fiebert (1997), taking into account the nature of that survey. Table 1.1 breaks these data down for the 12-month reporting period and the 5-year reporting period, as well as for current and previous partners. ${ }^{8}$

\footnotetext{
${ }^{8}$ Tables will always appear on the first page they are mentioned, or if space does not permit, at the top of the next page. Table 1.1 combines information from Pottie Bunge and Locke (2000: 52, Table A6) and Trainor and Mihorean (2001: 38, Table 4.5). All figures reported by Statistics Canada include homosexual partnerships, which comprise fewer than $1 \%$ of the total partnerships surveyed. A 'previous partner' is defined as someone who had been a husband, a wife, or a common-law partner at one point in time, but no longer was one at the time of the survey, and with whom the survey respondent had had contact within the previous 5 years.
} 


\begin{tabular}{|c|c|c|c|c|c|c|c|c|}
\hline \multicolumn{9}{|c|}{$\begin{array}{l}\text { Table } 1.1 \\
\text { Number and percentage of women and men who reported violence by a partner, } \\
\text { preceding } 12 \text { months and preceding } 5 \text { years }\end{array}$} \\
\hline \multirow{3}{*}{$\begin{array}{l}\text { 'n/a' means 'not available' } \\
(\mathrm{N} \times 1,000)\end{array}$} & \multicolumn{4}{|c|}{ preceding 12 months } & \multicolumn{4}{|c|}{ preceding 5 years } \\
\hline & \multicolumn{2}{|c|}{ female victim } & \multicolumn{2}{|c|}{ male victim } & \multicolumn{2}{|c|}{ female victim } & \multicolumn{2}{|c|}{ male victim } \\
\hline & $\begin{array}{l}\text { count } \\
(000 \mathrm{~s})\end{array}$ & $\% \mathrm{~N}$ & $\begin{array}{c}\text { count } \\
(000 \mathrm{~s})\end{array}$ & $\% \mathrm{~N}$ & $\begin{array}{c}\text { count } \\
(000 \mathrm{~s})\end{array}$ & $\% \mathrm{~N}$ & $\begin{array}{l}\text { count } \\
(000 s)\end{array}$ & $\% \mathrm{~N}$ \\
\hline $\begin{array}{l}\text { 1.Violence by current or previous partner } \\
(\mathrm{N}=8356 \text { females; } \mathrm{N}=8346 \text { males })\end{array}$ & 220 & 3 & 177 & 2 & 690 & 8 & 549 & 7 \\
\hline $\begin{array}{l}\text { 2. Violence by current partner } \\
(\mathrm{N}=7310 \text { females; } N=7558 \text { males })\end{array}$ & 120 & 2 & 129 & 2 & 259 & 4 & 303 & 4 \\
\hline $\begin{array}{l}\text { 3. Violence by previous partner } \\
(\mathrm{N}=1554 \text { females; } \mathrm{N}=1205 \text { males })\end{array}$ & 101 & 6 & 48 & 4 & 437 & 28 & 259 & 22 \\
\hline 4. Violence ceased at separation & $\mathrm{n} / \mathrm{a}$ & $\mathrm{n} / \mathrm{a}$ & $\mathrm{n} / \mathrm{a}$ & $\mathrm{n} / \mathrm{a}$ & 264 & 60 & 173 & 67 \\
\hline $\begin{array}{l}\text { 5. Violence after separation } \\
(\mathrm{N}=437 \text { females; } \mathrm{N}=259 \text { males })\end{array}$ & $\mathrm{n} / \mathrm{a}$ & $\mathrm{n} / \mathrm{a}$ & $\mathrm{n} / \mathrm{a}$ & $\mathrm{n} / \mathrm{a}$ & 172 & 39 & 83 & 32 \\
\hline 6. Violence increased & $\mathrm{n} / \mathrm{a}$ & $\mathrm{n} / \mathrm{a}$ & $\mathrm{n} / \mathrm{a}$ & $\mathrm{n} / \mathrm{a}$ & 39 & 22 & 23 & 28 \\
\hline 7. Violence did not increase & $\mathrm{n} / \mathrm{a}$ & $\mathrm{n} / \mathrm{a}$ & $\mathrm{n} / \mathrm{a}$ & $\mathrm{n} / \mathrm{a}$ & 69 & 40 & 25 & 30 \\
\hline $\begin{array}{l}\text { 8. Violence began after separation } \\
(\mathrm{N}=172 \text { females; } N=83 \text { males })\end{array}$ & $\mathrm{n} / \mathrm{a}$ & $\mathrm{n} / \mathrm{a}$ & $\mathrm{n} / \mathrm{a}$ & $\mathrm{n} / \mathrm{a}$ & 63 & 37 & 35 & 42 \\
\hline
\end{tabular}

The GSS found that in the 12-month period preceding the survey, an estimated 3\% of Canadian women and 2\% of Canadian men reported experiencing violence from their partners. Also, in the 5-year period from 1995 to 1999, an estimated 8\% of Canadian women and 7\% of Canadian men experienced violence from their partners. Beyond that, it is not easy to interpret these data accurately at a glance. This is in part because the data are aggregated in unhelpful ways for some purposes, in part because of anomalies which indicate that significant nonsampling errors abound in these data, and in part because the labels and definitions of the categories are somewhat misleading or counter-intuitive.

A new category can be created from Table $\mathbf{1 . 1}$ by separating out those respondents who had both a current and a previous partner in the 5-year period. This can be done by simply adding the number of women who had a current partner (line $2: \mathrm{N}=7,310,000$ ) to the number of women who had previous partner (line 3: $\mathrm{N}=1,554,000$ ), and then subtracting the total number of women who either a current or a previous partner (line 1: $\mathrm{N}=8,356,000$ ). This yields 508,000 women who had both a current and a previous partner when the GSS was taken. Parallel calculations reveal that $(7,554,000+1,205,000-8,346,000=) 417,000$ men had both a current and a previous partner when the GSS was taken. Of those who had both a current and a previous partner, one can calculate in a similar manner that 6,000 women and 13,000 men experienced violence from both partners in the preceding 5 years. (While the sample of reports from which these numbers was extrapolated is too small for the difference to be statistically significant, it is nevertheless interesting that men were much more likely than women to have reported having experienced violence from both a current and a previous partner. This suggests that abused men may be more likely than abused women to move from one abusive relationship to another.) One can also calculate the numbers and proportions of men and women who had only current partners, who had only previous partners, and who experienced violence in those relationships. These results appear on the left-hand side of Table 1.2. 


\begin{tabular}{|c|c|c|c|c|c|c|c|c|}
\hline \multicolumn{9}{|c|}{$\begin{array}{l}\text { Table } 1.2 \\
\text { Number and percentage of women and men who reported violence by a partner, } \\
\text { preceding } 5 \text { years - unadjusted and equalized }\end{array}$} \\
\hline \multirow[b]{3}{*}{$(\mathrm{N} \times 1,000)$} & \multicolumn{4}{|c|}{ preceding 5 years - unadjusted } & \multicolumn{4}{|c|}{ preceding 5 years - equalized } \\
\hline & \multicolumn{2}{|c|}{ female victim } & \multicolumn{2}{|c|}{ male victim } & \multicolumn{2}{|c|}{ female victim } & \multicolumn{2}{|c|}{ male victim } \\
\hline & $\begin{array}{l}\text { count } \\
(000 \mathrm{~s}) \\
\end{array}$ & $\% \mathrm{~N}$ & $\begin{array}{l}\text { count } \\
(000 \mathrm{~s}) \\
\end{array}$ & $\% \mathrm{~N}$ & $\begin{array}{l}\text { count } \\
(000 \mathrm{~s}) \\
\end{array}$ & $\% \mathrm{~N}$ & $\begin{array}{l}\text { count } \\
(000 \mathrm{~s}) \\
\end{array}$ & $\% \mathrm{~N}$ \\
\hline $\begin{array}{l}\text { 1. Violence by current or previous partner } \\
(\mathrm{N}=8356 \text { females; } \mathrm{N}=8346 \text { males })\end{array}$ & 690 & 8.3 & 549 & 6.6 & 642 & $\begin{array}{c}7.7 \\
\mathrm{~N}=8351\end{array}$ & 586 & $\begin{array}{c}7.0 \\
\mathrm{~N}=8351\end{array}$ \\
\hline $\begin{array}{l}\text { 2. Violence by both current and previous } \\
\text { partner }(\mathrm{N}=508 \mathrm{females} ; \mathrm{N}=417 \text { males })\end{array}$ & 6 & 1.2 & 13 & 3.1 & 6 & $\begin{array}{c}1.2 \\
\mathrm{~N}=463\end{array}$ & 14 & $\begin{array}{c}3.1 \\
\mathrm{~N}=463\end{array}$ \\
\hline $\begin{array}{l}\text { 3. Violence by current partner only } \\
(\mathrm{N}=6802 \text { females; } \mathrm{N}=7141 \text { males })\end{array}$ & 253 & 3.7 & 290 & 4.1 & 258 & $\begin{array}{c}3.7 \\
\mathrm{~N}=6972\end{array}$ & 286 & $\begin{array}{c}4.1 \\
\mathrm{~N}=6972\end{array}$ \\
\hline $\begin{array}{l}\text { 4. Violence by previous partner only } \\
(\mathrm{N}=1046 \text { females; } N=788 \text { males })\end{array}$ & 431 & 41.2 & 246 & 31.2 & 378 & $\begin{array}{c}41.2 \\
\mathrm{~N}=917\end{array}$ & 286 & $\begin{array}{c}31.2 \\
\mathrm{~N}=917\end{array}$ \\
\hline 5. Violence ceased at separation & 264 & 60.4 & 173 & 66.8 & 232 & 60.4 & 200 & 66.8 \\
\hline $\begin{array}{l}\text { 6. Violence after separation } \\
(\mathrm{N}=437 \text { females; } \mathrm{N}=259 \text { males })\end{array}$ & 172 & 39.4 & 83 & 32.1 & 151 & $\begin{array}{c}39.4 \\
\mathrm{~N}=384\end{array}$ & 96 & $\begin{array}{c}32.1 \\
\mathrm{~N}=300\end{array}$ \\
\hline 7. Violence increased & 39 & 22.7 & 23 & 27.7 & 34 & 22.7 & 27 & 27.7 \\
\hline 8. Violence did not increase & 69 & 40.1 & 25 & 30.1 & 61 & 40.1 & 29 & 30.1 \\
\hline $\begin{array}{l}\text { 9. Violence began after separation } \\
(\mathrm{N}=172 \text { females; } \mathrm{N}=83 \text { males })\end{array}$ & 63 & 36.6 & 35 & 42.2 & 55 & $\begin{array}{c}36.6 \\
N=151\end{array}$ & 41 & $\begin{array}{c}42.2 \\
\mathrm{~N}=96\end{array}$ \\
\hline
\end{tabular}

The second problem with the data in Table 1.1 concerns non-sampling errors. Logically, there should be the same number of men and women in each of the three main categories of Table 1.1 (lines 1-3), assuming that the relation 'having contact with' is symmetric and that the sample on which these numbers are based is representative. Yet in line 3, there were 1,554,000 women who claimed to have had contact with a previous partner in the 5-year period preceding the GSS, versus only 1,205,000 men. In other words, 349,000 more women than men reported being in this category. (The same discrepancy appears by adding the appropriate Ns in lines 2 and 4 of Table 1.2.) Such a large discrepancy - fully $29 \%$ more women than men - can only be explained plausibly as a product of non-sampling error. That is, men must be much more likely than women to forget about or simply neglect to report having had contact, including violent contact, with a previous partner. ${ }^{9}$

This conclusion is consistent with the finding mentioned earlier in the Introduction that men tend to under-report their own victimization to a very significant degree, even relative to the under-reporting of women's own victimization. It is also supported independently, though weakly, by the fact that Statistics Canada consistently reports more men than women in the 'refused' or 'not stated / don't know' category of its tables. It would appear that men are simply much less willing to respond to the survey as fully and as expansively as women are. Straus (1999) argues plausibly that since women tend to experience more fear, and receive more medical and other attention, when they experience violence, they tend to remember their experiences of violence longer and more vividly than men do, which means they would be more

\footnotetext{
${ }^{9}$ It is also true that 248,000 more men than women claimed to have had a current partner. But the 248,000 "extra" men in the 'current partner' category amounts to only 3.3\% of current partnerships, and so could be explained almost entirely as sampling error. Curiously, Statistics Canada neither notes nor comments upon any of these anomalies anywhere in the analysis of their data.
} 
frequently able to report it in greater detail, even if it had occurred in the more distant past. Also, violence that occurred outside the 5-year reporting period might be remembered as falling within the period more often by women than men, too. This phenomenon is apparently well-enough known that Ogrodnik and Trainor (1997: 8) refer to it as "telescoping events into the reference period." These memory effects appear to be highly significant, for what they imply is that women are much more likely than men to remember and report victimization in that kind of relationship in which violence is more prevalent.

In any case, comparisons between the number of women and men who report experiencing violence will be misleading unless the number of partners claimed by both women and men is the same. The right-hand side of Table 1.2 therefore equalizes the number, N, of men and women in each of the four main reporting categories by taking the average between the male and female Ns, and keeping the proportions of victims constant within each category. (This attempts to correct for only part of the non-sampling error inferred above - that part which is objectively determinable.) Thus 8,351,000 men and women are deemed to have had either a current or a previous partner (line 1); 463,000 men and women are deemed to have had a current partner as well as contact with a previous partner in the preceding 5 years (line 2); 6,972,000 men and women are deemed to have had a current partner only (line 3); and 917,000 men and women are deemed to have only had contact with previous partner in the preceding 5 years (line 4). When the totals are based on an equal population of men and women within each category, the difference in the overall number of men and women victims is reduced substantially, from 141,000 on the left side to only 60,000 on the right side - or from $55.7 \%$ female victims to $52.5 \%$ female victims. This adjustment brings the GSS data more into line with the majority of the studies in Feibert (1997).

The third problem with interpreting the data in Table $\mathbf{1 . 1}$ is that the category labels may be misleading to the unwary. This problem remains in Table 1.2. For example, one might infer from the numbers in line 3 of Table 1.2 that men were more at risk of violence than women while their relationship was still intact, since more men reported 'violence by current partner only'. This would be incorrect, however, since in fact all of the victims identified in Table $\mathbf{1 . 2}$ reported experiencing violence by a partner while their relationship was still intact, except those in the category 'violence began after separation' (i.e. 55,000 women and 41,000 men on the adjusted, right-hand side in line 9). If these numbers are subtracted from the totals in line 1 of Table 1.2, then it turns out that $7.0 \%$ of women and $6.5 \%$ of men experienced violence while their relationship was still intact. The real reason fewer women than men reported 'violence by current partner only' in line 3 of Table $\mathbf{1 . 2}$ is evidently that women were more likely to leave a violent partner than men were. This is why there are 32,000 more women than men in the category 'violence ceased at separation'. This analysis supports the intuitive belief that violence by a partner is a significant cause for ending a relationship, at least for women.

If violence is a cause of relationship failure (for women, at least), is it also an effect? One might be inclined to think so on the basis that only $4 \%$ of both women and men reported violence by current partners (Table 1.1, line 2), while $28 \%$ of women and $22 \%$ of men reported violence by a previous partner (Table 1.1, line 3). This comparison suggests that women experience a 7fold increase in the risk of violence after separation, while men experience more than a 5-fold increased risk. A similar comparison of the proportions in line 3 and line 4 of Table 1.2 would suggest that women experience nearly a 10 -fold increase, and men nearly an 8 -fold increase, in 
the risk of violence after separation. The problem with these analyses is that almost $40 \%$ of those reporting violence by a previous partner experienced that violence while the relationship was still intact. The correct numerator to use to assess the risk of experiencing violence after separation is found in line 6 of Table 1.2. On the adjusted side of the table, there are 151,000 women and 96,000 men in the category 'violence after separation'. The more difficult question is what to use as the denominator. From lines 2 and 4, an estimated $(463,000+917,000=)$ 1,380,000 men and women had had contact with a previous partner in the 5 years preceding the survey. Using that figure as the denominator suggests that $10.9 \%$ of women and $7.0 \%$ of men experienced violence by their previous partners after separation. This compares with $7.0 \%$ of women and $6.5 \%$ of men who experienced violence while their relationship was still intact (as found above). So it would seem that the risk of violence does increase after separation, particularly for women. However, these calculations do not take into account the fact that some couples never have contact with each other after separation, and therefore do not suffer violence after separation, either. Statistics Canada does not reveal how many such couples there were, so all that can be concluded is that the difference between $7.0 \%$ and $10.9 \%$ puts an upper bound on the increased risk of violence for women after separation - far from the 7-fold increase naïvely inferred..$^{10}$

Comparisons between the 12-month and 5-year periods for 'violence by previous partner' in line 3 of Table 1.1 suggest that violence after separation is relatively short-lived - i.e., it typically persists for less than a year. From line 4 of Table 1.1, 60\% of the women who had had contact with a previous partner in the preceding 5 years did not experience any violence after separation, which means that at least $60 \%$ of the 101,000 women who experienced violence by a previous partner in the 12-month period experienced that violence while the relationship was still intact. In other words, each year at most 40,000 women experience violence by a previous partner after separation. One can infer from line 6 of Table 1.2 that about 30,000 women enter the pool of separated-yet-victimized women each year, on average. That leaves at most only 10,000 women who experienced violence at the hands of a previous partner from whom they had been separated for more than 12 months. This amounts to only $0.7 \%$ of separated women who have had contact with a previous partner in the preceding 5 years.

Parallel calculations on the men's side run into difficulties. If at least $67 \%$ of the 48,000 men who reported experiencing violence by a previous partner in the preceding 12 months had experienced that violence prior to separation, then only 16,000 men experienced violence by a previous partner after separation in the preceding 12 months. Yet one can infer from line 5 of Table 1.1 and from line 6 of Table 1.2 that the number of men who experienced violence after separation in the preceding 5 years falls between 83,000 and 96,000 - or between 17,000 and 19,000 new cases per year. The fact that the 12-month victimization rates cannot be reconciled with the 5-year rates for men indicates the presence of non-sampling error, in this case men significantly under-reporting their experiences of victimization in the relatively short, 12-month reporting period. In any case, one supposes that it must be rare for a man to experience violence by a previous partner more than 12 months after separation.

\footnotetext{
${ }^{10}$ From line 7 of Table 1.2, in another $2.5 \%$ of cases for women and $2.0 \%$ of cases for men, violence increased in severity or frequency after separation. On the other hand, from line 8 , in $4.4 \%$ of cases for women and $2.1 \%$ of cases for men, the violence remained the same or decreased in severity or frequency after separation. So the conclusion in the text would seem to hold, even taking the frequency and severity of violence into account.
} 
Since the analysis for the present study was performed on data from the Edmonton region, it bears noting that rates of partner violence found in the GSS were higher in the province of Alberta than the national average. Thus, overall, $11 \%$ of women and $9 \%$ of men reported having experienced partner violence in the preceding 5 years (Pottie Bunge and Locke 2000: 51, Table A4), instead of the national average of $8 \%$ and $7 \%$ respectively. This compares with a typical all-acts survey that was carried out in 1986 as part of the All-Alberta Study conducted annually by the Population Research Laboratory at the University of Alberta. ${ }^{11}$ It found that, in $1985,11.2 \%$ of women but $12.4 \%$ of men had experienced physical abuse from a partner. Being an all-act survey, it is perhaps understandable that the All-Alberta Study would find the same percentage of women victims in a single year as the GSS found over a 5-year period. But the difference in the finding of male victimization is more difficult to account for. The All-Alberta Study found almost $40 \%$ more male victims of abuse in a single year than the GSS found in its 5year period, despite the fact that violence against men has been trending upward in the intervening years (Trainor 2002). This shows, perhaps, how sensitive the findings of surveys are to the methods and techniques of the interviewers - and thereby reinforces the earlier cautions about non-sampling errors possibly tainting the findings of the GSS.

Although significantly more Canadian women report experiencing victimization from partner violence than Canadian men do, it also bears noting that there are many sub-populations of men who report experiencing higher rates of victimization than Canadian women do, overall. As was just mentioned above, 9\% of Alberta men with current or previous partners reported experiencing partner violence, as opposed to only $8 \%$ of Canadian women. Also, separated men are 3 times more at risk of experiencing violence by a former partner with whom they have had contact $(31.2 \%)$ than Canadian women in an intact relationship (10.9\%). Again, 13\% of aboriginal men with current or previous partners report experiencing partner violence, as opposed to only $8 \%$ of Canadian women (Trainor and Mihorean 2001: 36, Table 4.1). While it is true that Albertan, separated, and aboriginal women experience even higher rates of victimization than do men in those sub-categories, it is clear from the overlap in the rates of victimization between sub-categories of men and women that violence by partners is not fundamentally a gendered phenomenon, as it is routinely portrayed in the popular media.

The GSS provides several ways to measure the frequency and severity of partner violence, although none is without problems. Table 1.3 sets out the responses received on the conflict tactics scale employed as the survey instrument. ${ }^{12}$ Female victims report that their partners use a greater variety of violent tactics in the course of their assaults than male victims report experiencing at the hands of their partners. This is true of every category except 'violence by current partner', where the tactics per victim were equal between the sexes. Note that women reported more violence in the more serious categories toward the bottom of the conflict tactics scale, whereas men reported as much or more violence in the less serious categories toward the top of the scale. This result is somewhat at odds with the preponderance of surveys canvassed by Fiebert (1997), which find that more women than men commit acts of abuse at both the low and high end of the scale. For example, Grandin and Lupri (1986), asking about perpetration rather than victimization, found that $9.9 \%$ of Canadian men and $15.5 \%$ of Canadian women admitted to

\footnotetext{
11 These unpublished data were acquired from the Population Research Laboratory by Dr. Ferrel Christensen, Professor Emeritus of the University of Alberta.
}

${ }^{12}$ Table 1.3 is based on Trainor and Mihorean (2001: 39, Table 4.6). 
employing at least one act of severe violence toward their partners. Likewise, the victimization rates obtained in the All-Alberta Study for actions generally considered to be more severe were $2.3 \%$ of women and $4.7 \%$ of men. (In all cases, however, the acts committed by men in the middle part of the range nevertheless tend to cause more injury to women than the acts committed by women at the higher end of the scale.)

\begin{tabular}{|c|c|c|c|c|c|c|c|c|}
\hline \multicolumn{9}{|c|}{$\begin{array}{c}\text { Table } 1.3 \\
\text { Types of violence by a partner, preceding } 5 \text { years }\end{array}$} \\
\hline \multirow{3}{*}{$\begin{array}{l}\text { * coefficient of variation is high } \\
-- \text { amount too small to be expressed }\end{array}$} & \multirow{2}{*}{\multicolumn{2}{|c|}{ Total }} & \multicolumn{4}{|c|}{ iolence by previous partner } & \multicolumn{2}{|c|}{$\begin{array}{l}\text { Violence by } \\
\text { current partner }\end{array}$} \\
\hline & & & Before & aration & After & ration & Count & \\
\hline & $\begin{array}{l}\text { Count } \\
(000 s)\end{array}$ & $\% \mathrm{~N}$ & $\begin{array}{l}\text { Count } \\
(000 \mathrm{~s})\end{array}$ & $\% \mathrm{~N}$ & $\begin{array}{l}\text { Count } \\
(000 s)\end{array}$ & $\% \mathrm{~N}$ & 000s) & 8018 \\
\hline Total violence to female victims & 437 & 100 & 264 & 100 & 172 & 100 & 259 & 100 \\
\hline Threatened to hit & 307 & 70 & 168 & 64 & 137 & 80 & 145 & 56 \\
\hline Threw something & 211 & 48 & 122 & 46 & 88 & 51 & 90 & 35 \\
\hline Pushed, grabbed & 378 & 87 & 228 & 87 & 150 & 87 & 187 & 72 \\
\hline Slapped & 203 & 46 & 113 & 43 & 89 & 52 & 77 & 30 \\
\hline Kicked, bit, or hit & 177 & 41 & 102 & 39 & 75 & 44 & 50 & 19 \\
\hline Hit with something & 127 & 29 & 65 & 25 & 61 & 35 & $28^{*}$ & $11^{*}$ \\
\hline Beat & 139 & 32 & 71 & 27 & 68 & 40 & $33^{*}$ & $13^{*}$ \\
\hline Choked & 114 & 26 & 56 & 21 & 58 & 34 & $26^{*}$ & $10 *$ \\
\hline Used or threatened to use knife or gun & 86 & 20 & 40 & 15 & 46 & 27 & -- & -- \\
\hline Sexual assault & 117 & 27 & 57 & 22 & 60 & 35 & $21^{*}$ & $8^{*}$ \\
\hline Total / (tactics per victim) & 1859 & $(4.25)$ & 1022 & $(3.87)$ & 832 & $(4.84)$ & 657 & $(2.54)$ \\
\hline Total violence to male victims & 259 & 100 & 173 & 100 & 83 & 100 & 303 & 100 \\
\hline Threatened to hit & 173 & 67 & 107 & 62 & 66 & 79 & 162 & 53 \\
\hline Threw something & 147 & 57 & 99 & 57 & 46 & 55 & 163 & 54 \\
\hline Pushed, grabbed & 135 & 52 & 84 & 48 & 51 & 61 & 103 & 34 \\
\hline Slapped & 162 & 63 & 109 & 63 & 53 & 64 & 153 & 51 \\
\hline Kicked, bit, or hit & 161 & 62 & 102 & 59 & 59 & 71 & 124 & 41 \\
\hline Hit with something & 93 & 36 & 60 & 35 & 33 & 40 & 53 & 17 \\
\hline Beat & 41 & 16 & $25^{*}$ & $14 *$ & $16^{*}$ & $20 *$ & $13^{*}$ & $4 *$ \\
\hline Choked & $18^{*}$ & $7 *$ & -- & -- & -- & -- & -- & -- \\
\hline Used or threatened to use knife or gun & $35^{*}$ & $14^{*}$ & 20 & 12 & 15 & 19 & -- & -- \\
\hline Sexual assault & -- & -- & -- & -- & -- & -- & -- & -- \\
\hline Total /( tactics per victim) & 965 & $(3.73)$ & 606 & $(3.50)$ & 339 & $(4.08)$ & 771 & $(2.55)$ \\
\hline
\end{tabular}

Nevertheless, more-direct questions about the frequency and severity of violence indicate that these data reflect genuine differences in the number of violent tactics employed by male and female perpetrators. The fact that men committed the preponderance of more-serious acts of violence, together with the fact that men are physically larger and have more experience with violent conflict generally, leads one to expect that women would suffer a higher proportion of the more severe injuries from partner violence. At the most extreme end of the spectrum are incidents which result in death. Interview methods are obviously incapable of identifying these victims; but since deaths are relatively difficult to hide from the authorities, as is guilt when the death results from a dispute between partners, ${ }^{13}$ the numbers reported by the police are likely to be as objective as can readily be found. According to Pottie Bunge and Locke (2000: 6), women were the victims in $77.2 \%$ of the cases of homicides by partners from 1979 to 1998. The

\footnotetext{
${ }^{13}$ Farrell (1993) adduces a surprising number of cases in which American women murdered their partners but were not even suspects in the death, or were never charged due to a lack of investigative rigor or for other reasons. So even official data on killings by partners might not be quite accurate.
} 
proportion of partner killings perpetrated by women is doubtless slightly more equal than this, since women who kill their partners are more likely than men to benefit from a lack of detection, reduced charges, and various mental-illness defences (Farrell 1993: Chapter 12; Paciocco 1999: 249ff). Still, even taking all of these factors into account, the ratio of female to male victims of homicides by partners in Canada is roughly $3: 1$.

In contrast, the ratio of women to men who feared for their lives as a result of a partner dispute is close to 6:1, as shown in Table 1.4. ${ }^{14}$ This indicates that women were twice as fearful for their lives as men were given a similar objective probability of death. ${ }^{15}$ In fact, that probability is really quite low. Over the 20 -year period mentioned in the previous paragraph, only 1,468 Canadian women and 432 Canadian men were murdered by a partner (Pottie Bunge 2000: 39, Table 5.1). In other words, only 1 in about 700 women who feared for her life as a result of a dispute with her partner was actually killed; and only 1 in about 350 men who feared for his life as a result of a dispute with his partner was actually killed. Ogrodnik and Trainor (1997: 1) point out that the Canadian public reported an increase in fear of crime at a time when real crime rates were actually holding steady. They attribute this increased fear to "media hype"

\begin{tabular}{|c|c|c|c|c|c|c|c|c|}
\hline \multicolumn{9}{|c|}{$\begin{array}{c}\text { Table } 1.4 \\
\text { Severity and frequency of violence by a partner, } \\
\text { preceding } 5 \text { years - unadjusted and equalized }\end{array}$} \\
\hline \multirow{3}{*}{ * coefficient of variation is high } & \multicolumn{4}{|c|}{ preceding 5 years - unadjusted } & \multicolumn{4}{|c|}{ preceding 5 years - equalized } \\
\hline & \multicolumn{2}{|c|}{ female victim } & \multicolumn{2}{|c|}{ male victim } & \multicolumn{2}{|c|}{ female victim } & \multicolumn{2}{|c|}{ male victim } \\
\hline & $\begin{array}{c}\text { count } \\
(000 \mathrm{~s})\end{array}$ & $\% \mathrm{~N}$ & $\begin{array}{c}\text { count } \\
(000 \mathrm{~s})\end{array}$ & $\% \mathrm{~N}$ & $\begin{array}{c}\text { count } \\
(000 \mathrm{~s})\end{array}$ & \%row & $\begin{array}{c}\text { count } \\
(000 \mathrm{~s})\end{array}$ & \%row \\
\hline Total partners reporting violence & 690 & 100 & 549 & 100 & 642 & 100 & 586 & 100 \\
\hline A. Feared for life & & & & & & & & \\
\hline Not stated / don't know & 16 & $2 *$ & 19 & $3 *$ & 15 & 42.9 & 20 & 57.1 \\
\hline Did not fear for life & 414 & 60 & 490 & 89 & 385 & 42.4 & 523 & 57.6 \\
\hline Feared for life & 259 & 38 & 41 & $7 *$ & 241 & 84.6 & 44 & 15.4 \\
\hline \multicolumn{9}{|l|}{ B. Physical injuries } \\
\hline Not stated / don't know & 15 & $2 *$ & 15 & 3 & 14 & 46.7 & 16 & 53.3 \\
\hline No physical injury & 396 & 57 & 462 & 84 & 369 & 42.8 & 493 & 57.2 \\
\hline Physical injury & 279 & 40 & 72 & 13 & 260 & 77.2 & 77 & 22.8 \\
\hline No medical attention received & 174 & 25 & 57 & 10 & 162 & 72.7 & 61 & 27.3 \\
\hline Medical attention received & 104 & 15 & 15 & $3 *$ & 97 & 85.8 & 16 & 14.2 \\
\hline C. Frequency of victimization & & approx & & approx. & & approx. & & approx \# \\
\hline Not stated / don't know & 17 & \# & 21 & \# & 16 & \# & 22 & 94 \\
\hline Once & 225 & 103 & 227 & 87 & 209 & 99 & 242 & 242 \\
\hline $2-5$ times & 197 & 225 & 194 & 227 & 183 & 209 & 207 & 725 \\
\hline $6-10$ times & 72 & 690 & 35 & 679 & 67 & 641 & 37 & 296 \\
\hline More than 10 times & 178 & 576 & 72 & 280 & 166 & 536 & 77 & $\underline{1155}$ \\
\hline \multirow[t]{2}{*}{ Total incidents (estimated) } & & $\underline{2670}$ & & $\underline{1080}$ & & $\underline{2490}$ & & 2512 \\
\hline & & 4264 & & 2353 & & 3975 & & \\
\hline
\end{tabular}

\footnotetext{
${ }^{14}$ Table 1.4 is based on Pottie Bunge and Locke (2000: 14, Tables 2.4 and 2.5). The right-hand side scales each subfigure linearly so as to sum to the equalized totals from line 1, right-hand side, Table 1.2.

${ }^{15}$ Subjective measures of the severity of violence are not very reliable indicators, since men and women differ significantly in terms of their perceptions of danger and their response to it. This difference persists even among men and women who have self-selected into dangerous occupations and have undergone intensive training for them. For example, a study of the U.K. military "found little psychological difference between men and women, though it found women were more likely to fear the consequences of aggressive behaviour” (Trickey 2002).
} 
accompanying the misreporting of data on crime. In fact, the partner-homicide rate for female victims has declined in Canada by about 50\%, from 15 per million couples in 1978 to 8 per million couples in 1999 (Trainor and Mihorean 2001: 35). Most of that decline (37\%) took place since 1991, at precisely the time when "media hype" over partner violence against women - and reported fear of such - was reaching its height in Canada (Fekete 1994).

If subjective fear as a measure of severity of violence is not a very reliable indicator, perhaps reports relating to injuries and medical attention received are more objective. The data in Table 1.4 show that women were almost 3 times more likely than men to have reported an injury that did not require medical attention, and were 6 times more likely to have reported an injury for which medical attention was received. These ratios are significantly higher than the results of many other nationally representative surveys of the same general type. The American National Criminal Victimization Survey found that three-quarters of the victims of aggravated assaults between intimate partners were women (Bachman and Saltzman 1995: Table 5.) The British Crime Survey in 1996 found that two-thirds of the victims of partner violence that produced an injury were women (Mirrlees-Black 1999). And, as mentioned previously, Archer's (2000) metaanalysis of partner-violence surveys produced a composite percentage of injury victims that is only $65 \%$ female. Non-representative sources of such numbers (counselling programs, police records, etc.) vary much more in their results, and the great majority are clearly skewed against finding male victims or female offenders in the first place. It is consequently highly significant that in spite of this, some of them yield figures similar to those of the majority of sociological surveys. Two U.S. examples are illustrative. Buzawa and Austin (1993) examined Detroit police records and found that $70 \%$ of seriously injured partners were women. Anson Shupe et al. (1994) interviewed arrested men and their wives in Austin, Texas, and also found that $70 \%$ of injuries were sustained by wives. In the absence of skewed sampling, the proportion of male injuries in that study would have been higher.

The data in Table 1.4 are based on self-reports, which makes them prone to the nonsampling errors noted previously. In particular, women and men almost certainly tend to perceive their injuries differently. A small scratch or bruise that most women would regard as an injury might not be regarded as an injury by most men, for example. Evidence also suggests that women are more inclined than men to seek medical attention for any number of conditions, and that propensity might well be reflected in the proportions of men and women receiving medical attention from partner disputes. Based on having read over 400 prosecutor files to collect data for the present study, this researcher is confident in saying that female victims of partner violence seek medical attention for relatively minor cuts and bruises much more readily than men do and the police obliged them in this. Although it is impossible to quantify the non-sampling errors introduced by the self-reporting of victimization, it should always be borne in mind that the differences they generate in the severity of victimization between men and women probably puts an upper bound on the real or objective differences in victimization.

The results of victim-based surveys are not directly helpful for an examination of police and prosecutor practices in dealing with partner violence, because the law-enforcement system is incident-based. Therefore, it is necessary to convert the victim-based survey results to incidentbased results by multiplying the former by the frequency of victimization. The figures on frequency of victimization from the GSS are reproduced in Table $\mathbf{1 . 4}$ as well, together with rough estimates of the overall number and proportion of incidents of violence experienced by 
men and women in Canada in the 5-year period studied. (For those who didn't state or didn't know how many times they had been victimized in the preceding 5 years, the average of the other respondents was used to estimate the number of incidents.) Based on these estimates, women were the victims in between $61 \%$ and $65 \%$ of all incidents of partner violence. In other words, women reported having suffered between 1.6 and 1.8 incidents of violence by their partners for every 1 incident reportedly suffered by men.

On the "unadjusted" side of Table 1.4, women were victims of an estimated 4,264,000 incidents of partner violence in the preceding 5-year period. Since 690,000 women claimed to have been victimized in this time period, they must have been victimized on average about 6.2 times in that 5-year period. Again, since women were victims of an estimated 4,264,000 incidents of partner violence in the preceding 5-year period, women must have been victims in an estimated 853,000 incidents per year, on average. From the left-hand side of Table 1.1, line 1, there were 220,000 female victims of partner violence in the 12-month period preceding the GSS. It therefore appears that women who experience partner violence in a given 12-month period experience it about 4 times that year, on average. Combining these results, it appears that the average woman who experiences partner violence will experience it rather intensely - about 4 times - within a relatively short 12-month period; but in the 4 years closest to that period of high-intensity victimization, she will experience partner violence only about 2 or 3 more times. These calculations tend to support the earlier hypothesis that violence against female partners tends to peak sharply but shortly around the time of a relationship break-down.

For men, the "unadjusted" side of Table 1.4 indicates they were victims of an estimated $2,353,000$ incidents of partner violence in the preceding 5-year period. Since 549,000 men claimed to have been victimized in this time period, they must have been victimized on average about 4.3 times in that 5-year period. Again, since men were victims of an estimated 2,353,000 incidents of partner violence in the preceding 5-year period, men must have been victims in an estimated 471,000 incidents per year, on average. From the left-hand side of Table 1.1, line 1, there were 177,000 male victims of partner violence in the 12-month period preceding the GSS. It therefore appears that men who experience partner violence in a given 12-month period experience it about 3 times that year, on average. Combining these results, the average man who experiences violence by a partner would experience it moderately intensely - about 3 times within a relatively short 12-month period; but in the 4 years closest to that period of higher intensity, he would experience partner violence only about 1 or 2 more times. Thus partner violence tends to peak shortly around the time of a relationship break-down for men as well.

Because of the way in which Statistics Canada reports its data, it is not possible to determine how frequency of victimization interacts with severity of injury suffered. One might suppose that the persons who are most frequently attacked would also be the ones who are most severely attacked. But since women in particular are inclined to leave abusive partners, this correspondence between severity and frequency of violence might actually hold in only a small proportion of cases - the true "battered partner" cases. More likely, the relationships which are characterized by the most frequent violence are those in which the violence is least severe - i.e. those cases that are least likely to show up in police-reporting data. Repeat victimizaton at the lower levels of violence might therefore be explained in part by the fact that the police are not called to intervene in these disputes, and so they continue. 
Pottie Bunge and Locke (2000: 19, Table 2.10) provide data from the GSS when victims were asked about whether any of the violent incidents they had been involved in had ever been reported to police. Table 1.5 summarizes these data, and estimates the numbers and proportions of male and female victims based on an equal number of partnerships.

\begin{tabular}{|c|c|c|c|c|c|c|c|c|}
\hline \multicolumn{9}{|c|}{$\begin{array}{l}\text { Table } 1.5 \\
\text { Violence by a partner reported to the police, } \\
\text { preceding } 5 \text { years - unadjusted and equalized }\end{array}$} \\
\hline \multirow{3}{*}{ * coefficient of variation is high } & \multicolumn{4}{|c|}{ preceding 5 years - unadjusted } & \multicolumn{4}{|c|}{ preceding 5 years - equalized } \\
\hline & \multicolumn{2}{|c|}{ female victim } & \multicolumn{2}{|c|}{ male victim } & \multicolumn{2}{|c|}{ female victim } & \multicolumn{2}{|c|}{ male victim } \\
\hline & $\begin{array}{c}\text { count } \\
(000 \mathrm{~s})\end{array}$ & & $\begin{array}{c}\text { count } \\
(000 \mathrm{~s})\end{array}$ & $\% \mathrm{~N}$ & $\begin{array}{c}\text { count } \\
(000 \mathrm{~s})\end{array}$ & \%row & $\begin{array}{c}\text { count } \\
(000 \mathrm{~s})\end{array}$ & \%row \\
\hline Total partners reporting violence & 690 & 100 & 549 & 100 & 642 & 100 & 586 & 100 \\
\hline Not stated / didn't know & 20 & $2.9^{*}$ & 17 & $3.1 *$ & 19 & 3.0 & 18 & 3.1 \\
\hline Total not reported to police & 414 & 60.0 & 450 & 82.0 & 385 & 44.5 & 480 & 55.5 \\
\hline Total reported to police & 256 & 37.1 & 82 & 14.9 & 238 & 73.0 & 88 & 27.0 \\
\hline Reported to police by victim & 199 & 28.8 & 41 & 7.5 & 185 & 80.8 & 44 & 19.2 \\
\hline Reported to police by someone else & 57 & 8.3 & 41 & 7.5 & 53 & 54.6 & 44 & 45.4 \\
\hline
\end{tabular}

Only $37.1 \%$ of the women who had suffered violence by a partner ever had an incident reported to the police; and only $14.9 \%$ of the men who had suffered violence by a partner ever had an incident reported to the police. Thus, overall, $72.7 \%$ of those who reported experiencing at least one incident of partner violence in the preceding 5 years on the GSS never had it reported to the police. Of those who suffered violence but never had it reported to the police, $55.5 \%$ were men. It does not follow from this that there were more unreported incidents of violence against men than women, because women report experiencing 1.6 to 1.8 times as many incidents per person. Still, assuming that this factor is applicable to the sub-category of victims who never had incidents of victimization reported to the police, it would follow that about $44 \%$ of unreported incidents of violence have male victims. Evidently, unreported violence against male partners is almost as big a problem as unreported violence against female partners.

This conclusion is reinforced by consideration of the fact that only $54.6 \%$ of the victims of violence reported to the police by someone other than the victim him- or herself were women. There are two typical situations to consider: those in which friends or relatives who were present when the violence occurred report to the police, and those in which a neighbour or stranger reported a fight on the basis of hearing noise or getting a brief glimpse of a fight through a window. In the first class of cases, one would expect the proportion of female victims to be somewhere between the proportion of incidents involving female victims (61\% to 65\%), and the proportion of incidents that were self-reported to the police $(80.8 \%)$. It follows that the proportion of cases involving female victims that were reported by neighbours or strangers who obtained only a very incomplete picture of the incident must be much lower than $54.6 \%$ perhaps lower than $50 \%$. This is interesting because it suggests that in cases of partner violence reported to the police when the gender of the victim was not known in advance, men were at least as likely to be the victim as women, though again the fact that women suffer 1.6 to 1.8 times as many incidents per victim needs to be taken into account here. 
The main reason a higher proportion of incidents of violence against women were reported to the police is that women were 4 times as likely as men to self-report their victimization. ${ }^{16}$ This perhaps reflects the fact that women were more likely to suffer more severe forms of violence, more repeat victimization, and greater fear from violence than men. It might also reflect the fact that women found the response of police to be more satisfactory - an hypothesis which is one of the purposes of this study to examine.

The right-hand, equalized side of Table 1.5 shows that $73.0 \%$ of the victims who have ever received police intervention were women. Being a victim-based datum, this does not mean that women were the victims in $73.0 \%$ of all incidents reported to police. It is likely that more than $73.0 \%$ of all incidents reported to the police involved female victims, since women reported experiencing more repeat victimization and a greater willingness to involve the police - and these differences apply also, presumably, to the sub-category of those whose victimization was ever reported to the police. Unfortunately, it is not possible to determine the exact ratio of female to male incidents reported to police from the GSS data because it is not safe to assume that the multiples by which women suffer repeat victimization and a greater willingness to involve the police apply in full force to the class of cases where police were called. The $73.0 \%$ figure for this class of cases already reflects these differences, but on a victim-based measure.

The GSS also asked respondents for their reasons for involving the police. ${ }^{17}$ The results are summarized below. Consistently with the finding that women were more likely to leave a violent relationship, women were also more likely to want the perpetrator arrested and punished. Another way to explain this disparity is to note that proportionately more of the partner violence that men experience takes place within intact relationships.

Women Men

To stop the violence or receive protection Considered it their duty to notify the police

To have their partners arrested and punished Someone else recommended that they involve the police

$\begin{array}{ll}93 \% & 79 \% \\ 55 \% & 58 \% \\ 48 \% & 34 \% \\ 31 \% & 27 \%\end{array}$

The main purpose of the GSS is to explain the sociological phenomenon of partner violence - its prevalence, effects, and associated risk factors. Thus Statistics Canada publications go into considerable detail showing how age, income, education, place of residence, and other factors are associated with partner violence. ${ }^{18}$ The purpose of the present study, however, is to determine whether the law-enforcement system responds differently to male and female

\footnotetext{
${ }^{16}$ A major U.S. all-acts survey on partner abuse in 1985 found that $8.5 \%$ of women and only $0.9 \%$ of men reported their victimization to the police (Straus and Gelles 1989). As would be expected from an all-acts survey, these numbers are lower than the numbers in Table 1.5, though the disparity between men and women is greater.

${ }^{17}$ The results are reported in Pottie Bunge and Lock (2000: 20, Figure 2.7). The coefficient of variation is high for all figures on the men's side except the first.

${ }^{18}$ Partner violence is significantly associated with age (i.e. younger couples experience greater violence), and place of residence (i.e. urban couples are twice as likely to experience violence as rural couples). It is not significantly associated with education level, however. Violence against women is significantly associated with lower incomes; but violence against men is not significantly associated with income level. Experiencing emotional or financial abuse is perhaps the most significant risk factor for partner violence, whether the victim is male or female (Pottie Bunge and Locke 2000: 15-18).
} 
perpetrators of partner violence. To do that effectively, it is necessary to take into account, not the risk factors associated with partner violence in general, but rather the aggravating and mitigating factors associated with a particular incident ${ }^{19}$ - things like the presence of children, the level of injury, and whether the act was done in self-defence or as a result of provocation. Of course, there is some overlap between risk factors for partner violence and aggravating factors. For example, alcohol abuse is a risk factor for partner violence (Pottie Bunge and Locke 2000: 16); but it is also considered to be an aggravating factor for the crime. Most of the analysis in the present study will focus on those risk factors for partner violence which are also aggravating factors, since these are the circumstances of an incident that the police generally record.

\section{Canadian Sources of Data - The 1999 and 2000 UCR}

When the police respond to disputes between partners, they may react in several ways. First, they may decide that nothing of consequence has happened and make no record of the incident. Obviously, no data are available to analyse this category incidents. Second, the police may decide that something significant has happened, even though they cannot be sure exactly what took place or who was at fault. In that case, they typically flag the residence to which they responded on their internal computer system, for future reference. The EPS data analysed in this study contains incidents in this category, and is in that way more complete than any other publicly available data-set on police response to partner violence. Third, the police may decide that the incident is serious enough that some positive intervention is in order. In this case, they make a report. The Uniform Crime Reporting $(U C R)$ survey data are derived from these reports.

The incident-based $U C R$ survey was developed by Statistics Canada in co-operation with the Canadian Association of Chiefs of Police. The UCR aggregates crime statistics reported by nearly all urban police agencies in Canada. The major reporting exception to the $U C R$ is the RCMP, which accounts for nearly $40 \%$ of the volume of crime in Canada, including nearly all of the rural crime. Because of that exception, the $U C R$ data are not nationally representative, but are broadly representative of large urban centres such as Edmonton, Alberta, to which the data for the present study relates. One of the most important differences between the GSS and the UCR surveys is that the latter employs the "most serious offence rule" (Ogrodnik and Trainor 1997): it reports only the most serious offence charged in an incident, whereas interview surveys typically ask about all violent acts. Small annual fluctuations in the incidents of partner violence compiled from police data are evident in the UCR survey. Since the present study analyses incidents arising in 1999 and 2000, the tables in this section report the totals from the annual reports for these two years. ${ }^{20}$

\footnotetext{
${ }^{19}$ Technically, an aggravating factor is a circumstance that tends to justify harsher treatment by the law-enforcement system; whereas a mitigating factor is a circumstance that tends to justify more lenient treatment. Thus having a prior criminal record would be a standard example of an aggravating factor; and pleading guilty (instead of going to trial) would be a standard example of a mitigating factor. In this study, these terms will be used rather more loosely. For example, convicts are generally given credit at sentencing for time served in pre-trial custody. Pre-trial custody is not technically a "mitigating factor," but since it does tend to lead to more lenient sentences, it will be treated as such for the purposes of this study.

${ }^{20}$ Table 1.6 is based on Pottie Bunge and Locke (2000: 22, 24, Table 2.11 and Table 2.13) and Trainor (2002: 19, 20, Table 1.1 and Table 1.2). An incident is "not cleared" if an accused has not been identified in connection with an incident. If the police decide not lay charges or recommend alternative measures, it is "cleared otherwise."
} 


\begin{tabular}{|c|c|c|c|c|c|c|}
\hline \multicolumn{7}{|c|}{$\begin{array}{l}\text { Table } 1.6 \\
\text { Violence reported to the police by partners and ex-partners, } \\
\text { and incidence clearance status, by sex of victim, } 1999 \text { and } 2000\end{array}$} \\
\hline & \multicolumn{3}{|c|}{ female $(\mathrm{N}=52,135)$} & \multicolumn{3}{|c|}{ male $(\mathrm{N}=8,740)$} \\
\hline & Count & $\% \mathrm{~N}$ & $\%$ row & Count & $\% \mathrm{~N}$ & \%row \\
\hline By a current partner & 34,355 & 65.9 & 86.3 & 5,455 & 62.4 & 13.7 \\
\hline By a previous partner & 17,780 & 34.1 & 84.4 & 3,285 & 37.6 & 15.6 \\
\hline Not cleared & 4,600 & 8.8 & 82.1 & 1,001 & 11.5 & 17.9 \\
\hline Cleared & 47,535 & 91.2 & 86.0 & 7,739 & 88.5 & 14.0 \\
\hline Cleared by charge & 39,322 & 75.4 & 88.3 & 5,208 & 59.6 & 11.7 \\
\hline Cleared otherwise than by charge & 8,213 & 15.8 & 76.4 & 2,531 & 29.0 & 23.6 \\
\hline Not laid at complainant's request & 5,908 & 11.3 & 77.1 & 1,758 & 20.1 & 22.9 \\
\hline Discretion exercised by police & 1,090 & 2.1 & 72.8 & 407 & 4.7 & 27.2 \\
\hline Other & 1,215 & 2.3 & 76.9 & 366 & 4.2 & 23.1 \\
\hline
\end{tabular}

As was shown earlier, the rate of partner violence increases sharply though shortly for both women and men immediately after separation. Still, it is unlikely that this can fully account for the fact that over one-third of the incidents for which police made a report involving female victims, and almost two-fifths of the incidents for which police made a report involving male victims, involved separated couples. On the contrary, since proportionately more male victims than female victims involved the police when experiencing violence by a previous partner, the explanation for these ratios from Table 1.6 has more to do with the greater willingness of separated people to involve the police in their disputes. The relatively low proportion of incidents in which a man reports victimization by a current partner to the police suggests that men in particular are reluctant to involve the police in disputes during intact relationships.

The category of cases classified as "not cleared" is not expressly reported or discussed in any of the Statistics Canada publications; it has been reconstructed here on the basis that this is the only category missing one from their analysis. This is curious omission, especially since nearly $10 \%$ of all incidents of partner violence are classified as "not cleared." According to Pottie Bunge and Locke (2000: 24) and Trainor (2002: 8), an incident is classified as "not cleared" when an accused has not been identified in connection with the incident. But if an accused has not been identified by the police, how could they classify it as one of partner violence? It would seem to be a precondition of classification as a case of partner violence that the police know the identity of the perpetrator.

One explanation for this category of cases might be that it captures those situations in which the police are able to satisfy themselves that a violent incident has taken place between partners, but they are unable to determine whether the perpetrator was the man or the woman or both. (Both might claim that the other party started the incident and that they were only acting in self-defence, for example.) That would explain how the police are able to identify it as a case of partner violence yet be unable to identify an accused. The problem with this explanation is that the gender of the victim is reported by the police even in cases that were "not cleared," and so it would follow that the identity of the accused must also be known. Perhaps in the kind of ambiguous case suggested above, the police report, for the sake of convenience, the gender of the "victim" as the gender of the party on whose behalf the call to the police was made. This is plausible, since $82.1 \%$ of the incidents in the "not cleared" category were classified as having 
female victims and $85.6 \%$ of the incidents in the whole population for which police made a report had female victims.

If this is the correct explanation for the category of cases classified as "not cleared," it would have been helpful for Statistics Canada to have explained and analysed it more carefully: as mentioned above, it contains nearly $10 \%$ of all incidents of partner violence for which police made a report. In particular, it bears noting that a higher percentage of incidents involving male victims was not cleared $(11.5 \%)$, than incidents involving female victims $(8.8 \%)$. This disparity seems to indicate that the police were more likely to find a situation too highly ambiguous to identify a perpetrator when men call in the complaint than when women call in the complaint, despite the fact that men are much less willing to call the police in the first place. This inference is consistent with the findings throughout the present study that the police exercise their discretion in such a way as to treat female perpetrators more favourably than male perpetrators.

Another complication needs to be noted in relation to reports to the police, namely the possibility that women are more likely than men to call the police even when they are the primary (or equal) aggressors. ${ }^{21}$ This kind of case does not fit neatly into the boxes the police have created to report the phenomenon of partner violence, which seem to assume that the person calling the police must be the sole victim in the incident. To the (considerable) extent that this is not a valid assumption, the data from both the GSS and the UCR may over-represent the extent of female victimization that comes to the attention of the police.

Table 1.4 estimates that between 6,487,000 and 6,617,000 incidents of partner violence occur in a 5-year period, or between 1,297,000 and 1,323,000 per year. But the UCR data generate only an average of 30,438 cases per year. Since the UCR data are derived from only about half of the police forces in Canada, a nationally representative survey of police forces would generate at most 60,000 cases per year. ("At most," since the main reporting exception is the RCMP, which deals mainly with rural crime, where domestic violence is only half as likely to occur.) As explained above, police will have responded to many more incidents than this in a given year, since they will have responded to cases where no report was made for various reasons. Nevertheless, the discrepancy between the number of incidents of partner violence claimed to have been experienced on the GSS and the number of incidents in which police took some positive action is very dramatic. It would seem that the number of incidents of partner violence that police report amounts to fewer than $5 \%$ of the total experiences of partner violence reported by victims in the GSS. This ratio of GSS to $U C R$ incidents - roughly 22:1 - is much higher than for any other crime for which these ratios are calculated. For comparison purposes, the ratio of GSS to UCR incidents for non-partner assault is $2: 1$, for sexual assault it is $1.8: 1$, and for robbery it is 3:1 (Ogrodnik and Trainor 1997: 9).

Table 1.5 indicates that $73.0 \%$ the victims whose violence was reported to the police were women. Table 1.6 indicates that $85.6 \%$ of the incidents for which police generated a report involved female victims. These are not inconsistent results; in fact, they can be reconciled in at

\footnotetext{
${ }^{21}$ A rather gruesome example of this phenomenon is reported by Kent (2002), who writes, "While Ray Snyder lay in his kitchen, dying from a stab would, killer housemate Karla Moen cleaned the floor so her dog would stop licking up his blood... The 36-year-old woman is described in a statement of facts as a nasty drunk who often attacked her one-time chum in $2001 \ldots$ She called police to their home 3 times that year. Each time the officers decided she was the aggressor." Evidently, she was not charged or arrested until the fourth time the police appeared that year.
} 
least two different ways, or by a combination of them. To begin with, the first figure is victimbased and the second is incident-based. As discussed previously, within the class of victims who have ever had their victimization reported to the police, it is likely that the women have had more incidents reported than the men, on average, since women in general suffer more repeat victimization and are more inclined to report to the police than men are. If conversion from victim-based to incident-based reporting were the whole explanation for the difference in percentages under examination here, then women reported, on average, 2.2 incidents of violence to the police for every incident reported by men.

While this factor falls within the bounds of plausibility based on what is known from the GSS about the general population of victims, it would be helpful if more complete data and a more complete analysis of the data were available so as to test the second possible explanation for the difference in percentages under examination here. This explanation is that when the police respond to incidents involving male victims, they may be more likely to determine that it is inconsequential or uncertain, and so do not make a formal report. Further, as suggested earlier, the police might misreport an incident of mutual violence as involving only a female victim if they were called by the woman or by someone else on her behalf. These errors would tend to exaggerate the proportion of incidents reported by police as involving female victims.

Table 1.6 shows that while $14.4 \%$ of the incidents for which police made a report involved male victims, women were charged in only $11.7 \%$ of the incidents in which charges were laid. This is because $75.4 \%$ of the incidents with female victims were cleared by charge, as opposed to only $59.6 \%$ of the incidents with male victims. Put another way, incidents with male victims were almost twice as likely to be cleared otherwise than by a charge $(29.0 \%)$ as compared to incidents with female victims $(15.8 \%)$. Most of that difference is accounted for by the fact that men were more likely to request that no charges be laid (20.1\%) than women $(11.3 \%)$. This is consistent with the GSS finding that almost half of the women who reported their victimization to the police did so in order to have their partner charged, whereas only about a third of the men who reported their victimization did so to have their partner charged. However, this is not consistent with the "no-drop" policy which is nearly universal among urban police forces in Canada. According to the no-drop policy, which is not as rigid as a "zerotolerance" policy, the police are supposed to exercise their own discretion in laying charges, rather than dropping charges at the request of the victim. ${ }^{22}$

Although the number of incidents is not large, it nevertheless bears noting that charges were not laid at the discretion of the police or for "other reasons" twice as often, proportionately, when men were the victims as compared to when women were the victims. An analysis of police-recorded information on calls to partner-violence incidents in British Columbia reveals that in single-offender incidents during 1993, officers refused to recommend charges against the

\footnotetext{
${ }^{22}$ In the 1990s in the U.S. and Canada, various jurisdictions adopted zero tolerance policies, thereby reducing officer discretion in the laying of charges in disputes between partners. Subsequently, there was a large increase in the number of men charged, but an even greater leap in the number of women charged - so much so that in some places the percentage of women rose from $5-10 \%$ of the total to $20-35 \%$. The only plausible explanation for this result is that a double standard that had been guiding the police was reduced to varying degrees by the adoption of a zerotolerance policy (Verburg 1996; Brown 1997; and Goldberg 1999). The full effect did not last. The forces that had promoted zero tolerance had done so to get more men charged, and they quickly put on further political pressure to restore the imbalance against men (Blumner 1999). No systematic statistical study appears to be available on this point; but Young (1999: Chapter 5) provides an overview of the political pressures.
} 
woman over 3 times as often, proportionally (66\% vs. 20\%), as they did regarding charges against the man (Ministry of the Attorney General 1996: 16, Table 2). Using the 5-year average from 1992-96 in B.C., 70.4\% of men who were accused of violence by their partners were charged, compared with only $23.6 \%$ of (a much lower number of) women who were accused by their partners of violence (Ministry of the Attorney General 1999: 12, Table 2). All of this tends to support the inference that police exercise their discretion in such a way as to treat female perpetrators more leniently than male perpetrators in general. ${ }^{23}$

Since such a small percentage of all claimed incidents of partner violence are reported to the police, one might expect that those incidents would be drawn disproportionately from the more-serious cases of partner violence. Two plausible selection mechanisms could be at work to achieve this result: first, victims might be more inclined to call the police to intervene in the more serious incidents of partner violence; and second, the police, in turn, might make reports on only the most serious of the incidents to which they are called. Indeed, it was hypothesized earlier that the proportion of incidents involving women was higher among those to which police responded than among the general population of claimed victims of partner violence because women suffer a much higher proportion of the more serious incidents of such violence, in particular incidents requiring medical attention. Since the $U C R$ also records the level of injuries suffered by the victims of partner violence, this hypothesis can now be tested. These data are presented in Table 1.7. ${ }^{24}$

\begin{tabular}{|c|c|c|c|c|c|c|}
\hline \multicolumn{7}{|c|}{$\begin{array}{l}\text { Table } 1.7 \\
\text { Injuries reported by the police from partner violence incidents, } \\
\text { by sex of victim, } 1999 \text { and } 2000\end{array}$} \\
\hline & \multicolumn{3}{|c|}{ female $(\mathrm{N}=51,481)$} & \multicolumn{3}{|c|}{ male $(\mathrm{N}=8,652)$} \\
\hline & Count & $\% \mathrm{~N}$ & \%row & Count & $\% \mathrm{~N}$ & \%row \\
\hline Not known & 2,778 & 5.4 & 85.6 & 467 & 5.4 & 14.4 \\
\hline No injury & 23,310 & 45.3 & 85.3 & 4,015 & 46.4 & 14.7 \\
\hline Minor injury & 24,260 & 47.1 & 86.1 & 3,906 & 45.2 & 13.9 \\
\hline Major injury or death & 1,133 & 2.2 & 81.1 & 264 & 3.1 & 18.9 \\
\hline
\end{tabular}

Since the police are supposed to record 'major injury' on the UCR when the victim receives medical attention, this category should correspond closely with the 'medical attention required' category on the GSS. This fact helps us to test the hypothesis put forward above. When the data in Table 1.7 are compared to the data in Table 1.4, the hypothesis tends to be refuted. Three different, mutually reinforcing, analyses can be made to support this conclusion.

First, recall that on the GSS women claimed to suffer, on average, about 1.6 to 1.8 times as many incidents of partner violence as men claimed. And recall that women claimed to be 4 times as likely as men to report their victimization to the police. So given that 6 times as many women as men claimed victimization that required medical attention on the GSS, one would

\footnotetext{
${ }^{23}$ In one major partner-abuse survey in the U.S. in 1985, when women called police about abusive husbands, the husbands were arrested or threatened with arrest over $50 \%$ of the time; when men called police about abusive wives, the wives were never arrested or threatened with arrest. (Gelles and Straus 1988: 262.)

${ }^{24}$ This table is based on Pottie Bunge and Lock (2000: 23, Table 2.12) and Trainor (2002: 24, Table 1.9). It is not clear why the total number of women and men is different between Table 1.6 and Table 1.7, but this difference derives from differences in the data for the year 2000 (i.e., from Trainor 2002).
} 
expect much more than 6 times as many women as men to be involved in incidents involving major injuries for which police made a report. In fact, only about 4 times as many women as men were victims of major injuries in incidents for which the police made a report in the $U C R$. This might be explained, in part, by the earlier suggestion that women tend to seek medical attention much more readily than men, which would inflate their numbers in the category 'medical attention received' in the GSS relative to their numbers in the 'major injury' category on the $U C R$. Also, since women are much more likely to leave abusive relationships, it is likely that the ratio of incidents where women received medical attention to incidents where men received medical attention is closer to 1 , rather than 1.6 or 1.8 in the general population of victims. In short, the cases involving the most repeat victimization of women are likely the no-injury cases. Still, the fact that only about 4 times as many women as men were victims of major injuries on the $U C R$ strongly suggests that the selection mechanisms outlined above are overwhelmed by other factors determining which cases reach the police reports.

A second way to reach the same conclusion is by comparing the $\% \mathrm{~N}$ figures between Table 1.4 and Table 1.7. Whereas, on the GSS, the proportion of female victims who claimed to require medical attention was 5 times as high as the proportion of male victims who claimed to require medical attention, on the $U C R$ the proportion of female victims suffering major injuries was actually $50 \%$ less than the proportion of male victims suffering major injuries. This is because the number of incidents involving no injuries that was claimed on the GSS was roughly equal between men and women, whereas women were almost 6 times as likely to be the victims in no-injury incidents for which police made a UCR report. This, in turn, is because women were much more likely than men to be repeat victims of no-injury offences, and they were also much more likely to report those incidents to the police than men were. The net effect is that the injurylevel-profile of the cases for which police made a report involving male victims is very similar to the injury-level-profile of the cases for which police made a report involving female victims. Contrary to what might be naïvely expected from the GSS data, men are actually slightly more likely to experience serious victimization in those cases for which police made a report. This is consistent with the findings of other studies. ${ }^{25}$

A third way to analyse these data is to compare the proportion of incidents involving female and male victims in each injury category from the GSS data to the $U C R$ data. This can be done only very roughly. The "equalized" numbers from Table 1.4 will be used. Also, the ratio of female to male incidents in the GSS data will be presumed to be 1.6:1 in each injury category, except in the 'medical attention required' category where (as suggested by the analysis in the previous paragraphs) a ratio of 1:1 will be used. Finally, the numbers for the 5-year period in Table 1.4 will be scaled back to reflect a time period more comparable to the 2-year period addressed by the $U C R$ data in Table 1.7. Calculations based on these assumptions suggest that police make a report on about $10 \%$ of the incidents of partner violence in which women suffer no

\footnotetext{
${ }^{25}$ McLeod (1984) found that $25 \%$ of assaults on wives were serious enough to be labeled "aggravated," whereas fully $86 \%$ of those on husbands were so designated. When the police laid charges against female perpetrators, $41 \%$ of the male victims had to be hospitalized overnight or longer, and nearly all required emergency medical attention. And a far higher percentage of the accused women had used weapons. Yet only $7 \%$ of all police-recorded partner assaults in the study were committed by women. Buzawa and Austin (1993) also found that, in cases where police laid charges, $14 \%$ of female victims of partner violence had serious injuries, whereas $38 \%$ of male victims of partner violence did so. By this date, the percentage of police-recorded attacks on men had risen to $15 \%$ of all partner attacks. These were both studies of the Detroit area.
} 
injuries, and on about $2 \%$ of the incidents in which men suffer no injuries. They also make a report on about $23 \%$ of the incidents of partner violence in which women suffer minor injuries, and on about $16 \%$ of the incidents in which men suffer minor injuries. And finally, the police make a report on about $3 \%$ of the incidents of partner violence in which women suffer major injuries, and on about $4 \%$ of the incidents in which men suffer major injuries.

It would appear that the incidents involving the highest injury levels are in fact the least likely to generate a police report, at least in the case of female victims. And even in the case of male victims, the most likely kind of incident to generate a police report is the minor-injury incident rather than the major-injury incident. Even admitting the roughness of the calculations, the explanation for this result probably has a lot to do with the fact that women are much more likely than men to report relatively minor incidents to the police. In any case, it is necessary to reject the hypothesis that the reason many more incidents involving female victims are reported to the police is that women suffer more frequent and more serious victimization. Some other factor, such as the stability of the relationship or the willingness of the victim to remain in an abusive relationship, is evidently driving a great deal of the reporting of partner violence to the police. The purpose of the present study is to determine whether differences in the way the lawenforcement system treats men and women might also help to explain why the profile of the cases in the system differ systematically from the profile of the general population of cases.

Given that the injury-level-profile is very similar between female and male incidents for which the police made a report, one would expect similar charging profiles, too. With some important caveats to be noted presently, Table $\mathbf{1 . 8}$ sets out the charging data from the 2000 UCR survey.$^{26}$ It is noteworthy that proportionately almost twice as many women as men were charged with aggravated assault, assault with a weapon, or assault causing bodily harm $(20.3 \% v s$. $11.2 \%)$. This could be either because women were charged more severely than men for offences involving injury, or else because men were charged more severely than women for offences involving no injury. (The latter would increase the numbers and proportions of men charged with criminal harassment and other violent offences, and thereby reduce the proportions of men charged with the various levels of assault.) Although it is not possible to determine on

\begin{tabular}{|c|c|c|c|c|c|c|}
\hline \multicolumn{7}{|c|}{$\begin{array}{c}\text { Table } 1.8 \\
\text { Violent offences reported by police from partner violence incidents, } \\
\text { by type of offence and sex of victim, } 2000\end{array}$} \\
\hline & \multicolumn{3}{|c|}{ female $(\mathrm{N}=28,633)$} & \multicolumn{3}{|c|}{ male $(\mathrm{N}=5,142)$} \\
\hline & Count & $\% \mathrm{~N}$ & $\%$ row & Count & $\% \mathrm{~N}$ & \%row \\
\hline Aggravated assault & 96 & 0.3 & 68.1 & 45 & 0.9 & 31.9 \\
\hline Assault with a weapon or causing harm & 3,122 & 10.9 & 75.7 & 1,003 & 19.5 & 24.3 \\
\hline Common assault & 18,135 & 63.2 & 85.6 & 3,046 & 59.2 & 14.4 \\
\hline Criminal harassment & 1,977 & 6.9 & 87.7 & 278 & 5.4 & 12.3 \\
\hline Other violent offences & 5,303 & 18.5 & 87.3 & 770 & 15.0 & 12.7 \\
\hline
\end{tabular}

the basis of Statistics Canada data which explanation is the better one, the latter hypothesis is consistent with the findings of the previous paragraphs, which suggest that women are more

${ }^{26}$ Table 1.8 is derived from Minister of Industry (2001: 56-7, Table 4.10), together with Trainor (2002: 7, Figure 1.1 and Figure 1.2; and 19, Table 1.1). There might be small rounding errors in the counts in Table 1.8, but they must be accurate within a small range to fit all of the data provided. 
likely to report no-injury and minor-injury incidents to the police. ${ }^{27}$ One purpose of this study is to determine whether discriminatory police charging practice is behind this pattern.

It is necessary in passing to register another complaint about the perplexing reporting of UCR data by Statistics Canada. Trainor (2002: 19, Table 1.1) reports that the police responded to 33,775 incidents of partner violence for which a record was made for the 2000 UCR: 28,633 involving female victims and 5,142 involving male victims. These numbers match the numbers implied by Minister of Industry (2001: 56-7, Table 4.10), as reported in Table 1.8; indeed, it was on the basis of these numbers that the counts set out in in Table $\mathbf{1 . 8}$ could be narrowed down so precisely. The problem is that Trainor (2002: 20, Table 1.2) goes on to report that only 25,192 of these 33,775 incidents were cleared by charge, meaning that 8,583 incidents were not cleared by charge. (Recall the mysteries of the 'not cleared' category of cases in this sample that was discussed previously.) If $100 \%$ of the incidents reported in the 'other violent offences' category in Table 1.8 were not cleared by charge, then there would still have to have been 2,510 incidents that were identified as some kind of an assault or criminal harassment where the police declined to lay a charge. One wonders how an offence was identified for this purpose if not by the "most serious charge rule" supposedly employed in the reporting of UCR data. Perhaps there are two distinct methods of reporting victimization for the purposes of the $U C R$; but if so, Statistics Canada nowhere explains how offences are identified when charges are not laid.

It gets worse. Trainor (2002: 6; 7, Figure 1.1 and Figure 1.2) explicitly discusses 'uttering threats' as a distinct category of victimization, noting that it is in fact the second most frequently recorded offence against women $(14 \%)$ and the third most frequently recorded offence against men $(13 \%)$ on the $2000 U C R$. Yet this category does not appear at all in Minister of Industry (2001: 56-7, Table 4.10), unless it is subsumed by 'other violent offences'. But if that were the case, it would comprise nearly $100 \%$ of the other violent offences, and nearly $100 \%$ of those incidents would not have been cleared by charge. That seems rather unlikely, as there would then be no room for cases of homicide, sexual assault, kidnapping, extortion, and similar offences reported by Minister of Industry (2001: 56-7, Table 4.10). Nor does the UCR data reported by Statistics Canada include any hint of the significant number of "administrative offences" that are reported in other police data (see Table 2.7 and Table 3.4.1). So it remains a mystery where the data on uttering threats fits into the picture presented by the UCR data from Statistics Canada, and why a more systematic and clear presentation of the full range of offences (or charges) is not presented.$^{28}$ In any case, if the UCR data reported by Statistics Canada does not include uttering threats and administrative offences, but does include the mysterious incidents that are "not cleared," then it is of limited value and its comparability to other data is questionable.

\section{Prosecutor and Judicial Response}

\footnotetext{
${ }^{27}$ It would be possible to test the hypothesis in the text through an in-depth study of individual cases dealt with by the police, interviewing the alleged victims and alleged victimizers. Unfortunately, such studies have to date generally ignored male victims and female victimizers. Local examples are: Edmonton Police Service and Community and Family Services, Family Violence: Follow-up team demonstration project (1992); and Family Violence: Follow-up team implementation/expansion phase (1994).

${ }^{28}$ Exactly the same analytical problems arise in the reporting of the 1999 UCR data by Minister of Industry (2001: 55-6, Table 4.10) and Pottie Bunge and Locke (2000: 22). For present purposes, it is sufficient to detail the problems for only one set of data, however.
} 
Very little Canadian data has been systematically collected in relation to the role of prosecutors in determining outcomes in cases of partner violence. One of the B.C. studies referred to earlier (Ministry of the Attorney General 1996: 19, Table 3) indicates that, even after the police recommended charges against women proportionally much less often than against men, prosecutors in turn elected not to pursue charges against women in proportionately more cases: $16 \%$ of the women who were recommended for charges by the police were not prosecuted, as opposed to only $6 \%$ of the men. In the end, the proportion of female suspects dropped from an initial level of $10 \%$ of those accused by the police to $2.3 \%$ of those convicted. ${ }^{29}$

Occasionally, Canadian judges comment from the bench upon the differences in treatment they perceive to exist between men and women who are accused of partner violence. In finding Darryl Arsenault not guilty of assaulting his common-law partner Susan Himmer, B.C. Provincial Court Judge Brian Saunderson said, "There are far too many prosecutors declining to make the hard decisions, lest they offend some interest group or incur the displeasure of their superiors who themselves are subjected to pressure from the same groups.... The result can be to work hardship in individual cases." The judge ruled that Arsenault was defending himself when he slapped Himmer after she verbally abused and assaulted him. Himmer testified that she was drunk and in an "out of control" rampage after Arsenault's ex-wife insulted her. Judge Saunderson criticized the Crown for not charging Himmer for her assaults, saying it created a double standard. "The mere fact of this prosecution sends a very clear message: a woman in a relationship with a man can provoke him, degrade him, strike him and throw objects at him with impunity, but if he offers the least physical response, he will be charged with assault" (Daisley 1999; reasons for judgment are available from FULL TEXT under $R$. v. Arsenault, 1833-01J1.).

However, such evidence as is available suggests that judges may be as much to blame for this state of affairs as Judge Saunderson suggests that procesutors are. The judicial response to partner violence is evidenced most clearly by sentencing outcomes. Scores of published studies have been conducted on sentencing outcomes generally, though evidently none of these has specifically addressed sentencing for partner violence. Though it is difficult to get information on and control for all of the relevant variables, the overall thrust of the published studies on sentencing strongly indicates a "female discount" in most jurisdictions. Feminist scholars have produced much literature on this subject, disputing the finding of leniency for women and sometimes arguing that it is justified, but there is far too much evidence to be easily explained away. A readable, non-technical survey of all of this Julian (1993). One recent analysis eliminates many of the variables by studying involuntary vehicular homicide cases. From sentence-length disparities, it finds striking evidence for bias against males both as victims and as perpetrators (Glaeser and Sacerdote 2000).

One of the most authoritative unpublished sources relating to sentencing disparities between male and female convicts in Canada is Justice Jack Watson's hand-out material for his course in criminal sentencing, which this researcher took in the Fall 2000 term. Based on an extensive review of Canadian cases, Justice Watson openly acknowledges that women receive more lenient sentences in Canadian courts. This conclusion was confirmed by the term paper this

\footnotetext{
${ }^{29}$ One of the rare studies to examine the role of prosecutors concluded that they were more likely, everything else being equal, to recommend deferred sentences for women (cited by Fallen 1987). It was not, however, dealing with partner violence. The main objective in doing Part B of the present study was to shed light where the paucity of empirical evidence in this area was the greatest.
} 
researcher wrote for Justice Watson's sentencing course (Brown 2000). Three categories of crime were examined - partner violence, narcotics possession, and theft - using cases from the "Alberta Judgements" database of Quicklaw. In all three categories of offence, women tended to obtain more lenient sentences than men. However, only four reported cases were found in the period 1989-2000 where women had been sentenced for violence against a partner, compared with dozens of reported cases involving convicted men. A qualitative analysis of even this small sample revealed inconsistencies in the principles of sentencing applied to male and female convicts. Although no statistical tests with significant results could be performed on such a small sample, pair-wise comparisons between similarly situated male and female convicts did suggest that women received lighter sentences.

Justice Watson attributes the female discount in sentencing mainly to the fact that women tend to be the primary care-providers for children. Judges, he says, are reluctant to punish children for the crimes of their mothers, especially in cases where no other reliable care-giver is present in the children's lives. While the practical need to keep children with their primary caregiver might arguably provide a reason for lenient sentences in some particular cases, it cannot provide an across-the-board justification in cases of partner violence in particular. In the first place, sentences for partner violence rarely involve jail terms and so rarely interfere significantly with the violent partner's ability to care for children, anyway. And in the second place, when a man is the perpetrator of partner violence in the presence of children, it is held as a matter of policy that a more severe sentence is warranted in order to deter him from teaching violence as a method for resolving disputes to the children. It is difficult to see why the same reasoning should not apply to female perpetrators of partner violence. So, whether children are present or not, the female discount in sentencing for partner violence is difficult to rationalize.

An impression of the magnitude of the female discount can be gleaned from this researcher's moot-court exercise for Justice Watson's sentencing course. That exercise was conducted before Justice Sterling Sanderman of the Alberta Court of Queen's Bench (QB), the province's superior court. The assignment was to argue an appeal, as prosecutor, from a 5-year sentence for a female narcotics importer. Several cases were presented where men had received 7- to 10-year sentences for a similar offence. While acknowledging the similarity of these cases, Justice Sanderman indicated that he would not disturb the 5-year sentence hypothetically imposed at trial, frankly admitting that women can generally expect to receive a discount in sentencing in the order of $25-33 \%$. Indeed, he coined the expression "female discount" in personal conversation following this mooting exercise. When pressed about the constitutionality of the female discount, Justice Sanderman explained that this form of judicial discrimination was "systemic" - an explanation that merely calls for a reiteration of the question.

\section{Method}


The present study attempts to shed light on the pivotal role of the prosecutor in partner violence cases, while at the same time subjecting the decisions of local police and judges to further examination based on data not so readily available from more public sources. It is hypothesized that men will be found to be treated significantly more harshly than women at each step of the law-enforcement process. The harsher treatment of men in partner violence cases is to be expected for at least two broad reasons. First, this subject has received a great deal of ideological attention in the media in recent years, and thus has become highly politicized (Fekete 1994; Young 1999). It would be unrealistic to suppose that the justice system has emerged unaffected by this pressure. Second, the sympathies of the criminal-justice system generally tend to operate in two ways, which converge in cases of partner violence. On the one hand, men who are charged with offences tend to be treated more suspiciously than women, while women tend to get the benefit of a doubt. ${ }^{30}$ And on the other hand, prosecution tends to be more vigorous, and punishment more harsh, for crimes involving female victims - which is to say, less vigorous and less harsh for crimes involving male victims. In cases of violence against partners, these forces converge, potentially subjecting men to a double dose of discrimination: their account of an incident of partner violence is less likely to be believed, and they are less likely to find sympathy with the authorities even when they are believed.

Data for the original analysis in this study was obtained from two separate sources. One source was the Edmonton Police Service (EPS), which is required by provincial law to collect, aggregate, and report data on partner-abuse incidents to which they respond. Although the publicly reported data is not helpful for the purposes of the present study, raw data has been made available to researchers outside of the EPS. The present study is the first systematic analysis of these data. When combined, the two-year EPS data-set contains 2,935 observations. ${ }^{31}$ This includes 617 observations where no arrest was made, a category of case not found in the $U C R$ or other reports of police response to partner abuse. Of course, since the data were collected by the EPS, any subjectivity in the coding of the data cannot be attributed to this researcher.

The other source of data for the present study was the Edmonton Crown Prosecutor's Office (ECPO). Permission was obtained to search the "spousal abuse" files for the first half of 2001. It should be noted that there are no separate Criminal Code sections relating to partner violence; suspects are charged under the same sections that would apply in similar non-domestic situations. However, for the past few years the ECPO has "flagged" cases involving partner violence in such a way that they can be identified in a computer database. From this database, a list of partner violence cases that had been closed in the first half of 2001 was produced. The list contained 713 entries, which represents the number of charges laid in partner violence cases that

\footnotetext{
${ }^{30}$ This is why all of the most notorious Canadian cases of wrongful convictions involve men: from Steven Truscott in the 1950s and David Milgard in the 1960s, to Thomas Sophonow, Guy Paul Morin, Donald Marshall, Jamie Nelson, and others in the 1990s. It is also why most of the notorious cases of dubious leniency involve women: Dorothy Joudry using the "automatism" defence for shooting her ex-husband; Karla Homolka using the "battered woman" defence for her part in kidnapping and killing two schoolgirls; and Carline Vandenelson using the defence of "necessity" for international child abduction.

${ }^{31}$ A few entry errors in the EPS data are evident from the fact that the number of cases sometimes totals to fewer than 2935 for some variables, and fewer that the expected total for some of the charging categories in some variablegroups. Since neither party was charged in 618 of these cases, and both parties were charged in 118, the actual number of charged parties arising from these cases is $(2935-617+118=) 2436$. For some purposes, such as making comparisons with the ECPO data to be analysed later, it will be necessary to calculate proportions leaving out the 'neither charged' category and taking double account of the 'both charged' category.
} 
were completed. ${ }^{32}$ Since a number of cases involved multiple charges against one accused stemming from a single incident, the number of person-incidents on the computer-generated list where charges were laid was only about 560. According to the EPS data, 2436 persons where charged in 1999 and 2000, or about 609 per half-year. Thus the number of cases on the computer-generated list from the ECPO corresponds reasonably closely to the number of EPS cases generated over the relevant period.

For a variety of reasons, data could not be collected for every case on the computergenerated ECPO list. At least 30 of these files were marked "N/A," indicating either that they had been transferred to another jurisdiction or that a prosecutor was still holding the file. Another 30 or 40 files were rejected for a variety of reasons, such as: (i) the dispute was between a samesex couple, a dating couple, or between a partner and a third party (e.g. a "mistress," a friend, or a child); (ii) important information was not apparent in the file, or was inconsistent and therefore unreliable; (iii) the person faced other charges relating to non-domestic offences, which were impractical to disentangle; (iv) the person had died before trial; (v) the dispute was strictly over property; (vi) the charge was improperly laid (e.g. outside of the limitation period for summary conviction offences); or (vii) the person was deemed mentally unfit to stand trial.

Data were collected by working through the computer-generated list alphabetically until 353 complete observations were reached. This occurred somewhere in the ' $R$ 's. At that point, there were 60 observations involving female subjects, making them $17.3 \%$ of this sample. This proportion is about 3 percentage points higher than would have been expected based on the EPS charging data for the second half of 2000, a discrepancy which can be accounted for by the number of cases involving men that were rejected for the reasons given in the previous paragraph. ${ }^{33}$ Due to time limitations, no more files of male subjects were examined at this point; however, the rest of the alphabetical list was searched for cases involving female subjects so as to increase the sample size of that category. An additional 15 observations were thereby obtained from the R-Z cases, which raised the overall proportion of cases involving female subjects to $20.5 \%(N=368 ; M=293 ; F=75)$. It should be borne in mind that because the cases involving female subjects were drawn from a larger class of cases (A to Z) than that from which cases of male subjects were drawn (A to R only), comparisons between genders from this data set must be made cautiously - e.g. by using proportions rather than raw counts (i.e. the 'N's). Nevertheless, because the study sample mirrors the externally available data so closely in most

\footnotetext{
${ }^{32}$ The list appears to have been slightly incomplete, as was discovered in three ways. (i) The first 30 boxes of files were searched before the list was made available, and in those boxes a few cases were found that belonged in the study but did not appear on the computer-generated list. (ii) Whenever there was more than one file on an accused, the researcher had to look at all of these files to determine which of them involved the charge(s) on the list. In several such cases, the researcher discovered that more than one incident relating to the accused should have been on the list. (iii) Finally, there were a few instances where the police report in one person's file indicated that both parties had been charged, yet only one of them appeared on the list. It would appear, then, that some cases of interest to this study had been missed as a result of not being on the list. These cases would be few in number and apparently random, so there is no reason to believe that any cases not flagged by the system would skew the sample.

${ }^{33}$ Data collection for cases involving female subjects was pursued more vigorously, so as to make sure that the female sample size was sufficiently large for analytical purposes. For example, in cases where the only bit of data missing from the file was the sentencing outcome, assistance was obtained to track this information down from a computer data-base when the subject was female. When the subject was male, the file was simply passed over in the interests of time. This explains why female files were less likely to have been rejected, and therefore why the proportion of female cases in the study sample is somewhat higher than the proportion in the EPS police data.
} 
cases, as will be noted throughout this study, a high degree of confidence is held that the sample used in this study is representative of the files reaching the prosecutor's desk.

The accused in all but 7 of the cases in the ECPO sample elected trial before a Provincial Court Judge, making it impractical to analyse separately cases slated for QB. Of those 7 QB cases, 2 involved men who pled guilty to manslaughter. (One stemmed from an incident in 1993, but the suspect had "disappeared" for the intervening years.) Those 2 cases are statistical outliers in the sample, with no comparable cases involving female offenders, and so do not figure in the analysis in the body of the report except where specifically mentioned. For the record, the sentences imposed in those 2 cases were life in prison and 8 years.

Translating the information found in the files into data to be analysed posed a number of interpretive challenges, and frequently involved judgement calls. A detailed explanation of what information was gleaned from the files and how it was transformed into data is provided in Appendix A. In Appendix $B$, data from a few of the files is briefly summarized in narrative form to provide illustrative examples of some points of interest. As well, the researcher attended Provincial Court one day to witness the trial process in several cases of alleged partner violence, and recorded some observations in Appendix B.

\section{Results and Interpretation}

\section{Part A: Analysis of the EPS data}

The EPS data analysed in this study is not directly comparable to the Statistics Canada data from the Introduction. Whereas the GSS data is person-based, the EPS data is incidentbased; and whereas the UCR data identifies only two categories (female and male victims), the EPS data is separated into four charging categories. For some purposes, of course, it is helpful to look separately at the categories 'both charged' and 'neither charged'; but for the purposes of comparability, it is necessary to select and combine the relevant categories. Thus the category 'female victim' in the UCR tables corresponds roughly to the combined 'both charged' and 'male charged' categories, and so on. Also, the EPS data is more complete than the UCR data in some respects, for example by describing the circumstances of both parties to an incident rather than the victim only. For these reasons, care is required when comparing these two data sources.

The first variable of interest is the marital status of the couples involved in domestic disputes to which the EPS responded. These data are set out in Table 2.1. Note that the proportion of incidents reported by the EPS involving separated or divorced parties is perhaps surprisingly low at only $22.3 \%$ of the total incidents. Compare this to the left-hand side of Table 1.1, where $37.5 \%$ of those claiming to have experienced partner violence in the preceding 12 month period on the GSS claimed to have been victimized by a previous partner. While these proportions are not directly comparable, the difference between them is large enough to raise questions about the representativeness of the EPS data. Likewise, $34.6 \%$ of the incidents reported in the UCR data in Table $\mathbf{1 . 6}$ involved violence between previous partners. This figure is consistent with the GSS data, but is difficult to reconcile with the EPS data in Table 2.1. Nevertheless, Table 2.1 tends to support the hypothesis that partner violence is more common in more ambiguous relationships, where the parties may be more likely to have different understandings, expectations, and goals. There are almost 3 times as many cases involving 
cohabiting couples as married couples, and almost 18 times as many cases involving separated couples as divorced couples. Indeed, it is striking how few cases in this sample involve divorced couples: only 35 incidents, resulting in only 24 charges being laid, were responded to in a twoyear period in Edmonton. These data therefore tend to refute the hypothesis that women are more at risk in marriage or divorce due to the patriarchal belief that the man "owns" his wife.

\begin{tabular}{|c|c|c|c|c|c|c|c|c|c|c|c|c|c|}
\hline \multicolumn{14}{|c|}{$\begin{array}{l}\text { Table } 2.1 \\
\text { Marital status in incidents of partner violence in Edmonton, 1999-2000 }\end{array}$} \\
\hline & \multicolumn{12}{|c|}{ Charging Category } & \multirow[b]{2}{*}{$\begin{array}{c}\text { total } \\
(\mathrm{N}=2934\end{array}$} \\
\hline & \multicolumn{3}{|c|}{$\begin{array}{l}\text { both charged } \\
(\mathrm{N}=118)\end{array}$} & \multicolumn{3}{|c|}{$\begin{array}{l}\text { female charged } \\
\quad(\mathrm{N}=155)\end{array}$} & \multicolumn{3}{|c|}{$\begin{array}{c}\text { male charged } \\
(\mathrm{N}=2044)\end{array}$} & \multicolumn{3}{|c|}{$\begin{array}{l}\text { neither charged } \\
\quad(\mathrm{N}=617)\end{array}$} & \\
\hline & Count & $\% \mathrm{~N}$ & \%row & Count & $\% \mathrm{~N}$ & \%row & Count & $\% \mathrm{~N}$ & \%row & Count & $\% \mathrm{~N}$ & \%row & Count $\% \mathrm{~N}$ \\
\hline Married & 15 & 12.7 & 2.5 & 29 & 18.7 & 4.7 & 394 & 19.3 & 64.5 & 173 & 28.0 & 28.3 & $611 \quad 20.8$ \\
\hline Cohabiting & 96 & 81.4 & 5.8 & 97 & 62.6 & 5.8 & 1142 & 55.9 & 68.4 & 334 & 54.1 & 20.0 & 166956.9 \\
\hline Separated & 7 & 5.9 & 1.1 & 27 & 17.4 & 4.4 & 486 & 23.8 & 78.5 & 99 & 16.0 & 16.0 & $619 \quad 21.1$ \\
\hline Divorced & 0 & 0 & 0 & 2 & 1.3 & 5.7 & 22 & 1.1 & 62.9 & 11 & 1.8 & 31.4 & $\begin{array}{ll}35 & 1.2\end{array}$ \\
\hline
\end{tabular}

Two cross-tabulations ${ }^{34}$ were performed to determine if the marital status of the couple is associated with the laying of charges by the police. Table 2.1.1 shows a statistically significant $(p<.001)$ association between marital status and whether or not a charge was laid at all. That is, a charge was least likely to have been laid if the dispute was between a married couple, and most

\begin{tabular}{|l|ccc|cc|}
\hline \multicolumn{9}{|c|}{ Table 2.1.1 } \\
Marital status * Charge / no charge laid \\
in incidents of partner violence in Edmonton, 1999-2000 \\
\hline \\
\end{tabular}

likely to have been laid if the dispute was between a separated couple. (Due to the small number of divorced couples in these data, they are henceforth included with the 'separated' category.)

\footnotetext{
${ }^{34} \mathrm{~A}$ cross-tabulation is the standard statistical method of determining the probability of a given pattern of values being the product of random selection. The $p$ value of a cross-tabulation indicates how likely it is that the actual sample would be found if the "null hypothesis" were true. In this study, the null hypothesis is generally that gender is an irrelevant circumstance of the offence and does not affect the way in which law-enforcement authorities respond to it. So the lower the value of $p$, the less likely it is that gender is irrelevant -i.e. the more likely it is that gender is relevant. A value for $p \leq .05$ is traditionally recognized as indicating "statistical significance." Crosstabulations have certain inherent limitations. One of these has to do with sample size: if the "expected count" is less than 5 in more than $20 \%$ of the cells in a given matrix, then the $p$ value will be a less reliable indicator of statistical significance. However, it may still be the best available test of the null hypothesis; and especially in situations where $p<.001$, it remains a useful indicator of the relevance of gender in this study. Note that the "expected count" is not the count one would expect based on evidence external to the study. It is the count one would expect to obtain on the assumption that the proportion of cases within any given category is valid, but that gender is not a factor in the distribution of cases within that category. Where the expected counts diverge sufficiently and systematically from the actual counts in a matrix, a "statistically significant" association exists between the two variables.
} 
Likewise, Table 2.1.2 shows a statistically significant $(p<.001)$ association between marital status and whether a major charge or a minor charge was laid was..$^{35} \mathrm{~A}$ major charge was most likely to have been laid in a dispute between cohabiting couples, while a minor charge was most likely to have been laid in a dispute between separated couples.

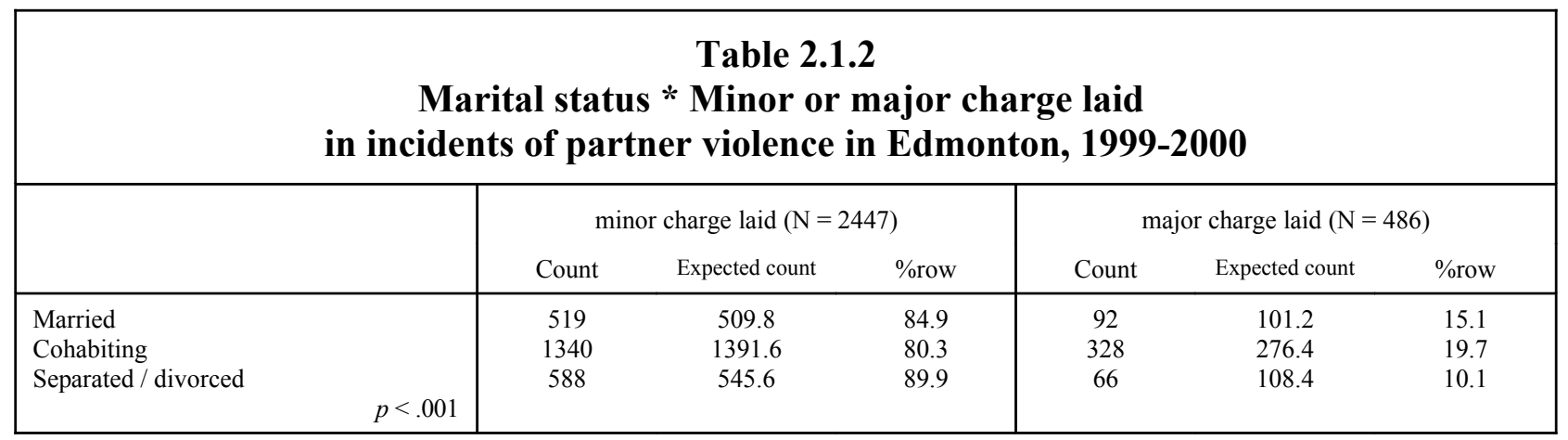

These charging patterns tend to support the hypothesis that separated couples were least likely, and married couples most likely, to urge the police not to lay charges. Separated couples were more likely to want charges to be laid even in relatively minor incidents, which is why a major charge was least likely to have been laid in a dispute between separated couples (10.1\%), as opposed to married (15.1\%) or cohabiting (19.7\%) couples. Combining this explanation with the fact that cohabiting relationships tend to be more conflict-ridden than married ones generally, the charging pattern revealed in the above tables is understandable, without supposing that the police treated couples more or less harshly because of their marital status.

However this may be, the purpose of the present study is not to see whether the police might discriminate against people on the basis of marital status; the purpose is to see whether the police might treat men and women differently, all other things being equal. Thus the important issue is whether marital status is associated with the gender of the accused in the EPS data. If it is, then it might be possible for the police to use marital status as a proxy for harsher treatment of one gender or the other. For example, if more charges were laid for less serious incidents between separated couples, and if men are more likely to be the accused in that category, then a form of systemic discrimination might be behind this pattern. Table 2.1.3 shows that in fact there is no statistically significant association between marital status and the gender of the accused ( $p$ $=.181$ ). (For the purpose of this analysis, only those cases in which a single party was charged were selected, since only in those cases is it clear who the putative victim was.) Nevertheless, men are slightly over-represented in the category where minor charges were most likely to have been made: men are $94.6 \%$ of those charged among the separated.

\section{Table 2.1.3 \\ Marital status * Gender of accused in incidents of partner violence in Edmonton, 1999-2000}

\footnotetext{
${ }^{35}$ A 'major charge' was a charge of aggravated assault, assault with a weapon, or assault causing bodily harm. A 'minor charge' was any less-serious charge, including cases where no charge was laid. For a breakdown of the charges included in the 'minor charge' category, see Table 2.7 below. Note that only the most serious charge was considered in cases where both parties were charged.
} 


\begin{tabular}{|l|ccc|ccc|} 
& \multicolumn{3}{|c|}{ female $(\mathrm{N}=155)$} & \multicolumn{3}{c|}{ male $(\mathrm{N}=2043)$} \\
& Count & Expected count & \%row & Count & Expected count & \%N \\
\hline Married & 29 & 29.8 & 6.9 & 394 & 393.2 & 93.1 \\
Cohabiting & 97 & 87.3 & 7.8 & 1141 & 1150.7 & 92.2 \\
Separated / divorced & & 29 & 37.9 & 5.4 & 508 & 499.1 \\
& & & & & & \\
\hline
\end{tabular}

The next variable to consider is intoxication. According to the EPS data set out in Table 2.2, intoxication was a factor in $55.7 \%$ of the incidents to which the police responded. The GSS found that only $35 \%$ of those who claimed victimization by a partner in the 5-year period preceding the survey claimed that their partner had been "drinking" at the time of the incident(s) (Pottie Bunge and Locke 2000: 16). Since alcohol is over-whelmingly the intoxicant of choice, it is unlikely that the large discrepancy between these two data sources can be explained fully in terms of other intoxicants - e.g. narcotic drugs - being a factor in the EPS data. More likely, the GSS data includes many low-level disputes not involving intoxicants that never reach the attention of the police.

Table 2.2

Intoxication in incidents of partner violence in Edmonton, 1999-2000

\begin{tabular}{|c|c|c|c|c|c|c|c|c|c|c|c|c|c|c|}
\hline & \multicolumn{14}{|c|}{ Charging category } \\
\hline & \multicolumn{3}{|c|}{$\begin{array}{l}\text { both charged } \\
(\mathrm{N}=118)\end{array}$} & \multicolumn{3}{|c|}{$\begin{array}{l}\text { female charged } \\
\quad(\mathrm{N}=155)\end{array}$} & \multicolumn{3}{|c|}{$\begin{array}{c}\text { male charged } \\
(\mathrm{N}=2042)\end{array}$} & \multicolumn{3}{|c|}{$\begin{array}{l}\text { neither charged } \\
\quad(\mathrm{N}=617)\end{array}$} & \multirow{2}{*}{\multicolumn{2}{|c|}{$\begin{array}{c}\text { total } \\
(\mathrm{N}=2932) \\
\text { Count } \% \mathrm{~N}\end{array}$}} \\
\hline & Count & $\% \mathrm{~N}$ & $\%$ row & Count & $\% \mathrm{~N}$ & \%row & Count & $\% \mathrm{~N}$ & \%row & Count & $\% \mathrm{~N}$ & $\%$ row & & \\
\hline Total & 77 & 65.3 & 4.7 & 99 & 63.4 & 6.1 & 1156 & 56.6 & 70.8 & 301 & 48.8 & 18.4 & 1633 & 55.7 \\
\hline Both & 65 & 55.1 & 8.6 & 48 & 31.0 & 6.3 & 486 & 23.8 & 64.3 & 157 & 25.4 & 20.8 & 756 & 25.8 \\
\hline Female & 5 & 4.2 & 3.9 & 46 & 29.7 & 36.2 & 31 & 1.5 & 24.4 & 45 & 7.3 & 35.4 & 127 & 4.3 \\
\hline Male & 7 & 5.9 & 0.9 & 5 & 3.2 & 0.7 & 639 & 31.3 & 85.2 & 99 & 16.0 & 13.2 & 750 & 25.6 \\
\hline Neither & 41 & 34.8 & 3.2 & 56 & 36.1 & 4.3 & 886 & 43.4 & 68.2 & 316 & 51.2 & 24.3 & 1299 & 44.3 \\
\hline
\end{tabular}

Intoxication should be positively associated with the laying of a charge, both directly and indirectly: directly, because it is regarded as an aggravating factor; and indirectly, because intoxicated people are less capable of self-control and so are more likely to aggress and cause an injury. This tends to be borne out by Table 2.2, since proportionately fewer cases where no charge was laid involved intoxication (48.8\%), compared with cases in which a charge was laid (55.9\%). Intoxication was also more prevalent among women who were charged $(60.1 \%)$ than among men who were charged (55.4\%), although Table 2.2.1 shows that this disparity is not statistically significant $(p=.174)$. Moreover, such disparities as exist are open to various explanations. One explanation is that violent woman are more likely than violent men to abuse substances. Another explanation is that non-intoxicated men are more aggressive than nonintoxicated women, which decreases the proportion of accused men who were intoxicated, relative to the proportion of women. These two explanations are both implausible for the same reason: according to the GSS findings noted above, violent men were in fact much more likely to have been intoxicated at the time of the incident than violent women were found to be. 


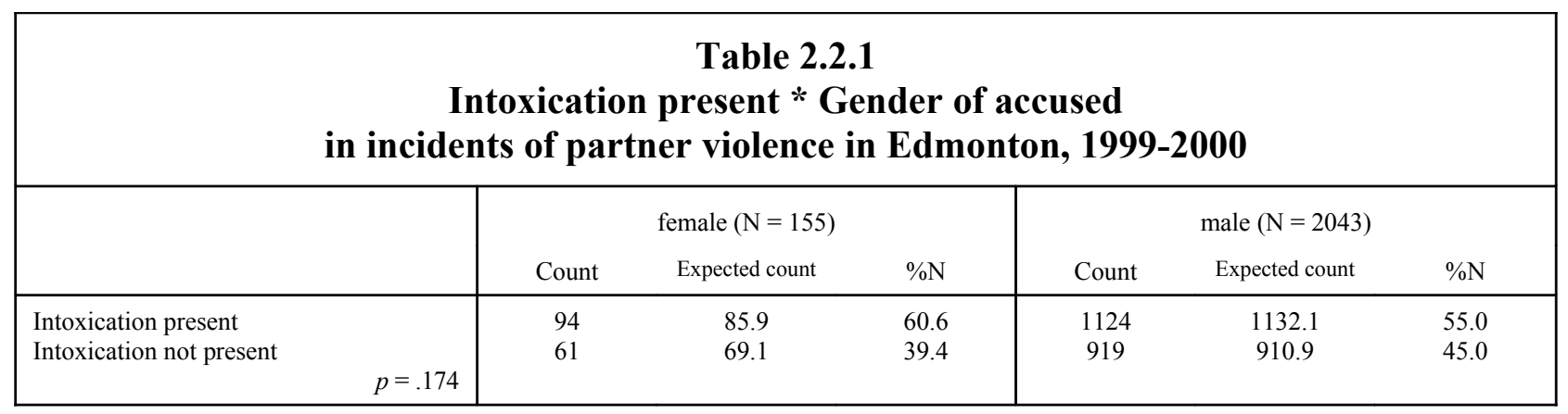

This leaves two plausible explanations for the gender disparities in intoxication noted in Table 2.2 and Table 2.2.1. One is that men are less inclined than women to call the police unless their partners are intoxicated, hence fewer non-intoxicated accused women enter the EPS sample. The other is that the police are less willing to lay charges against women without some kind of aggravating factor such as intoxication being present, thus artificially elevating the proportion of accused women who were intoxicated. Neither explanation entirely exonerates the police. The reason men might be less inclined than women to call the police without manifest justification could be that they are aware from anecdotal evidence or prior experience that their concerns will not be taken seriously or dealt with adequately anyway, absent clear proof of being at risk. In other words, men's reluctance to involve the police might be a product of systemic discrimination against them. An analysis of the EPS data on intoxication alone does not provide a direct test of these various hypotheses; however, the convergence of several findings consistent with the hypothesis of systemic discrimination against men tends to support it indirectly.

Almost a third of the incidents for which the EPS generated a report involved a repeat call. Other things being equal, police are more inclined to lay charges if they had been called to the same residence on a previous occasion. This is borne out by comparing the proportion of cases in Table 2.3 where neither party was charged at a repeat call $(25.6 \%)$ with the proportion of cases in the other three categories where someone was charged at a repeat call $(33.0 \%)$.

\begin{tabular}{|c|c|c|c|c|c|c|c|c|c|c|c|c|c|}
\hline \multicolumn{14}{|c|}{$\begin{array}{c}\text { Table } 2.3 \\
\text { Repeat calls in incidents of partner violence in Edmonton, 1999-2000 }\end{array}$} \\
\hline & \multicolumn{13}{|c|}{ Charging category } \\
\hline & \multicolumn{3}{|c|}{$\begin{array}{l}\text { both charged } \\
(\mathrm{N}=118)\end{array}$} & \multicolumn{3}{|c|}{$\begin{array}{l}\text { female charged } \\
\quad(\mathrm{N}=155)\end{array}$} & \multicolumn{3}{|c|}{$\begin{array}{c}\text { male charged } \\
(\mathrm{N}=2044)\end{array}$} & \multicolumn{3}{|c|}{$\begin{array}{l}\text { neither charged } \\
\quad(\mathrm{N}=617)\end{array}$} & \multirow{2}{*}{$\begin{array}{c}\text { total } \\
(\mathrm{N}=2934) \\
\text { Count } \% \mathrm{~N}\end{array}$} \\
\hline & Count & $\% \mathrm{~N}$ & $\%$ row & Count & $\% \mathrm{~N}$ & \%row & Count & $\% \mathrm{~N}$ & \%row & Count & $\% \mathrm{~N}$ & \%row & \\
\hline First call & 75 & 63.6 & 3.7 & 102 & 65.8 & 5.1 & 1376 & 67.3 & 68.4 & 459 & 74.4 & 22.8 & $2012 \quad 68.6$ \\
\hline Repeat call & 43 & 36.4 & 4.7 & 53 & 34.2 & 5.8 & 668 & 32.7 & 72.5 & 158 & 25.6 & 17.2 & $922 \quad 31.4$ \\
\hline
\end{tabular}

Men were more likely than women to be charged on the first call $(68.4 \%$ vs. $65.8 \%)$, although Table 2.3.1 shows that this disparity is not statistically significant $(p=.693)$. However, the lack of statistical significance in Table 2.3.1 might be misleading. Since women report experiencing repeat victimization at much higher rates than men (Table 1.4), and are also much more inclined to call the police to deal with their disputes (Table 1.5), the police have a much greater opportunity to lay charges against men than against women on a repeat call. The fact that the opposite happens therefore calls out for an explanation, even if the disparity is not 
statistically significant. The two main competing theories are that men start off being more aggressive toward their partners and hence are more likely to be charged on the first call; or that the police are not as inclined to charge women unless it is a repeat call. Doubt about the first possibility arises from the fact, to be shown later, that women involved with partner disputes that come to the attention of the police are actually more likely to cause injury (Table 2.4) and use weapons (Table 2.6) than men. Thus it would seem that, other things being equal, the police are less inclined to lay charges against a woman the first time they respond to a call on behalf of a man in a partner dispute. This tends to support the systemic discrimination hypothesis mentioned in relation to the discussion of intoxication.

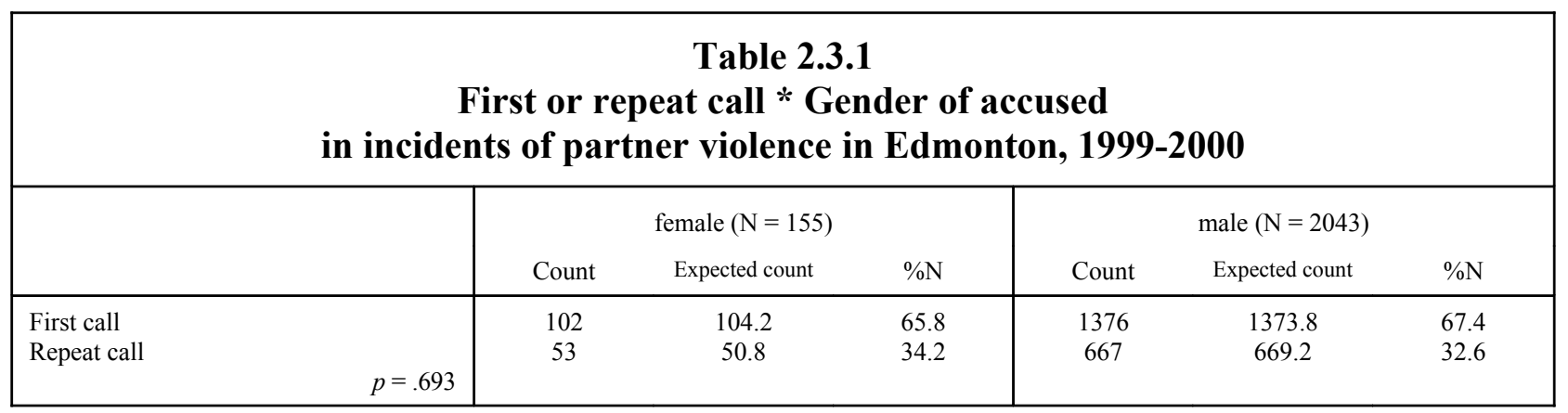

One of the most important variables relating to the response of the law-enforcement system to incidents of partner violence is the level of injury suffered by the victim. The EPS data on injuries are provided in Table 2.4. ${ }^{36}$ It is apparent that the category 'medical attention received' (line 8) overlaps significantly with the category 'major injury', since the total in the former category is 154 and the total in the latter is 123. Assuming that all of those who suffered a major injury received medical attention, only 31 persons who received minor injuries also

\begin{tabular}{|c|c|c|c|c|c|c|c|c|c|c|c|c|c|c|}
\hline \multicolumn{15}{|c|}{$\begin{array}{c}\text { Table } 2.4 \\
\text { Injury levels in incidents of partner violence in Edmonton, 1999-2000 }\end{array}$} \\
\hline & \multicolumn{12}{|c|}{ Charging category } & \multirow{2}{*}{\multicolumn{2}{|c|}{$\begin{array}{c}\text { total } \\
(\mathrm{N}=2934)\end{array}$}} \\
\hline & \multicolumn{3}{|c|}{$\begin{array}{l}\text { both charged } \\
(\mathrm{N}=118)\end{array}$} & \multicolumn{3}{|c|}{$\begin{array}{l}\text { female charged } \\
\quad(\mathrm{N}=155)\end{array}$} & \multicolumn{3}{|c|}{$\begin{array}{c}\text { male charged } \\
(\mathrm{N}=2044)\end{array}$} & \multicolumn{3}{|c|}{$\begin{array}{l}\text { neither charged } \\
\quad(\mathrm{N}=617)\end{array}$} & & \\
\hline & Count & $\% \mathrm{~N}$ & \%row & Count & $\% \mathrm{~N}$ & $\%$ row & Count & $\% \mathrm{~N}$ & $\%$ row & Count & $\% \mathrm{~N}$ & \%row & Count & $\% \mathrm{~N}$ \\
\hline Male: & & & & & & & & & & & & & & \\
\hline 1. major & 3 & 2.5 & 14.3 & 14 & 9.0 & 66.7 & 1 & 0 & 4.8 & 3 & 0.5 & 14.3 & 21 & 0.7 \\
\hline 2. minor & 10 & 8.5 & 5.4 & 97 & 62.6 & 52.4 & 20 & 1.0 & 10.8 & 58 & 9.4 & 31.4 & 185 & 6.3 \\
\hline Female: & & & & & & & & & & & & & & \\
\hline 3. major & 1 & 0.8 & 1.0 & 0 & 0 & 0 & 95 & 4.6 & 99.0 & 0 & 0 & 0 & & 3.3 \\
\hline 4. minor & 11 & 9.3 & 0.8 & 4 & 0.3 & 2.6 & 1216 & 59.5 & 89.6 & 126 & 9.3 & 20.4 & 1357 & 46.3 \\
\hline Both: & & & & & & & & & & & & & & \\
\hline 5. major & 1 & 0.8 & 33.3 & 0 & 0 & 0 & 2 & 0.1 & 66.7 & 0 & 0 & 0 & 3 & 0.1 \\
\hline 6. minor & 84 & 71.2 & 30.3 & 10 & 6.5 & 3.7 & 109 & 5.3 & 39.9 & 70 & 11.3 & 25.6 & 273 & 9.3 \\
\hline 7. none & 8 & 6.8 & 0.8 & 30 & 19.4 & 3.0 & 601 & 29.4 & 60.2 & 360 & 58.3 & 36.0 & 999 & 34.0 \\
\hline $\begin{array}{l}\text { 8. Medical } \\
\text { attention }\end{array}$ & 8 & 6.8 & 5.2 & 14 & 9.0 & 9.1 & 112 & 5.5 & 72.7 & 20 & 3.2 & 13.0 & 154 & 5.3 \\
\hline
\end{tabular}

\footnotetext{
${ }^{36}$ There were no deaths resulting from partner disputes in Edmonton in 1999-2000, and so those empty lines are omitted from this table. Also, it would seem that cases involving a major injury to one party and a minor injury to the other, if any, were codified as 'both minor'.
} 
received medical attention for those injuries (as far as the police knew), out of 2087 victims who received a minor injury (1.5\%). In other words, a "minor injury" truly is minor. It also bears noting that relatively few incidents to which the police responded involved major injuries $(4.1 \%)$, or injuries for which medical attention was provided $(5.3 \%)$. As small as these percentages are, they are almost double the national UCR rate shown in Table 1.7, where only $2.2 \%$ of female victims and $3.1 \%$ of male victims suffered a major injury or death. It is not clear why the EPS data are so unrepresentative of the national data in this respect.

From lines 1 and 2, there were 206 cases in which only the male partner was injured, and the female partner was charged in 124 of those (60.2\%). In contrast, from lines 3 and 4 , there were 1452 cases in which only the female partner was injured, and the male partner was charged in 1323 of those $(91.1 \%)$. In other words, a man is 50\% more likely to be charged if his partner is injured than a woman is to be charged if her partner is injured in a dispute to which the Edmonton police responded. Similarly, in the 276 cases in which both partners were injured (lines 5 and 6), the female partner was charged in 95 of them (34.4\%) and the male partner was charged in 196 of them (71.0\%). Thus when both partners were injured, the man was twice as likely to be charged as the woman. Finally, there were 999 cases in which neither party suffered an injury; women were charged in 38 of those (3.8\%), while men were charged in 609 of them $(61.0 \%)$. Thus when neither party was injured in a dispute to which the Edmonton police responded, the man was 16 times more likely to be charged than the women. When only one party was charged in an incident involving no injury to either party, it was the man who was charged in $95.3 \%$ of the cases. That is, the man was 20 times more likely to be charged under these circumstances.

It is difficult to say which of the above disparities is more striking. On the one hand, the fact that a man was 16 or 20 times more likely to be charged than a woman in the no-injury cases is surprising since Table 1.3 indicates that men and women are virtually equal in the perpetration of violence at the lower levels were injury is less likely. Yet the EPS data show that this is precisely the category of offence where men and women are charged at the most disparate rates. On the other hand, one of the reasons frequently given for regarding violence by women to be less socially significant than violence by men is that men are bigger and stronger and therefore are more likely to do greater physical damage. Indeed, men often cause injuries to their partners by accident, or unintentionally, in the course of a confrontation, whereas it must be relatively rare for women to cause injuries to their partners by accident or unintentionally. It follows that in cases where women do cause physical injury, it is more likely to represent a determined effort to injure - e.g. by catching the man at a vulnerable moment, while preoccupied with something else, or by surprise - and therefore should be taken more seriously.

Another pattern in Table 2.4 is noteworthy. When women were charged with an offence, the male victim suffered a major injury $6.2 \%$ of the time; whereas when men were charged with an offence, the female victim suffered a major injury only $4.4 \%$ of the time. Again, when only the woman was charged, the victim received medical attention in $9.0 \%$ of the incidents; whereas when only a man was charged, the victim received medical attention in only $5.5 \%$ of the incidents. Similarly, $73.6 \%$ of all charges against women involved minor injury to their partner, whereas only $65.7 \%$ of all charges against men involved minor injury to their partner. These comparisons indicate that the cases in which women were charged involve proportionately more injury to the victims than the cases in which men were charged. There are several possible 
explanations for these patterns, the most plausible of which seem to be the following: either abusive women, though fewer in number, are more violent on average than abusive men; or else the police are charging men in more no-injury cases than they would be if they were charging men and women equally in that category of case.

The disparities noted above are large enough to indicate that different criteria are operating when charges are laid against women and men. Further breaking down the data by injury level helps to show this. Of all of the major injuries suffered in disputes between partners to which the EPS responded in $1999-2000$, women suffered $80.5 \%$ of them. ${ }^{37}$ But there is an evident difference in treatment between cases in which men and women suffer major injuries: A man was charged in $100 \%$ of the 99 cases where a woman suffered a major injury, while a woman was charged in only $75 \%$ of the 24 cases in which a man suffered a major injury. The cross-tabulation in Table 2.4.1 shows that this disparity is statistically significant $(p<.001$, although the number of cells in which the expected count is less than 5 makes this result somewhat unreliable). Of course, it is possible to suffer an injury from one's own aggression; and it is possible to inflict an injury in self-defence. But in 4 of the cases where the man suffered a major injury, the woman suffered no injury at all. That suggests either serious incompetence on the man's part or overly aggressive self-defence on the woman's, if the charging pattern for major-injury cases is to be justified in these ways.

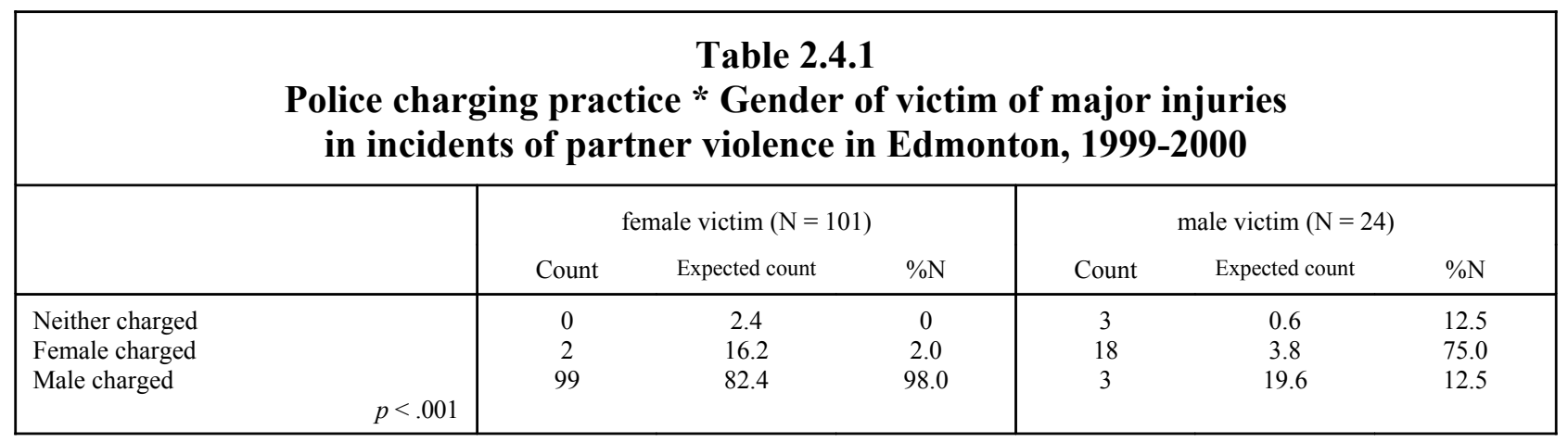

A woman suffered minor injuries in 1630 cases; a man in 458 cases. Thus women were the victims in $78.1 \%$ of all cases reported by the EPS in which a party suffered a minor injury. ${ }^{38}$ Again, differences in police charging practices are evident. In 1357 cases, the female partner was the only party to suffer a minor injury, and the male partner was charged in $90.4 \%$ of those cases. In contrast, the male partner was the only one to suffer a minor injury in 185 cases, and the female partner was charged in only $57.8 \%$ of those. Of the 1630 cases in which a woman

\footnotetext{
${ }^{37}$ This is somewhat lower than the findings of the GSS, according to which women comprised $85.8 \%$ of the victims of partner violence where there were injuries requiring medical attention (Table 1.4). As noted previously, since women report a greater frequency of victimization and a greater propensity to involve the police, the $85.8 \%$ figure from the GSS should, if anything, be an under-estimate the incident-based proportion of female victimization at this level of injury. The discrepancy here might be explained, in part, by the different perceptions of the police and the victims as to what constitutes a "major injury" requiring medical attention - especially in cases where medical attention was sought after the police intervention had ended.

${ }^{38}$ This compares with $72.7 \%$ found in the GSS for those who suffered an injury which did not require medical attention (Table 1.4). Since the EPS figure reflects the fact that women are more victimized more frequently and are also more likely to involve the police, the difference between the EPS and GSS figures is fully understandable. Thus the injury-profile of cases to which the EPS responded is reasonably representative of the general population.
} 
suffered a minor injury, the male partner was charged in 1420 of them (87.1\%). In contrast, the male partner suffered a minor injury in 458 cases, and the female partner was charged in only 201 of those $(43.9 \%)$. In other words, men were proportionately twice as likely to be charged in cases where the woman suffered a minor injury as women were to be charged when the man suffered a minor injury - despite the fact that, in general, women must make a more deliberate attempt to cause a minor injury than a man would. Again, the cross-tabulation in Table 2.4.2 shows that the EPS pattern of charging is statistically significant $(p<.001)$. But in this case, the disparity between the "count" and the "expected count" in each cell is so large as to make any explanation relating to clumsy attackers and injurious self-defenders highly improbably.

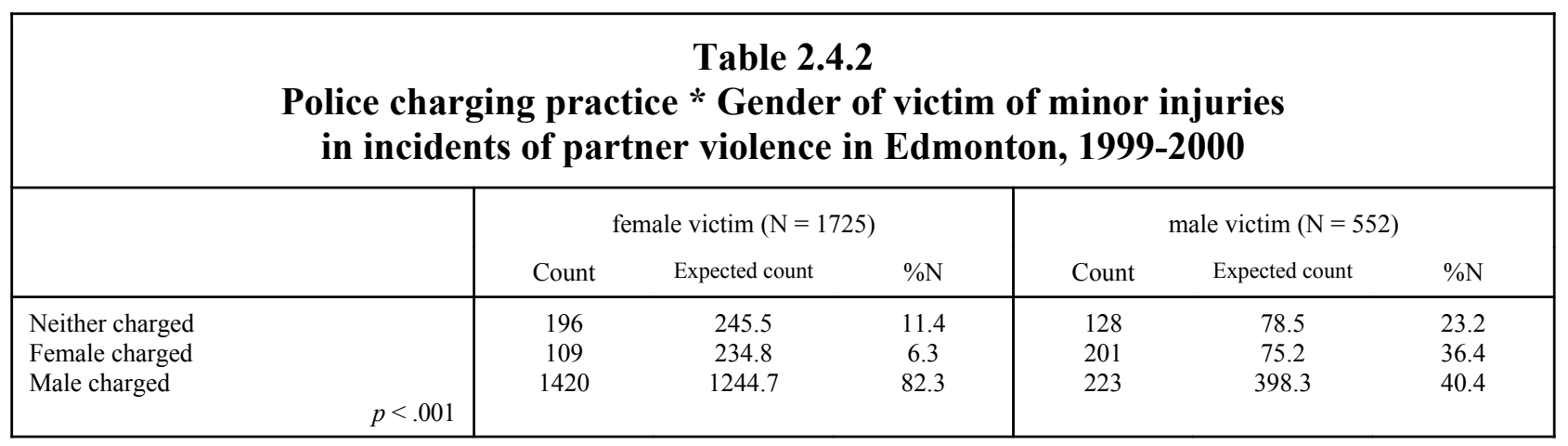

Finally, men were charged in 643 of the 1205 cases where the female partner suffered no injury $(53.4 \%)$, whereas women were charged in only 54 of the 2451 cases in which the male partner suffered no injury (2.2\%). Again, the cross-tabulation in Table 2.4.3 shows that this charging pattern is statistically significant $(p<.001)$, indicating that men were much more likely than women to be charged with an offence when no injury was suffered by their partner.

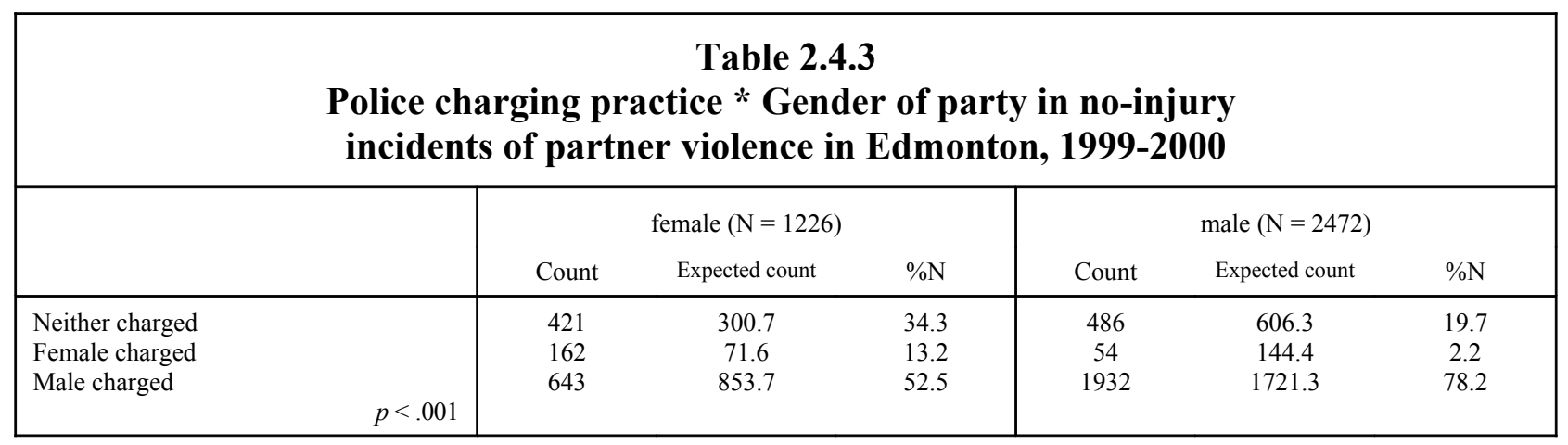

As has been said above, when statistically significant disparities in charging patterns are shown, the onus is on the law-enforcement authorities to produce credible explanations which could account for the size of the disparities in question. In response to an earlier release of some of the analysis in this study, a spokesperson for the EPS indicated that part of the reason men are more likely to be charged with an offence is that female victims tend to be more fearful of their partners even when the level of injury is the same, and the police respond to that heightened fear (Staples 2002: D8). This explanation raises important policy issues relating to whether it is appropriate for the police to take subjective fear into account when determining whether to lay charges. One reason this is questionable is that there are significant differences between the genders when it comes to expressing emotions like fear (see footnote 15 and the text related to 
Table 1.4). In fact, as Table 2.4 and Table 2.6 show, men in partner disputes to which the EPS responded were actually at significantly greater objective risk of harm than women, even if they might have exhibited less fear. It is submitted that responding to the objective risk of harm would be a better basis for laying charges than responding to the complainant's subjective fear. Furthermore, failing to respond to violence against a man by laying charges against the woman, just because the victim does not exhibit sufficient outward signs of fear, puts the man in jeopardy of further violence from his partner and in effect tells him that he must take the law into his own hands to protect himself. Yet if he does take the law into his own hands, and his partner suffers injury due to his acts of self-defence, that is bad for the woman as well as for the man, who risks being charged with an offence. Finally, laying charges against a man just because his partner exhibits signs of fear leads to men being highly vulnerable to false allegations, since fear is easily faked or exaggerated. There is now enough case law in the Edmonton jurisdiction to suggest that the police can be quite gullible or incautious when pursuing allegations by women against their partners. ${ }^{39}$ Far from alleviating concern about the harsher treatment men face, illconsidered self-justificatory comments from the EPS like the one under consideration here actually tend to support concerns about systemic discrimination against men.

The police do not report explanations when a charge was laid, but they do report explanations when a charge was not laid. The majority (58.4\%) of cases in which a charge was not laid were no-injury cases, for obvious reasons. Since it is impossible to determine with any degree of certainty which party might have been the victim or the suspect in these cases, no further analysis is possible for them. However, there were 327 cases in which there was an injury to one party or both, and yet where no charge was laid. The distribution of reasons offered for not laying charges in these cases is provided in Table 2.5. (The man is deemed to be the suspect when the woman suffered the injury, and vice versa.)

\begin{tabular}{|c|c|c|c|c|}
\hline \multicolumn{5}{|c|}{$\begin{array}{l}\text { Table } 2.5 \\
\text { Reasons provided for not laying charges in incidents of } \\
\text { partner violence involving injuries, in Edmonton, 1999-2000 }\end{array}$} \\
\hline & \multicolumn{2}{|c|}{ male suspect $(\mathrm{N}=1630)$} & \multicolumn{2}{|c|}{ female suspect $(\mathrm{N}=458)$} \\
\hline & Count & $\% \mathrm{~N}$ & Count & $\% \mathrm{~N}$ \\
\hline Informal resolution & 10 & 0.6 & 10 & 2.2 \\
\hline Both at fault & 53 & 3.3 & 47 & 10.2 \\
\hline Insufficient evidence & 63 & 3.9 & 36 & 7.8 \\
\hline Officer discretion & 32 & 2.0 & 20 & 4.3 \\
\hline Other reason & 38 & 2.3 & 18 & 3.9 \\
\hline Total & 196 & 12.0 & 131 & 28.4 \\
\hline
\end{tabular}

For every excuse available, officers were more likely to employ it so as not to lay a charge against a female suspect as opposed to a male suspect. Overall, women who injured their partners were proportionately more than twice as likely to benefit from an excuse not to lay a charge than men who injured their partners were $(28.4 \%$ vs. $12.0 \%)$. The fact that male injury victims were more willing than female injury victims to resolve the matter informally might reveal something genuinely positive about the men rather than something untoward about the

${ }^{39}$ Upon finding the defendant not guilty of a whole range of charges in a recent, as yet unreported case, $R$. $v$. Lawless, Sanderman J. went out of his way to excoriate the police for pursuing the female partner's allegations with such vigour, given the scant evidence she provided. 
charging practices of the police; but the other excuses for not laying charges seem particularly unlikely to be gender related. If anything, there would more often be a lack of evidence when women were injured than when men were injured, since women are more likely to have been injured unintentionally or by accident - e.g. in the man's self-defence - due to size and strength differences. And the excuse that "both parties were at fault," which was used by the police proportionately 3 times as often when the man was injured as when the woman was injured, also defies the preponderance of sociological evidence that mutual aggression is the most typical form of partner violence.

The cross-tabulation in Table 2.5.1 shows that the disparity by which the police find excuses not to lay charges in cases involving injury is statistically significant $(p<.001)$. If excuses for not laying charges were used in the same proportions for men and women, then 59 fewer men, and 59 more women, would have been be charged, just among those cases involving injury. Charging 59 more women would represent a $21.6 \%$ increase.

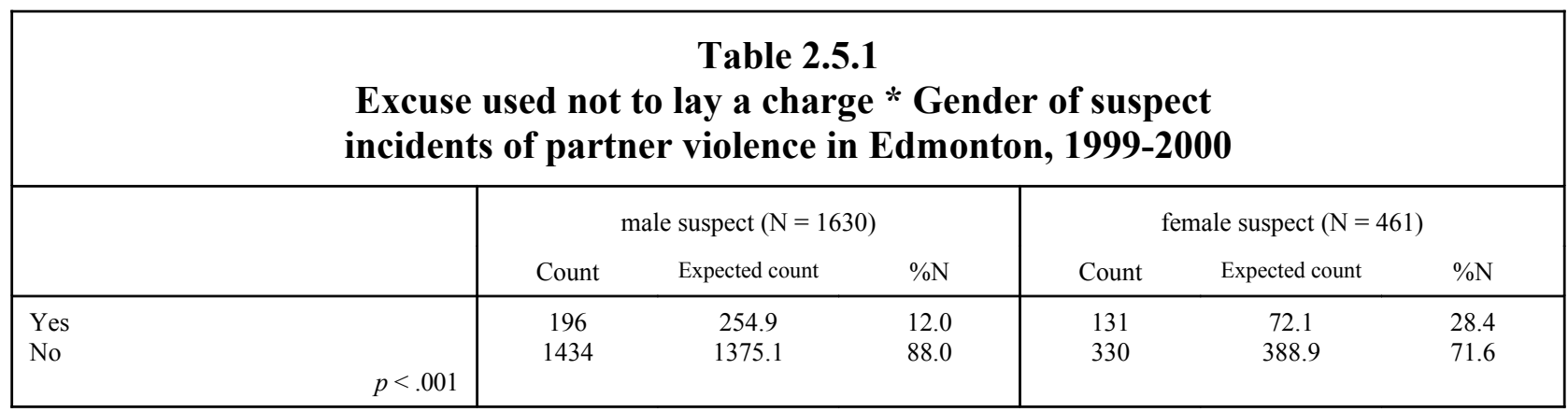

From the discussion of Table 2.4 to Table 2.4.3, women who were charged with an offence were proportionately more likely than men to cause both major and minor injuries to their partners, despite their size and strength disadvantage. One explanation for this that was canvassed earlier is that when women attack their partners they are more likely to do so with greater determination and effort than men do, including catching men when they particularly vulnerable. Indeed, women who were charged with an offence might have compensated for their smaller size and lesser strength by being more likely to use weapons in the perpetration of their violence, thus causing more injury as well. Table $\mathbf{2 . 6}$ shows that women who were charged with

\begin{tabular}{|c|c|c|c|c|c|c|c|c|c|c|c|c|c|c|}
\hline \multicolumn{15}{|c|}{ Table 2.6} \\
\hline & \multicolumn{12}{|c|}{ Charging category } & \multirow{2}{*}{\multicolumn{2}{|c|}{$\begin{array}{c}\text { total } \\
(\mathrm{N}=2921)\end{array}$}} \\
\hline & \multicolumn{3}{|c|}{$\begin{array}{l}\text { both charged } \\
(\mathrm{N}=118)\end{array}$} & \multicolumn{3}{|c|}{$\begin{array}{l}\text { female charged } \\
\quad(\mathrm{N}=155)\end{array}$} & \multicolumn{3}{|c|}{$\begin{array}{c}\text { male charged } \\
(\mathrm{N}=2036)\end{array}$} & \multicolumn{3}{|c|}{$\begin{array}{l}\text { neither charged } \\
\quad(\mathrm{N}=612)\end{array}$} & & \\
\hline & Count & $\% \mathrm{~N}$ & \%row & Count & $\% \mathrm{~N}$ & $\%$ row & Count & $\% \mathrm{~N}$ & \%row & Count & $\% \mathrm{~N}$ & \%row & Count & $\% \mathrm{~N}$ \\
\hline Firearm & 1 & 0.8 & 7.1 & 0 & 0 & 0 & 12 & 0.6 & 85.7 & 1 & 0.2 & 7.1 & & 0.5 \\
\hline Knife & 22 & 18.6 & 12.6 & 44 & 28.4 & 25.3 & 95 & 4.7 & 54.6 & 13 & 2.1 & 7.5 & 174 & 6.0 \\
\hline Blunt instr. & 6 & 5.1 & 5.5 & 17 & 11.0 & 15.5 & 77 & 3.8 & 70.0 & 10 & 1.6 & 9.1 & 110 & 3.8 \\
\hline Other & 6 & 5.1 & 5.4 & 12 & 7.7 & 10.8 & 73 & 3.6 & 65.8 & 20 & 3.3 & 18.0 & 111 & 3.8 \\
\hline Physical & 62 & 52.5 & 4.1 & 56 & 36.1 & 3.7 & 1129 & 55.5 & 74.5 & 268 & 43.8 & 17.7 & 1515 & 51.9 \\
\hline Threats & 1 & 0.8 & 0.8 & 5 & 3.2 & 3.9 & 89 & 4.4 & 70.1 & 32 & 5.2 & 25.2 & 127 & 4.4 \\
\hline No weapon & 20 & 16.9 & 2.3 & 21 & 13.5 & 2.4 & 561 & 27.6 & 64.5 & 268 & 43.8 & 30.8 & 870 & 29.8 \\
\hline
\end{tabular}


an offence did indeed use weapons proportionately more often than did men. (For the purposes of this analysis, it is necessary to ignore the 'both charged' and 'neither charged' categories, since it is impossible to tell which party used the weapon in those cases.)

While men who were charged with an offence were slightly more likely than women to have used a firearm, the difference is too small to be significant $(0.6 \% v s .0 \%) .{ }^{40}$ On the other hand, $28.4 \%$ of the women, but only $4.7 \%$ of the men who were charged, had used a knife in the commission of their offence; $11.0 \%$ of the women, but only $3.8 \%$ of the men, had used a blunt instrument; and $7.7 \%$ of the women, but only $3.6 \%$ of the men, had used some other weapon. Conversely, men who were charged with an offence were more likely than women to have relied upon physical force only $(55.5 \% v s .36 .1 \%)$, or to have only uttered threats $(4.4 \% v s .3 .2 \%)$. And men were twice as likely as women to have been charged with an offence despite using no weapon, no physical force, and no threats $(27.6 \%$ vs. $13.5 \%)$. The cross-tabulation in Table 2.6.1 shows that these charging disparities are statistically significant $(p<.001)$. In fact, in almost half of the cases where a woman alone was charged, she had used a weapon, while men used a weapon in only $13.0 \%$ of the cases where they were charged.

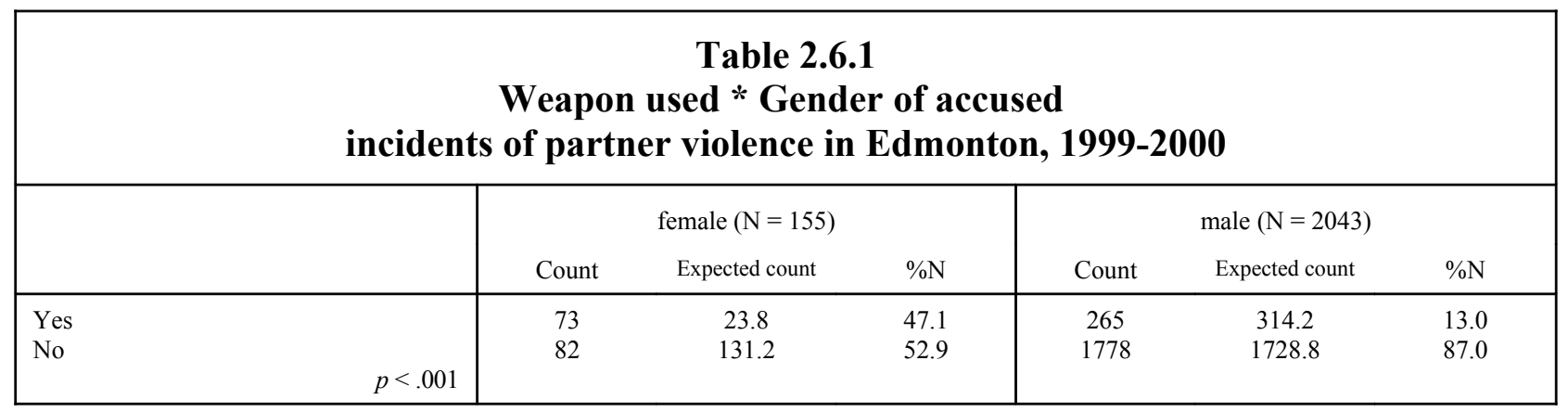

Since the women in the EPS sample were significantly more likely than the men to have used a weapon against their partners, and were significantly more likely to have caused an injury, one would expect that women would have been charged with proportionately more of the serious offences, and men would have been charged with proportionately more of the minor offences. This is borne out in Table 2.7. Women who faced charges were proportionately 2.5 times as likely to face an aggravated assault charge as men (5.8\% vs. $2.2 \%)$; and women who faced charges were proportionately 2.25 times as likely to face a charge of assault with a weapon or assault causing bodily harm (37.4\% vs. 16.5\%). At the less-serious end of the charging spectrum, women in the EPS sample were about $50 \%$ as likely to face an assault charge as men (43.2\% vs. $61.4 \%$ ). Women who faced charges were also proportionately slightly less likely to face the other, more minor charges, as well. ${ }^{41}$

\footnotetext{
${ }^{40}$ The importance of the data relating to firearms charges needs to be discounted, also, because some of these charges resulted from incidents in which the firearm was not actually used in the commission of the partner violence - e.g. when the offender was charged with improper storage of a firearm that was discovered serendipitously in the course of an investigation of a partner dispute.

${ }^{41}$ The proportions of both men and women charged with serious offences in Table $\mathbf{1 . 8}$ are much lower than in Table 2.7, although the ratios remain relatively similar. Also, the proportions of both men and women charged with criminal harassment (and uttering threats) in Table 2.7 is much lower than in Table 1.8, with women enjoying the benefit of this reduction more than men in the EPS sample. Due to concerns raised in the Introduction over the reporting of UCR data by Statistics Canada, these comparisons are probably of limited usefulness, however.
} 


\begin{tabular}{|c|c|c|c|c|c|c|c|c|c|c|c|}
\hline \multicolumn{12}{|c|}{$\begin{array}{c}\text { Table } 2.7 \\
\text { Most serious charge laid in incidents of partner violence in Edmonton, 1999-2000 }\end{array}$} \\
\hline & \multicolumn{9}{|c|}{ Charging category } & \multirow{3}{*}{\multicolumn{2}{|c|}{$\begin{array}{l}\text { total } \\
(\mathrm{N}=2316) \\
\text { Count } \% \mathrm{~N}\end{array}$}} \\
\hline & \multicolumn{3}{|c|}{$\begin{array}{l}\text { both charged } \\
(\mathrm{N}=118)\end{array}$} & \multicolumn{3}{|c|}{$\begin{array}{l}\text { female charged } \\
\qquad(\mathrm{N}=155)\end{array}$} & \multicolumn{3}{|c|}{$\begin{array}{l}\text { male charged } \\
(\mathrm{N}=2043)\end{array}$} & & \\
\hline & Count & $\% \mathrm{~N}$ & $\%$ row & Count & $\% \mathrm{~N}$ & $\%$ row & Count & $\% \mathrm{~N}$ & $\%$ row & & \\
\hline Aggravated assault & 5 & 4.2 & 8.6 & 9 & 5.8 & 15.5 & 44 & 2.2 & 75.9 & & 2.5 \\
\hline Assault with a weapon & 32 & 27.1 & 7.5 & 58 & 37.4 & 13.6 & 338 & 16.5 & 79.0 & 428 & 18.5 \\
\hline Common assault & 77 & 65.3 & 5.5 & 67 & 43.2 & 4.8 & 1255 & 61.4 & 89.7 & 1399 & 60.4 \\
\hline Criminal harassment & 0 & 0 & 0 & 1 & 0.6 & 3.8 & 25 & 1.2 & 96.2 & 26 & 1.1 \\
\hline Uttering threats & 1 & 0.9 & 1.0 & 4 & 2.6 & 4.0 & 94 & 4.6 & 94.9 & 99 & 4.3 \\
\hline Breach of a court order & 1 & 0.9 & 0.5 & 7 & 4.5 & 3.8 & 176 & 8.6 & 95.7 & 184 & 8.0 \\
\hline Other & 2 & 1.7 & 1.6 & 9 & 5.8 & 7.4 & 111 & 5.4 & 91.0 & 122 & 5.3 \\
\hline
\end{tabular}

The cross-tabulation in Table 2.7.1 shows that this charging pattern is statistically significant $(p<.001)$. The party causing injury is identified for reference purposes as the "aggressor," even though the injured party was actually charged with an offence in a significant number of cases. Those cases are broken down for analytical purposes into two categories: cases where only the injured party was charged, and cases where both parties were charged. The former category is labelled "self-defence," which seems to be the most likely explanation for why an injury was sustained only by the only accused in an incident. The latter category presumably involves mutual violence; but since it is not possible to determine from the EPS data which party was charged with the most serious offence, further analysis of this category is limited. The remaining charging categories are the mirror image of the categories in Table 2.7, increasing in severity rather than decreasing. (Among the injury cases in the EPS data, there was none in which the most serious charge laid was criminal harassment, so that line does not appear in Table 2.7.1.)

\begin{tabular}{|c|c|c|c|c|c|c|}
\hline \multicolumn{7}{|c|}{$\begin{array}{c}\text { Table } 2.7 .1 \\
\text { Most serious charge laid * Gender of aggressor } \\
\text { in incidents of partner violence in Edmonton, 1999-2000 }\end{array}$} \\
\hline & \multicolumn{3}{|c|}{ male $(\mathrm{N}=1452)$} & \multicolumn{3}{|c|}{ female $(N=206)$} \\
\hline & Count & Expected count & $\% \mathrm{~N}$ & Count & Expected count & $\% \mathrm{~N}$ \\
\hline Self-defence & 4 & 21.9 & 0.3 & 21 & 3.1 & 10.2 \\
\hline Both charged & 12 & 21.9 & 0.8 & 13 & 3.1 & 6.3 \\
\hline Neither charged & 125 & 162.9 & 8.6 & 61 & 23.1 & 29.6 \\
\hline Other (lesser) charge & 17 & 14.9 & 1.2 & 0 & 2.1 & 0 \\
\hline Breach of a court order & 3 & 3.5 & 0.2 & 1 & 0.5 & 0.5 \\
\hline Uttering threats & 6 & 5.3 & 0.4 & 0 & 0.7 & 0 \\
\hline Assault & 970 & 895.9 & 66.8 & 53 & 127.1 & 25.7 \\
\hline Assault with a weapon & 276 & 283.7 & 19.0 & 48 & 40.3 & 23.3 \\
\hline Aggravated assault & 39 & 42 & 2.7 & 9 & 6 & 4.4 \\
\hline \multicolumn{7}{|c|}{$p<.001$} \\
\hline
\end{tabular}

The man was deemed to have aggressed against his partner in self-defence, causing her injury, in only $0.3 \%$ of the cases where a man caused injury to his partner. In contrast, the women was deemed to have aggressed against her partner in self-defence, causing him injury, in $10.2 \%$ of the cases where a woman caused injury to her partner. This charging pattern does not reflect the sociological data canvassed in the Introduction, which indicates that self-defence is 
about as likely to be claimed by men as by women. In fact, since men are generally bigger and stronger than women, they are more likely to cause an injury to their partners when acting in self-defence. This would lead one to believe that proportionately more women than men would be charged despite being the only injured party. The fact that so few women were charged in this category suggests that the police do not take male self-defence as a serious possibility when men injure their partners.

Both parties were charged in less than $1 \%$ of the cases in which only the woman was injured; but both parties were charged in over $6 \%$ of the cases in which only the man was injured. In other words, the police were more likely to treat a case as involving mutual violence if the man rather than the woman was the only injured party. This suggests that if the police feel they must charge a woman because she had caused injury to her partner, they were more inclined to charge the man as well, perhaps unconsciously mitigating the charge against the woman by indicating that the violence was really mutual. Such mitigation was rarely shown toward men.

A much more pronounced disparity in treatment arises in the 'neither charged' category. When only the man was injured, neither party was charged in $29.6 \%$ of the cases, whereas when only the woman was injured, neither party was charged in only $8.6 \%$ of the cases. As in the previous two paragraphs, this pattern suggests that the police were much more reluctant to charge a woman who caused injury than they were to charge a man who had caused an injury, despite the fact that an injury to only the bigger and stronger party in a dispute would generally signal a greater determination and effort to injure on the part of the (female) perpetrator. This corroborates the findings of harsher treatment of male aggressors revealed in Table 2.4.1 to Table 2.4.3. It also corroborates the findings of Table 2.5.1 that the police are significantly more likely to find an excuse not to lay a charge against a female aggressor.

The number of cases in the next three categories - 'other (lesser) charge', 'breach of a court order', and 'uttering threats' - is too small to draw any firm conclusions. By far the most common police response when a woman was the only party injured in a dispute was to charge the man with assault. This happened in $66.8 \%$ of all cases in which the woman was injured. Conversely, when a man was the only injured party, the woman was charged with assault in only $25.7 \%$ of the cases - proportionately less than $40 \%$ as often. Based on the expected counts in this category, at least 74 more women (and 74 fewer men) should have been charged with assault than actually were in the two years under investigation. ("At least," since this calculation does not take into account the disparity in treatment favouring women noted in the 'self-defence', 'both charged', and 'neither charged' categories.) This, too, corroborates the earlier findings.

The foregoing disparities favouring women might at first appear to be mitigated by the fact that a higher proportion of women than men were charged in the two most serious categories: assault with a weapon (23.3\% vs. 19.0\%), and aggravated assault (4.4\% vs. 2.7\%). However, in the first place, the numbers in these categories are too small to account for the much greater disparities in treatment in the categories where women received relatively favourable treatment. And in the second place, as was shown in Table 2.4 and Table 2.6, women who were charged with an offence were more likely than men to have caused injuries and to have used weapons. It follows that a slightly higher proportion of women than men should be charged with the most serious two categories of offence. Thus this charging pattern actually reinforces the conclusion indicated in several places previously, namely that the police were most likely to 
over-charge men relative to women in the low-injury and no-injury cases. The conclusion that the charging pattern in Table 2.7.1 reveals a statistically significant favouritism toward women cannot easily be avoided. ${ }^{42}$

In summary: The statistically significant charging patterns discussed above are open to various explanations, some of which are more innocent than others. While it is not possible to analyse these data so as to prove precisely how much of the disparities in charging might be accounted for by each hypothesis, what can be said is that the more innocent explanations seem to be the more implausible or the least important. For example, one might take the charging patterns at face value and say that women, though much less likely than men to be violent in the first place, are nevertheless more aggressive than men when they choose to be violent toward a partner. This is not supported by the sociological data canvassed in the Introduction ${ }^{43}$ Clearly, the EPS data diverge in important ways from the sociological data, which raises the second possible explanation: only the more serious incidents involving female aggression against their partners find their way into the police reports from which the EPS data is derived, for one reason or another. This explanation almost certainly accounts for a large part of the disparities in charging patterns discussed above; but it is not entirely innocent. If men and women were equally encouraged to report their victimization to the police, and if men and women received equally satisfactory responses from the police, then the charging patterns discussed above would not be what they are. In other words, the pre-selection of incidents that generate the EPS data already reflects a significant element of systemic discrimination against men. (Consider, for example, the EPS's own suggestion that the police react to cases based on their perception of the subjective fear of the complainant.) Moreover, this explanation cannot be the whole story, since it is not capable of accounting for the significant associations that were found between gender and whether or not a charge was laid in cases involving any given level of injury.

The analyses in Part $A$ are based entirely upon data collected by the EPS themselves. This is important for two reasons. First, it means that there is no possibility that researcher bias in the codification of the data could infect the conclusions of the foregoing analysis, namely that the police tend to treat men significantly more harshly than women in disputes between partners. Second, and potentially more importantly, it could well mean that the foregoing analyses actually understate the extent of the disparity in treatment. Individual police officers presumably want to be seen as upholding the law impartially. They would therefore have a strong psychological

\footnotetext{
${ }^{42}$ More than 20\% of the cells in Table 2.7.1 have an expected count of less than 5; so technically, the conclusion that there is a statistically significant disparity in treatment must be qualified. Nevertheless, the level of statistical significance $(p<.001)$ suggests that the conclusion as stated is sound. Indeed, a further cross-tabulation was performed on the data when the 'self-defence' and 'both charged' cases were deleted and small number of 'breach of a court order' and 'uttering threats' cases were collapsed into the 'other (lesser) charge' category. There was then only 1 cell out of 10 which contained an expected count of less than 5 , and the charging pattern continued to be highly statistically significant $(p<.001)$.

${ }^{43}$ Nor is it politically correct. A Quebec judge created a storm of controversy in the media a few years ago when he explicitly endorsed the second of these two explanations. In the course of sentencing a woman who had slit her partner's throat and then happily watched him struggle to summon emergency medical attention, he stated that, while women are generally nicer than men, when they do become nasty they could be more vicious than any man. The premise that women are generally nicer than men was not disputed or even noticed by commentators on this issue; what drew people's ire was the suggestion that women could sometimes be more vicious than men. Yet the former bit of (anti-male) sexism would undoubtedly have more pervasive effects on the administration of justice than the latter (anti-female) sexism, which was explicitly limited by this judge to extraordinary, rare cases.
} 
tendency to reduce any cognitive dissonance between their reporting of the circumstances of the incidents they respond to and the charges they lay. As a result, officers would tend, consciously or unconsciously, to codify the data they collect in such a way as to justify in their own minds the actions they take in a given case. If, as the foregoing analysis indicates, the police treat men much more harshly than women, even given their own perceptions of the cases they handle, it is likely that a more neutral observer, codifying the data more objectively, would find greater disparities in treatment still. Testing this hypothesis is one purpose of the analysis of the data derived from the files of the ECPO.

\section{Part B: Analysis of the ECPO data}

The ECPO data-set has a quite different, and in some respects opposite, mix of strengths and weaknesses to that of the EPS data-set. The main weakness of the ECPO data-set relative to the EPS data-set is its smaller sample size: 366 cases as opposed to 2,935. This means that some analyses end up being no more than suggestive rather than statistically significant. Still, a sample size of 366 cases is quite sufficient to generate statistically significant results most of the time. It is certainly not an unusually small sample by the standards of studies of this general type, including studies upon which public policy has been based in the past (e.g., Ministry of the Attorney General 1996). Since the codification of the data in the ECPO data-set requires a moderate element of judgement (see Appendix A), the other weakness of the ECPO data-set is the risk of it being infected by researcher bias. Two considerations mitigate concern over this weakness, however. First, since the source of the ECPO data is information produced by the subjects of the study, it is at least as likely that the codification of the data will reflect the subjectivity of the police and prosecutors rather than the researcher. Second, as will be shown in the analyses that follow, there are enough ways to compare the ECPO data generated by the researcher to objective information (e.g. the GSS, the UCR surveys, and the EPS data) that the possibility of researcher bias in the codification of the data can be shown to be unlikely.

On the other hand, the main strength of the ECPO data-set is that it was collected with the specific goal of the present research in mind, from the best possible source of relevant information. Because the ECPO data were collected with the goal in mind of testing whether gender discrimination in the law-enforcement system exists, the researcher was able (within the constraints noted in Appendix $A$ ) to select the level of detail for each of the relevant variables to properly test this specific hypothesis. This is something that no publicly available data-set allows to the same extent, as has been noted in the analyses in Part A. Furthermore, because the ECPO data were collected from the prosecutor's own files, the relevant information about each case is complete so far as the law-enforcement system knew it at the time of making its decisions. Thus the researcher was able to test the hypothesis of the study with respect to the full range of actors in the law-enforcement system: police, prosecutors, and judges. A couple of further advantages of the ECPO data-set are worthy of mention. First, because only one person's judgement was used to codify all of the data, there is bound to be greater consistency from case to case in the codification of the ECPO data, as compared to the EPS data which was compiled from the reports of hundreds of individual officers whose perceptions of the circumstances of the offences might differ significantly. Second, information which was not specifically codified permits the researcher to make at least impressionistic reports about various aspects of the phenomenon of partner violence, based on familiarity with hundreds of cases. 
The first such impressionistic report that is worth making at the start has to do with the motivation of the accused in partner-violence cases. In particular, the prevailing ideological view that partner violence is largely if not entirely a product of men's "patriarchal" attitude toward women as their "chattels" is completely insupportable. While it may be true that this mentality plays a part in a small proportion of incidents of partner violence in Edmonton, the truth about what motivates the vast majority of the incidents is rather more prosaic. In fact, the proximate cause for partner violence ranges quite broadly, from a general disaffection with life or the relationship to specific complaints about the partner's behaviour or lifestyle: staying out too late, being a poor cook, smoking or drinking too much, appearance, driving ability, neglecting the children, depriving the parent of contact with the children, associating with unwelcome friends, jealousy, gambling, sloth, etc. In addition, it was evident that some cases involved persons with deep-seated personality problems or substance-abuse problems. Importantly, the full range of motivations was found to have been exhibited by both men and women in the ECPO sample (although "heartbreak" was specifically mentioned only by a few of the men). Indeed, the researcher was struck by how similar the genders seemed to be in their reported motivations, overall. Also, abuse became physical as a reaction to the kinds of complaints listed above almost as often as it was perpetrated by way of expressing them. Note that self defence was raised infrequently by either gender in the files searched by the researcher, presumably because where it was a credible claim - at least for a woman - the police would not have laid charges. (As illustrative cases $\mathrm{C}$ and $\mathrm{D}$, Appendix $B$, show, men also act in self defence, but are more likely to be charged anyway.) Any suggestion that partner violence derives from a single, gender-specific cause is therefore highly dubious.

An imperfect though objective indication of the degree of similarity in partner violence between those cases involving men and those involving women is suggested by the ways in which gender is associated with other circumstances of the offence. If such factors as marital status, substance abuse, and the presence or absence of children at the time of the incident are not associated with gender, then this would suggest that the overall circumstances of the offence are similar in the two types of case. Table 3.1 summarizes these relationships.

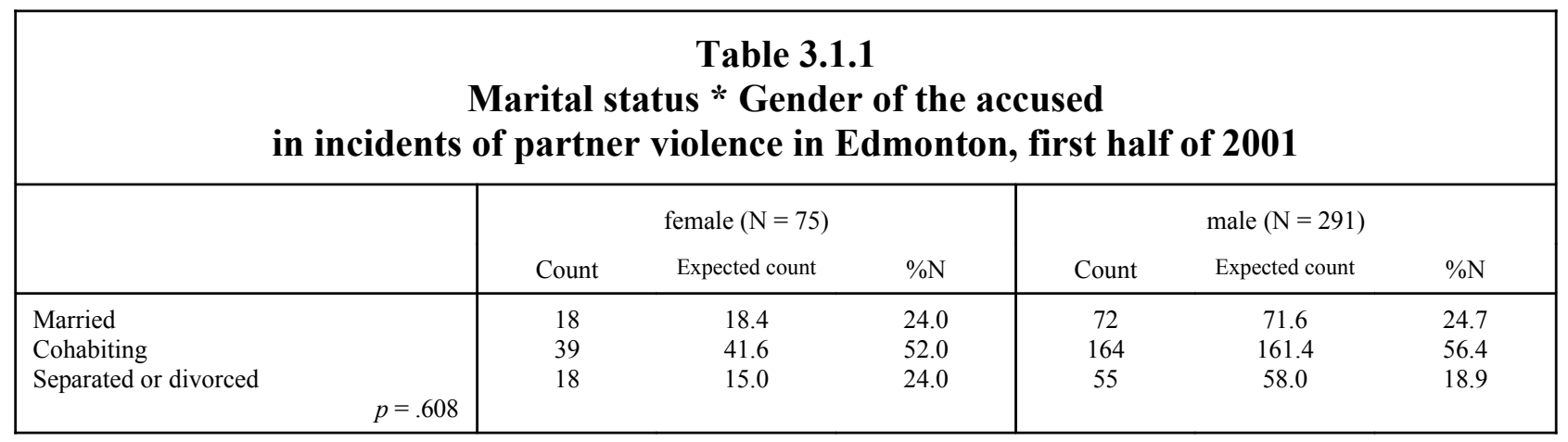

Table 3.1.1 shows that there is no statistically significant association between the gender of the accused in the ECPO partner-violence cases and the marital status of the couple $(p=.608)$. If there is any surprise here, it is that almost one-quarter of the charged women had been separated at the time of the incident, while fewer than one-fifth of the charged men were in this category $(24.0 \%$ vs. $18.9 \%)$. Although not statistically significant, this disparity is nevertheless interesting because it refutes the common belief that only men seek to control the relationship 
after separation. ${ }^{44}$ (Illustrative cases A and B, Appendix B, both involve female perpetrators who were separated at the time of their incidents.) It is especially surprising to see such a high proportion of separated women accused of partner violence, relative to men, given all of the problems separated men have in continuing a relationship with their children - problems which drive many of them to violence, including suicide. ${ }^{45}$ Nevertheless, this finding is consistent with the GSS data from Table 1.1 (lines 6 and 8), according to which 28\% of abused men, as opposed to only $22 \%$ of abused women, claimed that violence by their partners increased in severity after separation; and $42 \%$ of abused men, as opposed to only $37 \%$ of abused women, reported that violence by their ex-partners began only after separation. It also bears noting that the proportions of cases involving married, cohabiting, and separated couples in Table 3.1.1 are very close to the proportions in Table 2.1. This tends to confirm the reliability of the codification of ECPO data.

According to Table 3.1.2, there is no statistically significant association between the gender of the accused and substance abuse at the time of the incident $(p=.981)$. (The abused substance was overwhelmingly alcohol.) Given how intoxication was recorded (see Appendix $A$ ), it was found to be a factor in at most half of all cases, whether the person charged was a man or a woman. This compares favourably with the finding reported in Table $\mathbf{2 . 2}$ that intoxication was a

\footnotetext{
${ }^{44}$ A typical media example of this is Warwaruk (2002), who writes, "'The whole issue is about power and control,' said Sandra Danco, executive director of WIN house, a shelter for abused women. 'Life is so dangerous for women in abusive relationships and, unfortunately, it can end in tragedy. Separation does not necessarily mark the end of a violent relationship." The gender-specific language in this quotation is evidently unwarranted.

${ }^{45}$ How the treatment of men in family-law courts affects and is affected by their treatment in the criminal-law courts deserves much more attention and research than can be provided in the present study. Nevertheless, it can be said that these reverberations almost certainly promote partner violence after separation, rather than muting it. Based on 1,600 interviews in August 2001, Goldbarb Consultants found that only 10\% of Canadians endorsed the family-law system as balanced. "The vast majority of those who saw bias... think the system is badly tilted towards the mothers" (Aubry 2002). Note that the 10\% figure for those who see the system as "balanced" is so small that even many of those who benefit from the perceived bias against men must agree that the system is tilted in their favour.

The high level of frustration many men experience upon separation is understandable given that they stand to lose their home, a large part of their income, and meaningful contact with their children, along with their partners as often as not, through no fault of their own. A study by Fathers Are Capable Too (which is available on their web site at $h t t p: / / w w w$.fact.on.ca.) compares the fates of ex-partners who start with equal initial incomes. It shows that $60 \%$ of men paying support for one child fall within Statistics Canada's "relatively impoverished" zone, and $80 \%$ of men paying support for two or three children fall into this category. The women recipients, on the other hand, end up well into the comfort zone, regardless of the number of children or income quintile. A host of draconian measures is employed by government agencies to make sure that fathers pay this child support on time. Meanwhile, there is great reluctance on the part of the courts to do anything other than issue lame warnings to mothers who regularly deny fathers access to their children. On April 28, 1998, lawyer Karen Selick presented these findings to the Senate Committee on Social Affairs, Science and Technology, which was studying the impact of the child-support guidelines that came into effect in 1997. (A transcript of her testimony is available on her web site at http://www.karenselick.com/Senatespeech.html. She reports this event in Selick (2001), which is available online at http://www.karenselick.com/CL0101.html.) She concluded her testimony by "predict[ing] that we would soon see more divorced men slipping into the underground economy, leaving the country, committing suicide, or committing murder" as a result of the unbearably oppressive nature of their condition. Senator Marjorie LeBreton responded, with unfortunately typical unconcern for the fate of these men: "I hate to see that kind of language used in hearings such as this." But, Selick writes, "several recent widely publicized father suicides seem to justify my concern." A list of dozens of fathers who have committed suicide or murder-suicide expressly as a consequence of their unbearable post-separation situation is available at $h t t p: / / w w w . m e s a c a n a d a . c o m$. In short, to repeat, it is surprising that women nevertheless appear to become more violent after separation. Perhaps separated women accurately perceive that the family and criminal courts are firmly on their side; and seeing that their partners are vulnerable due to their straitened circumstances, they feel relatively unconstrained in "kicking them while they are down."
} 
factor in $55.7 \%$ of the incidents to which the EPS responded. ${ }^{46}$ Insofar as intoxication might affect the response of law-enforcement to the incident - e.g. in the laying of charges, opposition to bail, and severity of sentencing - no differences between men and women overall would be warranted based on these data.

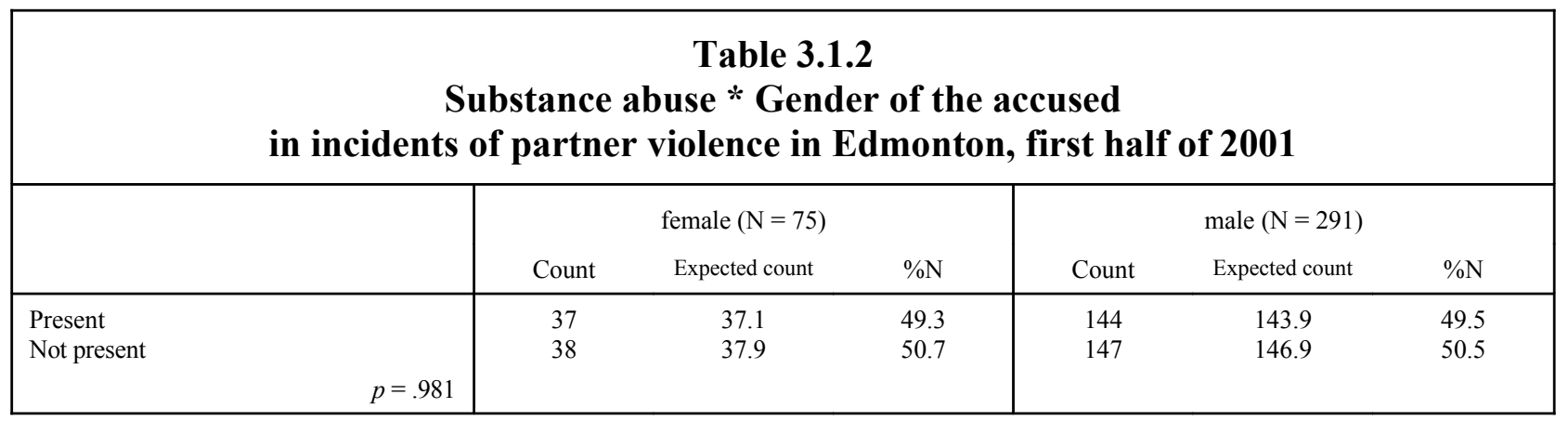

Table 3.1.3 shows that there is no statistically significant association between the gender of the accused and the presence or absence of children at the time of the incident $(p=.381)$, even though children were slightly more likely to have been present when the mother was the victim. While the EPS data did not include a variable for the presence of children, the ECPO result is broadly consistent with the GSS finding that children were present in roughly $37 \%$ of all incidents of partner violence. However, the GSS noted a significant gender disparity on this score, with $47 \%$ of the female victims reporting the presence of children at the time of the incident as opposed to only $25 \%$ of the male victims (Pottie Bunge and Lock 2000: 16). In any event, the pattern in Table 3.1.3 indicates that this circumstance of an offence is not significantly different whether men or women are the ones being charged, and therefore should not significantly affect the response of the law-enforcement system as between the genders.

\begin{tabular}{|l|ccc|ccc|}
\hline \multicolumn{7}{|c|}{ Table 3.1.3 } \\
Children present * Gender of the accused \\
in incidents of partner violence in Edmonton, first half of 2001 \\
\hline \\
\end{tabular}

The most important factor in how a case should be handled by the law-enforcement authorities is the seriousness of the offence, as measured by the level of injury sustained by the complainant or by the inherent dangerousness of the weapon used in the commission of the offence. Understanding the relationship of these factors to the gender of the person charged is therefore critical to the findings of this study. Table 3.2 shows that the gender of the accused is in fact significantly associated with the level of injury sustained by the partner $(p=.010) .{ }^{47}$ In the ECPO sample, women who were prosecuted for partner violence tended to inflict higher levels

${ }^{46}$ The Ministry of the Attorney General (1999: 18, Figure 2) found that intoxication was present in $53 \%$ of the incidents of partner violence in their survey. According to the GSS, $43 \%$ of women but only $25 \%$ of men reported that their partner had been drinking at the time of the incident (Pottie Bunge and Locke 2000: 16). 
of injury upon their partners than did the men. Thus proportionately fewer women than men were prosecuted in no-injury cases $(21.3 \%$ vs. 36.8\%), while proportionately more women than men were prosecuted in both medium- and high-injury cases $(25.3 \% v s .16 .8 \%$ and $12 \% v s .4 .8 \%$ respectively).

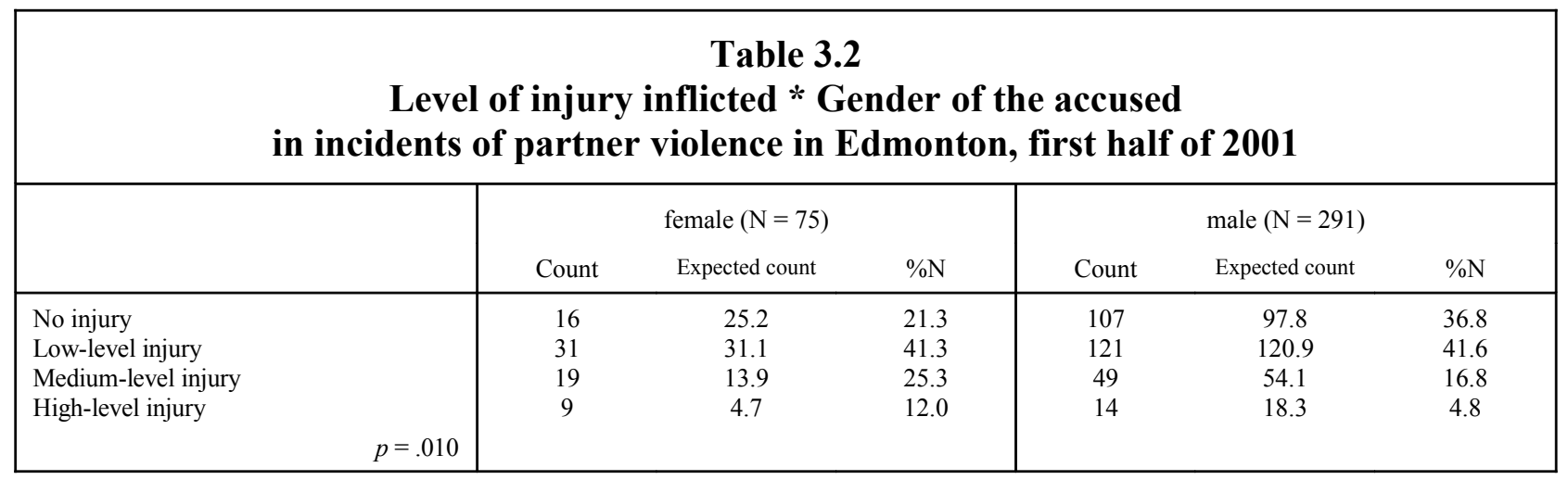

These disparities warrant clarification and emphasis. They do not mean that more women than men in the sample (much less in society) caused high-level injuries to their partners; they did not. What they mean is that if a woman was prosecuted for partner violence, then she was more likely to have inflicted a medium- or high-level injury upon her partner than a man who was prosecuted for partner violence. This is mainly because so many more men than women were prosecuted despite causing no injury - i.e. in just the kind of case where one would expect from the sociological data the greatest degree of equality in the perpetration rates. That result is, of course, entirely consistent with what was found in the analysis of the EPS data.

Another way in which the data in Table 3.2 show that women who were prosecuted for partner violence tended to inflict significantly higher levels of injury upon their partners than did the men is by comparing the proportion of women who were prosecuted for an offence at each level of injury. Thus only $(16 / 123=) 13.0 \%$ of those prosecuted in no-injury cases were women; $(31 / 152=) 20.4 \%$ of those prosecuted in low-injury cases were women; $(19 / 68=) 27.9 \%$ of those prosecuted in medium-injury cases were women; and $(9 / 23=) 39.1 \%$ of those prosecuted in high-injury cases were women. Notice that there is almost a linear increase in the proportion of women prosecuted with an offence as the injury level inflicted upon the victim increases: Women were proportionately 1.5 times as likely to be prosecuted in a low-injury incident than in

\footnotetext{
${ }^{47}$ As noted elsewhere, the validity of the figures in this table depends upon the reliability of the information relating to the injury that appears in the police reports in the prosecutor's files. While there is no practical way to objectively test the reliability of the information provided by police to the prosecutor, the evidence marshaled in previous sections of this study suggests that the police tend not to see harm to male complainants as being as serious as equal harm to female complainants. This could be in part because women exhibit greater fear than men during the police investigation, all other circumstances of the offence being equal. In any case, this researcher acquired the distinct impression from reading over 400 reports that police were much more careful in detailing the extent and nature of injuries sustained by women compared to men. (A particularly dramatic illustration of this is case $\mathrm{B}$, Appendix B, although similar tendencies can be detected in cases E, F, and H.) For example, police routinely noted the placement and size of mere "red marks" on female complainants - marks that are consistent with restraining actions such as a slap or a firm grip - while failing to report even the length of the cut or the number of stitches received by men when they received medical attention for injuries. It is therefore almost certain that Table 3.2 under-states the true association of gender to level of injury sustained by the victims in the sample. While noteworthy, the suggested under-statement of injuries to men relative to women is not relied upon in any subsequent analysis.
} 
a no-injury incident; they were proportionately twice as likely to be prosecuted in a mediuminjury incident than in a no-injury incident; and they were proportionately 3 times as likely to be prosecuted in a high-injury incident than in a no-injury incident.

The fact that women were prosecuted in almost $40 \%$ of the cases involving high-level injuries might suggest that the ECPO sample is skewed, since this is a higher proportion than is found in most of the sociological evidence. However, this high proportion can be accounted for in two ways. First, the count for women is derived from the larger data-source (A-Z) than the count for men (A-R only). To draw from similar-sized data-sources, the female count would have to be reduced by the proportion of female cases added after data from male cases were no longer collected (i.e. by $15 / 75$, or $20 \%$, or 2 cases). Second, the count for men is missing the 2 cases where manslaughter convictions were obtained, and may be missing another 1 or 2 cases due to the rejection of some male-suspect cases for reasons noted in the Method section. Adding 4 cases to the men's count and subtracting 2 cases from the women's count for high-level injuries results in a proportion of $28 \%$ women in this category. This is within the range predicted by the sociological evidence, suggesting that at the highest levels of injury - but only at the highest levels, where discretion to lay charges is least open to them - local police charge women, and they are subsequently prosecuted, on the same basis as men.

If the pattern in Table 3.2 had not already been seen and discussed in regard to the EPS data, it might seem counter-intuitive. Given that women comprise fewer than $17 \%$ of persons charged and prosecuted with partner violence in Edmonton in the second half of 2000 - and much fewer yet in Canada-wide surveys - one might suppose that female partners are much less violent than male partners in general, and therefore that women who are charged and prosecuted would be less violent on average than men who are charged and prosecuted. The pattern in Table 3.2 is open to the same possible explanations as was discussed previously in relation to Table $\mathbf{2 . 4}$ to Table 2.4.3. One might accept these facts at face value as evidence that women are much less inclined to resort to violence to begin with, although when they do resort to violence they cause greater injury than men, on average. This explanation was rejected as being inconsistent with the evidence canvassed in the Introduction and in Part $A$ above. The more plausible explanation for the data in Table 3.2 is that, while women commit about as many minor acts of partner violence as men, they are simply not being charged as readily in those cases. In other words, women must inflict more serious injuries upon their partners before charges will be laid.

Given men's strength advantage, one might wonder how women who were charged with partner violence were nevertheless able to cause proportionately greater injury than men. The EPS data indicate that women compensate in violent disputes by using weapons more frequently than men. Table 3.3 tends to confirm this $(p<.001)$. Men used weapons in about $15 \%$ of the cases where they were charged, whereas weapons were used in fully $40 \%$ of the cases where women were charged. In fact, women were more likely to use every kind of weapon except guns, although in this and some other categories too few observations existed to make meaningful comparisons. The weapon of choice for women was obviously a knife or similar piercing object: in more than one-quarter of the cases where women were charged with partner violence, they had used a knife. This compares with only $3.4 \%$ of cases involving use of a knife when men were charged. All of this is highly consistent with the EPS data reported in Table 2.6. 


\begin{tabular}{|l|l|l|lcl|}
\hline \multicolumn{7}{|c|}{ Table 3.3 } \\
Weapon used * Gender of the accused \\
in incidents of partner violence in Edmonton, first half of 2001 \\
\hline \\
\end{tabular}

The greater use of weapons by women who were charged and prosecuted for partner violence is likely an artefact of the lower levels of reporting to police, and of action taken by police, when women do not use weapons. In any event, for the purpose of Part B of this study the key point is that by the time files land on the prosecutor's desk, they have been pre-selected in such a way that, proportionately, those involving women concern inherently more-serious offences than those involving men - whether seriousness is measured by actual injury inflicted or by the use of a weapon (or both). The next question is whether the charges laid against women in the ECPO sample reflect this profile. Table 3.4 sets out these comparisons.

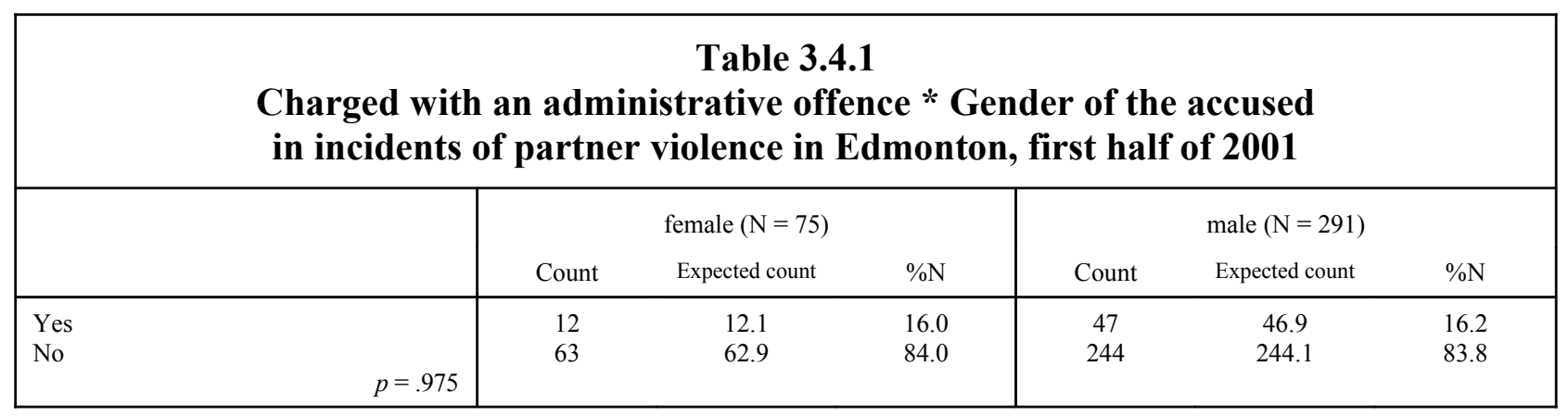

Table 3.4.1 shows that men and women who were charged with an offence against their partners were equally likely to have been charged with an "administrative offence." This is surprising inasmuch as a higher proportion of men than women in the general population are subject to the kinds of conditions which might result in an administrative offence being charged. This category of offence includes: failure to appear in court on a summons, a promise to appear, or a recognizance; failure to comply with the terms of an undertaking or a probation order; or breach of a no-contact order as part of a peace bond. Importantly, it does not include breaching a child access order by denying the non-custodial parent access, since that is a civil rather than a criminal matter. (However, breaching a custody order by not returning a child promptly at the end of one's access period may be considered kidnapping, which is a Criminal Code offence.) Although a person who flagrantly breaches a civil court order can in theory be held in contempt of court, and criminal charges can in theory follow from this, the courts never seem to take the enforcement of their access orders that seriously (see footnote 45).

By way of comparison to external data, breach of a court order was the most serious charge laid in $8.0 \%$ of the cases in the EPS data (Table 2.7). The relatively low number for the 
EPS data as compared to the ECPO data is undoubtedly a product of the 'most-serious offence' rule by which the EPS data were codified, since an administrative offence was counted in a significant number of cases in the ECPO data-set when a more serious charge was also laid. (The comparability of the EPS and ECPO data improves with the seriousness of the charge, as the 'most serious offence' rule becomes less of a factor.) The disparity between these figures could also be partly a result of the fact that some of the administrative offences included in the data for Table 3.4.1 might have been categorized as 'other' in the EPS data-set.

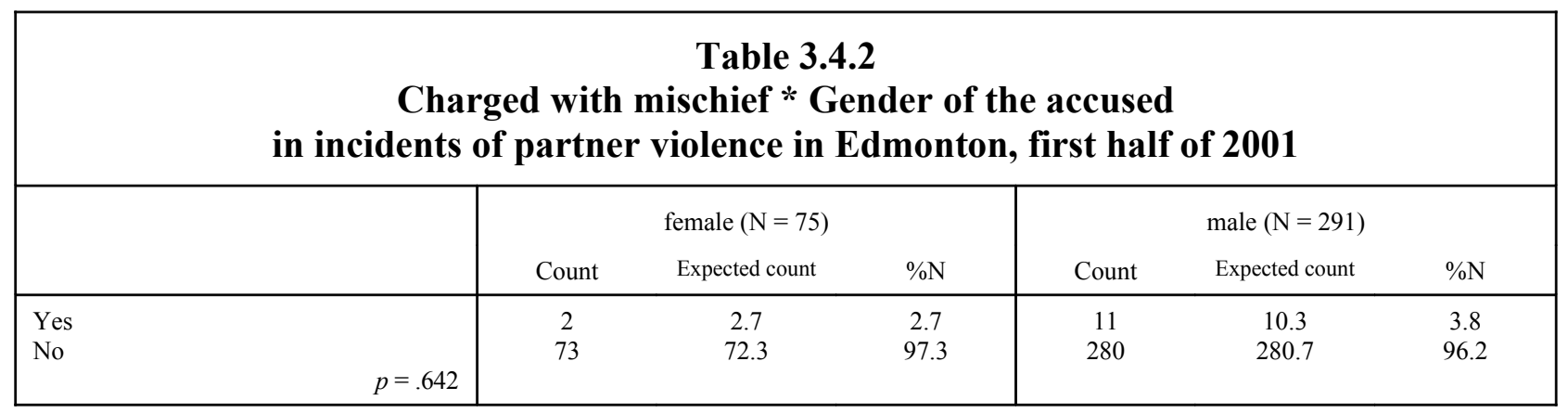

Table 3.4.2 shows that there is no statistically significant association between the gender of the accused and being charged with mischief $(p=.642$, although the expected counts are too small in this table to make that measure highly reliable). Mischief was not a very common charge, as can be seen from the fact that it does not even appear in the EPS data in Table 2.7. Nor does it appear in the much more comprehensive Table 4.10 of Minister of Industry (2001: 56-7). The best comparison available is with Ministry of the Attorney General (1999: 22, Table 5 ), where mischief was the most serious charge laid in $3 \%$ of the cases.

\begin{tabular}{|l|ccc|ccc|}
\hline \multicolumn{7}{|c|}{ Table 3.4.3 } \\
Charged with break \& enter with intent * Gender of the accused \\
in incidents of partner violence in Edmonton, first half of 2001 \\
\hline \\
\end{tabular}

Table 3.4.3 shows that there is no statistically significant association between the gender of the accused and being charged with break \& enter with intent $(p=.123$, although again the expected counts are too small in this table to make that measure highly reliable). Again, the only available data for comparison purposes is with Ministry of the Attorney General (1999: 22, Table 5), where the categories 'break \& enter', 'forcible entry', 'theft', 'robbery' and 'unlawfully in dwelling' together comprise roughly $3 \%$ of the most serious charges laid.

Table 3.4.4 shows that there is a statistically significant association between the gender of the accused and being charged with a weapons offence $(p=.047)$. Curiously, women were proportionately more likely to have faced this charge. It should be recalled that a 'weapons offence' includes such things as improper storage or use of a weapon, and does not include 
assault with a weapon (for which see Table 3.4.11). Typically, this offence was uncovered serendipitously during the investigation of a partner dispute where weapons had not actually been used. Given that men are much more likely to own firearms and are therefore more likely to have been found in non-compliance with safe-storage laws, the fact that proportionately more women than men were charged with a mere weapons offence calls for explanation. The only one that comes to readily mind is that in cases where a charge of assault with a weapon would have been warranted against a male suspect, the police were more likely to charge women with the lesser offence of common assault combined with a minor weapons offence - or even with a simple weapons offence alone. In any event, the only available data for comparison purposes is with Ministry of the Attorney General (1999: 22, Table 5), where a 'weapons offence' was the most serious charge laid in $2 \%$ of the cases.

\begin{tabular}{|l|ccc|ccc|}
\hline \multicolumn{7}{|c|}{ Table 3.4.4 } \\
Charged with a weapons offence * Gender of the accused \\
in incidents of partner violence in Edmonton, first half of 2001 \\
\hline \\
\end{tabular}

Table 3.4.5 shows that there is no statistically significant association between the gender of the accused and being charged with unlawful confinement $(p=.175)$. In this case, the finding of no statistical significance may be a somewhat misleading artefact of the small sample size. After all, 100\% of the cases involving unlawful confinement charges involved male accuseds. That is because confinement was typically effected with physical force alone - blocking the exit - and women were generally not strong enough to achieve this result, even though there were cases in the ECPO files where she had tried. It should be noted that male victims in that situation face a catch-22: if they do not attempt to overcome their partner's blocking of the exit with physical force, then the police are not likely to see it as a genuine case of unlawful confinement on the ground that he "could have left whenever he wanted to;" but on the other hand, if he does use physical force to shove his partner aside and leave, then he risks injuring her and thereby inviting criminal charges. This is one of a large number of scenarios in which men are "damned if they do and damned if they don't" - where the police are reluctant to enforce the law strictly on behalf of men because men are expected to be able deal with the problem themselves; but when they do deal with it themselves, they may be accused of taking the law into their own

\begin{tabular}{|l|ccc|ccc|}
\hline \multicolumn{7}{|c|}{ Table 3.4.5 } \\
Charged with unlawful confinement * Gender of the accused \\
in incidents of partner violence in Edmonton, first half of 2001 \\
\hline \\
\end{tabular}


hands. In any event, for comparison purposes, Ministry of the Attorney General (1999: 22, Table 5) reports less than $1 \%$ of cases where unlawful confinement was the most serious charge laid.

\begin{tabular}{|c|c|c|c|c|c|c|}
\hline \multicolumn{7}{|c|}{$\begin{array}{l}\text { Table 3.4.6 } \\
\text { Charged with overcoming resistance * Gender of the accused } \\
\text { in incidents of partner violence in Edmonton, first half of } 2001\end{array}$} \\
\hline & \multicolumn{3}{|c|}{ female $(\mathrm{N}=75)$} & \multicolumn{3}{|c|}{ male $(\mathrm{N}=291)$} \\
\hline & Count & Expected count & $\% \mathrm{~N}$ & Count & Expected count & $\% \mathrm{~N}$ \\
\hline $\begin{array}{l}\text { Yes } \\
\text { No }\end{array}$ & $\begin{array}{c}0 \\
75\end{array}$ & $\begin{array}{c}1.4 \\
73.6\end{array}$ & $\begin{array}{c}0 \\
100\end{array}$ & $\begin{array}{c}7 \\
284\end{array}$ & $\begin{array}{c}5.6 \\
285.4\end{array}$ & $\begin{array}{c}2.4 \\
97.6\end{array}$ \\
\hline
\end{tabular}

Table 3.4.6 shows that there is no statistically significant association between the gender of the accused and being charged with overcoming resistance to the commission of an offence ( $p$ $=.175)$. As with the previous charge, for which the counts are identical, the finding of no statistical significance may be a misleading artefact of the small sample size. As before, $100 \%$ of the cases involving charges for overcoming resistance to the commission of an offence involved male accuseds. Because of differences in physical strength, women were typically unable to overcome their partner's physical resistance to the commission of an offence in the usual way. Instead, they were more likely to overcome resistance by non-standard means such as using weapons, threats of proxy abuse via the courts, surprise attacks, and waiting until their partner was incapacitated (while intoxicated or driving, for example). These tactics, of course, do not invite the specific charge of overcoming resistance to the commission of an offence, even when that is what they were consciously aimed at doing. Since men face greater jeopardy of having this charge laid against them than women, it is not surprising that men comprise $100 \%$ of the accuseds in this category of offence. (No data for comparison purposes was found.)

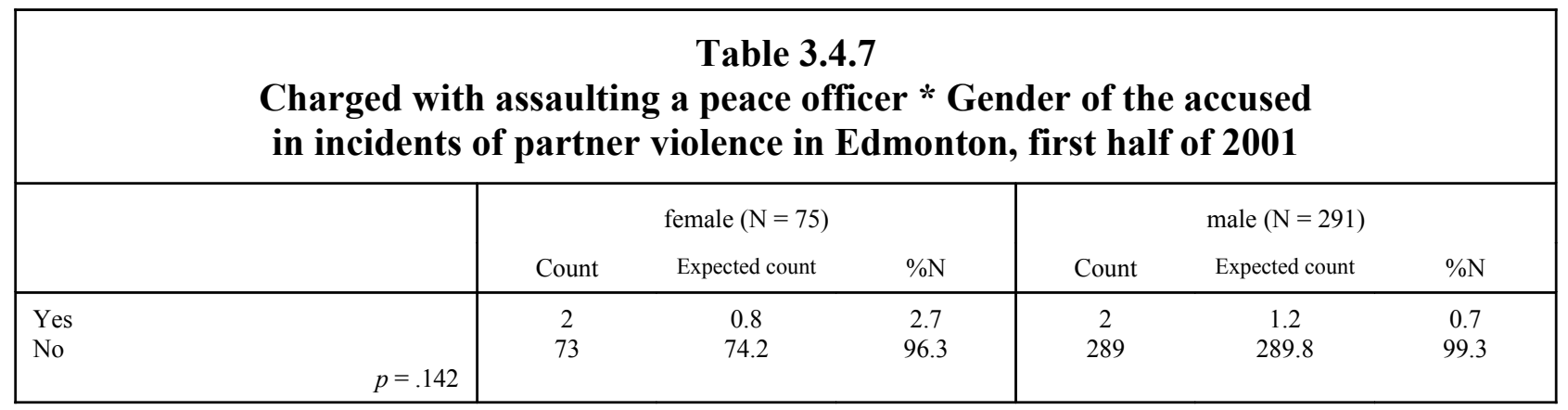

Table 3.4.7 shows that there is no statistically significant association between the gender of the accused and being charged with assaulting a peace officer $(p=.142)$. In this case, the finding of no statistical significance may well be the product of a small sample size, since just as many women as men were charged in this category despite the fact that there are almost 4 times as many male accuseds in the sample. Again, the only available data for comparison purposes is with Ministry of the Attorney General (1999: 22, Table 5), where assaulting or obstructing a peace officer was the most serious charge laid in $2 \%$ of the cases. 


\begin{tabular}{|l|ccc|ccc|}
\hline \multicolumn{7}{|c|}{ Table 3.4.8 } \\
Charged with criminal harassment or uttering threats * Gender of the accused \\
in incidents of partner violence in Edmonton, first half of 2001 \\
\hline \\
\end{tabular}

Table 3.4.8 shows that there is a statistically significant association between the gender of the accused and being charged with criminal harassment or uttering threats $(p=.008)$, with men being proportionately 3 times as likely as women to face these charges. While it may be true that men are more likely than women to engage in harassing and threatening behaviour which might attract a criminal charge, it is doubtful that the gender differences are as great as the ECPO data indicate. According to Table 1.3, men and women were about equally likely to threaten to hit each other, while men were somewhat more likely to make threats with weapons. (Note that the GSS is anomalous in its finding that men were more likely to make the more serious kinds of threats. Also, bear in mind that the number of men and women reporting having been threatened with a weapon is much smaller than the number reporting having been threatened with being hit.) Indeed, both Trainor (2002: 7) and Pottie Bunge and Locke (2000: 22) report that uttering threats was the second most-common charge laid by the police in partner disputes, with men and women being almost equally likely to be the victims (13\% and $14 \%$ respectively).

As for criminal harassment, Table 1.8 shows only a small difference in victimization rates. Further, Trainor and Mihorean (2001: 33) report that women were the victims in $77 \%$ of criminal harassment incidents reported to the police in 1999, whereas the EPS data in Table 2.7 suggests - more consistently with the figures in Table 3.4.8 - that this ratio for Edmonton was as high as $96.2 \%$. According to Table 2.7, criminal harassment or uttering threats was the most serious charge laid by the EPS in only $5.4 \%$ of the cases, while according the Ministry of the Attorney General (1999: 22, Table 5), 'uttering threats', 'criminal harassment', and 'harassing telephone calls' was the most serious charge laid in $13 \%$ of the cases. This compares with similar charges being laid in $16.9 \%$ of the cases in the ECPO sample. While the comparability of these widely divergent data is questionable due to reporting problems discussed previously, the general conclusion seems to be that criminal harassment and uttering threats are relatively rarely charged by the EPS in isolation from more serious charges, and further that the EPS is much more likely to lay these charges against men than women, even relative to other police forces in Canada.

\begin{tabular}{|l|ccc|ccc|}
\hline \multicolumn{7}{|c|}{ Table 3.4.9 } \\
Charged with criminal negligence causing harm * Gender of the accused \\
in incidents of partner violence in Edmonton, first half of 2001 \\
\hline \\
\end{tabular}


A meaningful analysis of this category of offence is not possible given that only one charge was laid. It is included only for the sake of completeness.

\begin{tabular}{|l|ccc|ccc|}
\hline \multicolumn{7}{|c|}{ Table 3.4.10 } \\
Charged with assault * Gender of the accused \\
in incidents of partner violence in Edmonton, first half of 2001 \\
\hline \\
\end{tabular}

Table 3.4.10 shows that there is a statistically significant association between the gender of the accused and being charged with assault $(p=.020)$, with men being over-charged in this category relative to their proportions in the ECPO sample. Whether this charging pattern reflects unduly harsh treatment of men, however, depends upon whether the circumstances of the alleged offences warrant harsher treatment of men. Table 3.2 shows that the women in the ECPO sample were more likely to have caused greater injury to their partners, which suggests that it is unduly harsh for the men to have been significantly more likely to have been charged with assault. One cannot draw firm conclusions by consideration of charging patterns for a single offence in isolation; so this tentative conclusion will be tested in several further ways later in the study.

Meanwhile, for comparison purposes, when women were prosecuted they faced an assault charge $56.0 \%$ of the time, while when men were prosecuted they faced an assault charge $70.1 \%$ of the time. This produces an overall charging rate for assault of $67.2 \%$. The UCR data for 2000 set out in Table 1.8 shows that assault was the most serious charge in $63.2 \%$ of the cases in which a man was charged, and in $59.3 \%$ of the cases in which the woman was charged. Overall, assault was the most serious charge in $62.6 \%$ of the cases where charges were laid. The EPS data set out in Table 2.7 shows that assault was the most serious charge in $61.4 \%$ of the cases in which only the man was charged, and in $43.2 \%$ of the cases in which only the woman was charged. Overall, assault was the most serious charge laid on $60.4 \%$ of the cases in the EPS sample, a proportion also found in the B.C. data (Ministry of the Attorney General 1999: 22, Table 5). Part of the reason why a higher proportion of assault charges appear in the ECPO sample than in the other sources of data is that the "most serious offence" rule eliminates some assault charges from the sources derived from police codification. Second, assault was the most serious offence charged in $65.3 \%$ of the cases where both parties were charged in the EPS sample; distributing these cases across the male and female accuseds would therefore raise their proportions somewhat. Nevertheless, the ECPO sample does appear to include a higher overall proportion of assault charges than the external data suggests might be representative, mostly as a result of a much higher proportion of men facing this charge.

Table 3.4.11 shows that there is a statistically significant association between the gender of the accused and being charged with assault causing bodily harm or with a weapon $(p=.008)$, with women this time being over-charged relative to their proportions in the ECPO sample. Whether this charging pattern reflects unduly harsh treatment of women, however, depends upon whether the circumstances of the alleged offences warrant harsher treatment of women. Table 
3.2 shows that the women in the ECPO sample were more likely to have caused greater injury to their partners, and Table 3.3 shows that they were more likely to have employed weapons against them - all of which suggests that the circumstances of the offence might justify the disproportionately harsh treatment of women who were prosecuted. This tentative conclusion will also be tested in several further ways later in the study.

\begin{tabular}{|l|l|l|ccc|}
\hline \multicolumn{7}{|c|}{ Table 3.4.11 } \\
Charged with assault causing bodily harm or with a weapon * Gender of the accused \\
in incidents of partner violence in Edmonton, first half of 2001 \\
\hline \\
\end{tabular}

Meanwhile, for comparison purposes, when women were prosecuted they faced a level-2 assault charge $36.0 \%$ of the time, while when men were prosecuted they faced a level-2 assault charge $21.3 \%$ of the time. This produces an overall charging rate for level-2 assault of $24.3 \%$. The data set out in Table 2.7 shows that level-2 assault was charged in 18.5\% of the cases, although again this figure is not directly comparable due to the "most serious charge" rule and the fact that the category 'both charged' may include cases where both parties were charged with level-2 assaults. In any event, the gender split for charges in this category is very close in the EPS data as compared to the ECPO data: in $37.4 \%$ of the cases where only the woman was charged she was charged with level-2 assault, while $16.5 \%$ of the cases where only the man was charged he was charged with a level-2 assault.

\begin{tabular}{|l|ccc|ccc|}
\hline \multicolumn{7}{|c|}{ Table 3.4.12 } \\
Charged with aggravated assault * Gender of the accused \\
in incidents of partner violence in Edmonton, first half of 2001 \\
\hline \\
\end{tabular}

Table 3.4.12 shows that there is no statistically significant association between the gender of the accused and being charged with aggravated assault $(p=.208$, although the expected counts are small enough to make that measure unreliable). Comparisons with the EPS data set out in Table $\mathbf{2 . 7}$ are not particularly meaningful given the small numbers involved, but they do fall within the range one would expect: women faced a level-3 assault charge in $5.8 \%$ of those cases where women were the only ones charged, while men faced a level-3 assault charge in $2.2 \%$ of the cases where men were the only ones charged. If the numbers from Table 3.4.11 and Table 3.4.12 are combined, they should be comparable to the UCR data in the top category of Table 1.8. It is noteworthy that while the ratio of women to men charged with level-2 and level-3 assaults is similar in these two data-sets (slightly less than 2:1), the actual proportions 
differ significantly $(42.7 \%$ of women in the ECPO data-set $v S$. only $20.3 \%$ in the UCR; and $24.7 \%$ of the men in the ECPO data-set $v s$. only $11.2 \%$ in the UCR). These differences are difficult to explain, although the small sample size of the ECPO could be part of the explanation.

\begin{tabular}{|l|ccc|cc|}
\hline \multicolumn{7}{|c|}{ Table 3.4.13 } \\
Charged with sexual assault * Gender of the accused \\
in incidents of partner violence in Edmonton, first half of 2001 \\
\hline \\
\end{tabular}

Table 3.4.13 shows that there is no statistically significant association between the gender of the accused and being charged with sexual assault $(p=.377)$. As with the charges for unlawful confinement and overcoming resistance to the commission of an offence, the finding of no statistical significance may be a misleading artefact of the small sample size. And as before, $100 \%$ of the cases involving charges for sexual assault involved male accuseds. This is by no means a necessary result; the only reason the woman in Case B, Appendix B, was not charged with (aggravated) sexual assault is that the police do not seem to conceptualize this kind of an attack on a man as being sexual in nature, unfortunately. In any event, the finding that only $1 \%$ of cases where men were charged with an offence included a charge of sexual assault is consistent with the B.C. data (Ministry of the Attorney General 1999: 22, Table 5). The fact that $20 \%$ of the women who reported being victimized by partner violence in the preceeding 5 years on the GSS reported experiencing sexual assault (Table 1.3) suggests either that the police use stricter criteria for defining sexual assault than the interviewers did, or else that women do not tend to report this particular form of victimization to the police very often.

\begin{tabular}{|c|c|c|c|c|c|c|}
\hline \multicolumn{7}{|c|}{$\begin{array}{l}\text { Table } 3.4 .14 \\
\text { Charged with attempted murder * Gender of the accused } \\
\text { in incidents of partner violence in Edmonton, first half of } 2001\end{array}$} \\
\hline & \multicolumn{3}{|c|}{ female $(\mathrm{N}=75)$} & \multicolumn{3}{|c|}{ male $(\mathrm{N}=291)$} \\
\hline & Count & Expected count & $\% \mathrm{~N}$ & Count & Expected count & $\% \mathrm{~N}$ \\
\hline $\begin{array}{l}\text { Yes } \\
\text { No }\end{array}$ & $\begin{array}{c}0 \\
75\end{array}$ & $\begin{array}{c}0.4 \\
74.6\end{array}$ & $\begin{array}{c}0 \\
100\end{array}$ & $\begin{array}{c}2 \\
289\end{array}$ & $\begin{array}{c}1.6 \\
289.4\end{array}$ & $\begin{array}{c}0.7 \\
99.3\end{array}$ \\
\hline
\end{tabular}

A meaningful analysis of this category of offence is not possible given that only two charges were laid. It is included only for the sake of completeness.

Because the breakdown of charges presented in Tables 3.4 above created too many categories where the expected counts were too small to achieve reliable statistical significance, several of the smaller charging categories were merged and the resulting categories were arranged by order of seriousness in Table 3.4.15. The seven resulting charging categories were given the following labels: administrative offences (same group of charges as before); minor 


\begin{tabular}{|c|c|c|c|c|c|c|}
\hline \multicolumn{7}{|c|}{$\begin{array}{l}\text { Table } 3.4 .15 \\
\text { Offence charged * Gender of the accused } \\
\text { in incidents of partner violence in Edmonton, first half of } 2001\end{array}$} \\
\hline & \multicolumn{3}{|c|}{ female $(N=102)$} & \multicolumn{3}{|c|}{ male $(\mathrm{N}=435)$} \\
\hline & Count & Expected count & $\% \mathrm{~N}$ & Count & Expected count & $\% \mathrm{~N}$ \\
\hline $\begin{array}{l}\text { Administrative offences } \\
\text { Minor incidental offences } \\
\text { Secondary offences } \\
\text { Uttering threats and criminal harassment } \\
\text { Common assault } \\
\text { Mid-range assaults } \\
\text { Major assaults } \\
\quad p=.032\end{array}$ & $\begin{array}{c}12 \\
9 \\
2 \\
5 \\
42 \\
27 \\
5\end{array}$ & $\begin{array}{c}11.2 \\
7.6 \\
3.4 \\
11.8 \\
46.7 \\
17.1 \\
4.2\end{array}$ & $\begin{array}{c}11.8 \\
8.8 \\
2.0 \\
4.9 \\
41.2 \\
26.5 \\
4.9\end{array}$ & $\begin{array}{c}47 \\
31 \\
16 \\
57 \\
204 \\
63 \\
17\end{array}$ & $\begin{array}{c}47.8 \\
32.4 \\
14.6 \\
50.2 \\
199.3 \\
72.9 \\
17.8\end{array}$ & $\begin{array}{c}10.8 \\
7.1 \\
3.7 \\
13.1 \\
46.9 \\
14.5 \\
3.9\end{array}$ \\
\hline
\end{tabular}

incidental offences (mischief, break \& enter with intent, and weapons offence); secondary offences (unlawful confinement, overcoming resistance to the commission of an offence, assaulting a peace officer); criminal harassment and uttering threats; common assault; mid-range assault (assault with a weapon, assault causing bodily harm, and criminal negligence causing harm); and major assault (aggravated assault, sexual assault, attempted murder, manslaughter). For the sake of completeness, the two manslaughter cases were included in the major assaults.

Table 3.4.15 shows that the charging pattern is statistically significant $(p=0.32)$. Men were charged with more offences in the middle of the table than expected, while women were charged with more of the serious offences toward the bottom of the table than expected, on the basis of the null hypothesis. The more critical question is whether this pattern reflects the reality behind the offences. One might suppose that this charging pattern does reflect the reality behind the ECPO sample, given that the women were more likely to have caused a serious injury to their partners than the men were, on average. (Recall the parallel discussion of this issue in relation to the EPS data in Part A.) To test this, consider how the charges men and women faced relate to the injuries they had inflicted. From Table 3.2, women in the ECPO sample had inflicted medium- or high-level injuries upon their partners in 28 cases; but according to Table 3.4.15, women were charged with 32 mid-range or major assaults. Thus women were charged with a mid-range or major assault in only 5 cases where the injury they had inflicted upon their partners was low or none (15.6\%). In contrast, men in the ECPO sample had inflicted medium- or highlevel injuries upon their partners in 63 cases, but were charged with 80 mid-range or major assaults. Thus men were charged with a mid-range or major assault in 17 cases where the injury they had inflicted upon their partners was low or none $(21.3 \%)$. Men were more likely than women in the ECPO sample to have been charged with a mid-range or major assault without having inflicted a major injury upon their partner.

Women in the ECPO sample inflicted low-level injuries upon their partners in 31 cases, but were charged with 42 common assaults. Thus women were charged with common assault in only 11 cases where they had inflicted no injury upon their partners $(26.2 \%)$. Men on the other hand inflicted low-level injuries upon their partners in 121 cases, but were charged with 204 common assaults. Thus men were charged with common assault in 83 cases where they had inflicted no injury upon their partners (40.7\%). Again, men were much more likely than women in the ECPO sample to have been charged with common assault without having inflicted any injury upon their partner. This latter finding is particularly revealing, since there are undoubtedly 
many more instances where women attack their partners with kicks or punches that do no damage than vice versa. In other words, not only is the charging pattern in Table 3.4.15 statistically significant, it almost certainly understates the true degree of disparity in charging faced by men and women in the ECPO sample.

In further support of the hypothesis that men were over-charged relative to women in partner disputes, it bears noting that men faced more charges on average than women. The 75 women in the ECPO sample faced a total of 102 charges, or 1.36 charges per accused; while the 291 men faced a total of 433 charges, or 1.49 charges per accused. ${ }^{48}$ This is unexpected given the injury- and weapon-use profile of the male and female cases in the ECPO sample, which indicate that the women were significantly more aggressive than the men, on average. A question deserving of further research, therefore, is whether the police tend to "pile on" charges with male suspects more than with similarly situated female suspects (illustrative case $\mathrm{H}$, Appendix B, is indicative of this); or conversely, whether police are more lenient with the laying of charges against female suspects (see cases B and D, Appendix B).

After charges are laid, the next decision the police have to make is whether to take the suspect into custody or release him or her on an "undertaking" or a "promise to appear." Data relating to this decision are not collected by the EPS and are not reported in the UCR or GSS, so at this point the data from the ECPO launches into previously uncharted territory. Table 3.5 shows the proportions of male and female suspects who were taken into custody.

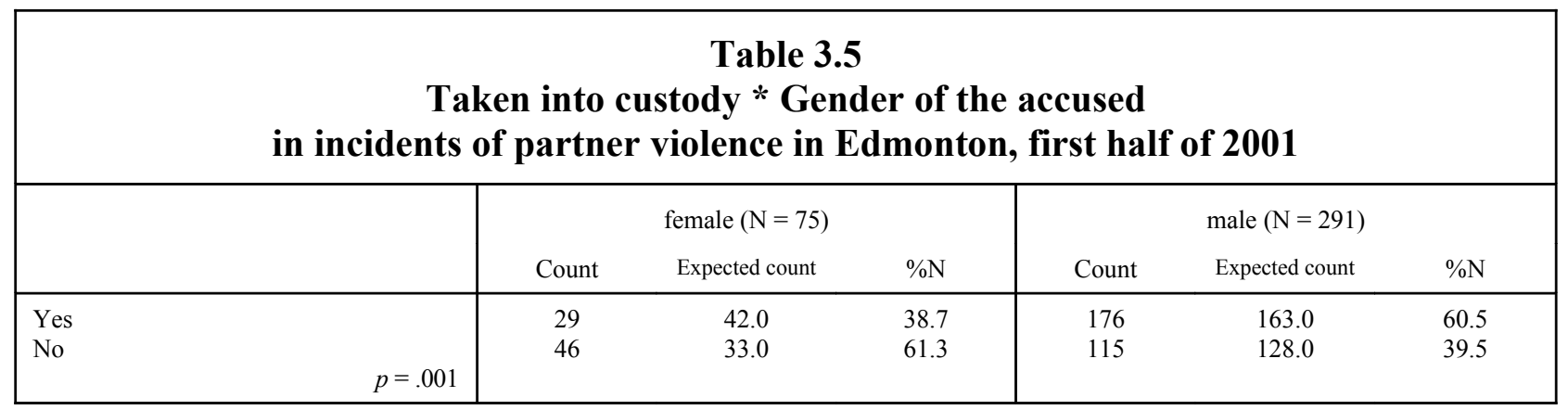

Three-fifths of men who were charged, but only two-fifths of women, were taken into custody. That is, the proportion of men taken into custody was $50 \%$ higher than the proportion of women taken into custody. Gender was highly statistically significant $(p=.001)$, which leads to the question whether this can be explained on the basis of sound legal reasons. According to s. 515(10)(a) of the Criminal Code, the primary reason for taking a suspect into custody is to ensure appearance at trial. There were very few cases in the ECPO sample in which suspects were detained on the ground of being at risk to flee the jurisdiction. (These few involved either separated couples where the suspect was living out of the province, or aboriginal suspects who had close ties to bands outside of the province and frequently travelled there.) In addition to

\footnotetext{
${ }^{48}$ It should be noted that the Ns in Table 3.4.15 involve some double-counting as well as some under-counting. They involve double-counting in those cases where one offence was charged but a lesser offence was pled guilty to in a plea bargain. They involve under-counting in those cases where a person was charged with more than one offence in the same Criminal Code section, since only one count was encoded. Taking these two effects into account, the figures cited for charges per case is, if anything, an under-estimate of the disparity between the charges per incident involving men and women.
} 
flight risk, pre-trial custody might have been ordered on primary grounds where the suspect had a prior record of failing to appear in court or breaching some other court order. However, only 22 of the 291 men who were charged had a prior record for an administrative offence $(7.6 \%)$, while 4 of the 75 women who were charged had a prior record for an administrative offence (5.3\%). Furthermore, according to Table 3.4.1, men and women in the ECPO sample were equally likely to have been charged with an administrative offence. It would appear, then, that the much greater likelihood of men being taken into custody cannot be explained on primary grounds.

The secondary grounds for taking a suspect into custody is to ensure public safety, according to s. 515(10)(b) of the Criminal Code. In the case of partner-violence incidents, this would mean ensuring the safety of the putative victim. Since women who were charged with an offence were as likely to have been intoxicated at the time of the incident (Table 3.1.2), but were significantly more likely to have caused a serious injury (Table 3.2), were significantly more likely to have used a weapon (Table 3.3), and were significantly more likely to have been charged with certain categories of serious offence (Table 3.4.4, Table 3.4.11, and Table 3.4.12), it stands to reason that they posed a greater risk to public safety (i.e. to their partners) than the men in the sample, and so should tend to be taken into custody proportionately more often. Table 3.5.1 shows that the opposite is actually the case. Women who were charged in mediumand high-injury cases were less likely to be taken into custody (only $50.0 \%$ of the time) than men who were charged in no-injury cases $(54.2 \%$ of the time). While the proportion of men who were taken into custody rose steadily with the level of injury inflicted (as one would expect), there was no relationship between the likelihood of being taken into custody and the level of injury inflicted by women except at the highest level of injury.

\begin{tabular}{|c|c|c|c|c|c|}
\hline \multicolumn{6}{|c|}{$\begin{array}{l}\text { Table } 3.5 .1 \\
\text { Level of Injury * Taken into custody } * \text { Gender of the accused } \\
\text { in incidents of partner violence in Edmonton, first half of } 2001\end{array}$} \\
\hline \multirow[b]{2}{*}{ Injury level } & \multirow[b]{2}{*}{ Custody } & \multicolumn{2}{|c|}{ female $(\mathrm{N}=75)$} & \multicolumn{2}{|c|}{ male $(\mathrm{N}=291)$} \\
\hline & & Count & $\%$ within injury level & Count & $\%$ within injury level \\
\hline None & $\begin{array}{l}\text { Yes } \\
\text { No }\end{array}$ & $\begin{array}{c}6 \\
10\end{array}$ & $\begin{array}{l}37.5 \\
62.5\end{array}$ & $\begin{array}{l}58 \\
49\end{array}$ & $\begin{array}{l}54.2 \\
45.8\end{array}$ \\
\hline Low & $\begin{array}{l}\text { Yes } \\
\text { No }\end{array}$ & $\begin{array}{c}9 \\
22\end{array}$ & $\begin{array}{l}29.0 \\
71.0\end{array}$ & $\begin{array}{l}75 \\
46\end{array}$ & $\begin{array}{l}62.0 \\
38.0\end{array}$ \\
\hline Medium & $\begin{array}{l}\text { Yes } \\
\text { No }\end{array}$ & $\begin{array}{c}6 \\
13\end{array}$ & $\begin{array}{l}31.2 \\
68.8\end{array}$ & $\begin{array}{l}32 \\
17\end{array}$ & $\begin{array}{l}65.3 \\
34.7\end{array}$ \\
\hline High & $\begin{array}{l}\text { Yes } \\
\text { No }\end{array}$ & $\begin{array}{l}8 \\
1\end{array}$ & $\begin{array}{l}88.9 \\
11.1\end{array}$ & $\begin{array}{c}11 \\
3\end{array}$ & $\begin{array}{l}78.6 \\
21.4\end{array}$ \\
\hline
\end{tabular}

Perhaps police were influenced by the suspect's prior criminal record in determining whether he or she posed a risk to public safety. To test this hypothesis, a series of binary logistic regressions was performed to determine whether gender was significantly associated with being taken into custody even when level of injury and prior record are taken into account. ${ }^{49}$

\footnotetext{
${ }^{49}$ A binary logistic regression is a statistical method that tests whether a given variable (the "dependent variable") is associated with other variables ("covariates"). The dependent variable must be binary - i.e. having only two values, such as 'yes' or 'no', 'high' or 'low' - which means that some of the ECPO data had to be recodified into binary form for the purposes of this analysis. In the present instance, the three values of the variable 'pre-trial restrictions' (none, short incarceration, or jail to trial) were collapsed into two: none or some.
} 
Model A:

dependent variable $=$ taken into custody

covariates gender $\quad p<.001$

injury level $\quad p=.022$

Model B: $\quad$ dependent variable $=$ taken into custody

covariates gender $\quad p=.002$

injury level $\quad p=.029$

personal-injury prior record $\quad p<.001$

Model C: $\quad$ dependent variable $=$ taken into custody

$\begin{array}{lll}\text { covariates } & \text { gender } & p=.003 \\ \text { injury level } & p=.049 \\ & \text { any prior record } & p=.001\end{array}$

The most significant correlate with being taken into custody is indeed having a prior criminal record, especially a record relating to a personal-injury offence. This suggests that some of the discrepancy in the use of custody between male and female suspects can be accounted for as proper precautionary procedure. Nevertheless, gender remains a highly significant factor even when prior records and level of injury are taken into account - more significant even than the level of injury inflicted upon the victim.

It is, of course, possible that factors not considered in this study might account for this disparity in treatment. Responding to the fear of the putative victim was addressed earlier, in relation to the EPS data. Another possible explanation is that police make their decision whether to take a suspect into custody based on an unofficial history of abuse, developed in the course of responding to incidents at the same address on previous occasions. However, Table 2.3 suggests that, if anything, the women in this sample are more likely than the men to have been charged at a repeat call; the men were more likely to have been charged at the first call by the police. The many cases in the prosecutor's files resembling to one degree or another Case F, Appendix B, suggest that a decision to treat men more harshly in this respect is more likely the explanation for the above findings with respect to pre-trial custody. ${ }^{50}$

Requiring a person to spend a night (or longer) in the remand centre and likely to hire a lawyer to obtain bail is a form of pre-trial punishment, and punishment without the benefit of a trial should be resorted to in only the clearest of cases. Yet in the vast majority of cases when a suspect was taken into custody after a partner dispute, the suspect made bail. This is true whether the suspect was male or female, although female suspects were even more likely than male suspects to have made bail despite the fact that women were less likely to have been taken into custody in the first place. Of the 29 women who were taken into custody, only 2 failed to make bail. (Both of them had committed high-injury offences with a major weapon.) In contrast, $10.3 \%$ of the men taken into custody in no-injury cases failed to make bail; $13.2 \%$ of the men

\footnotetext{
${ }^{50}$ For the sake of completeness, mention should be made of the tertiary grounds for pre-trial custody in s. 515(10)(c) of the Criminal Code. Detention may also be justified when it "is necessary in order to maintain confidence in the administration of justice." Factors mentioned as being relevant to this ground for detention are "the apparent strength of the prosecutor's case, the gravity of the nature of the offence..., and the potential for a lengthy term of imprisonment." Since the women were charged with, on average, more serious offences than the men, tertiary grounds for detention should not function negatively against men, overall.
} 
taken into custody in low-injury cases failed to make bail; $22.5 \%$ of the men taken into custody in medium-injury cases failed to make bail; and $71.4 \%$ of the men taken into custody in highinjury cases failed to make bail. The fact that three-quarters of the women who were taken into custody for high-injury offences made bail, but fewer than a third of the men did, suggests that Justices of the Peace (J.P.s) who make these decisions are less concerned about the safety of male victims than female victims. It should be noted, however, that just because such a high proportion of detainees is released by J.P.s, it does not follow that there were not sufficient legal grounds for detention in the first place. In many of the cases where a suspect made bail, they did so only on conditions - e.g. to have no contact with the putative victim, to abstain from alcohol consumption, or to post a bond. Still, the question remains why police more readily seek to impose such conditions on male suspects than female suspects, especially given that the profile of female cases in the ECPO sample was more-injurious than that of male cases overall. ${ }^{51}$

While conditions of release might not count as pre-trial punishment in the way that "time served" does, nevertheless they can be a significant burden. No-contact orders are particularly onerous, since they frequently prevent suspects from enjoying the use of their own property and place them in legal jeopardy if they should try to reconcile with their partners. ${ }^{52}$ Given that mutual aggression is the most common form of partner violence according to the sociological evidence, there is no justification for depriving men of the enjoyment of their property or placing them in greater legal jeopardy in the majority of cases. In those cases, police should be seeking mutual restraining orders instead of seeking conditions against men only. Given the disparate police treatment with respect to detention, apparently exacerbated by J.P.s, it is not surprising that men end up with longer prior records for administrative offences relating to disputes between partners. While the data in this study show that male suspects were more likely to face the imposition of conditions of release than female suspects, further research needs to be done to determine whether the actual conditions of release imposed on male suspects differ substantially from those imposed on comparable female suspects.

Two "pragmatic" (i.e. non-legal) considerations are sometimes raised to account for the disparity in treatment between men and women with respect to pre-trial custody. First, men may be taken into custody following a dispute with their partners as a means of separating the parties long enough for them to "cool off." But this fails to explain why men in particular should bear the burden of being deprived of their liberty, albeit temporarily. In fact, women have options not available to men that could be explored before men are taken from their homes and deprived of their liberty. Edmonton, like most cities in North America, has relatively well-funded facilities specifically for women who might be in danger of partner violence, whereas men have nothing comparable available to them. In the modal case of mutual aggression, if the police fear

\footnotetext{
${ }^{51}$ The data in this study might significantly under-estimate the extent of the extra legal jeopardy and reduction of freedom men may be subject to as a consequence of being charged. Another tactic available to the Edmonton police is to threaten to take the accused into custody unless he signs an undertaking not to have contact with the putative victim - essentially evicting the man from his own home. These undertakings have all the force of a court order, without the benefit of judicial approval. Since police do not record their use of these undertakings, it is impossible to know the extent to which they are used. The use of police-induced undertakings requires further research.

${ }^{52}$ This researcher is aware of anecdotal evidence to the effect that women sometimes contact their partners who are under no-contact orders, ostensibly to reconcile, only to call the police when the man arrives at the home. In these cases, the man is charged with breaching an order, but the woman is never charged with counseling a breach or with mischief. If both parties were given no-contact orders, this form of entrapment would not be available.
} 
continued violence but do not want to take both the man and the woman into custody, the least they could do by way of mutual accommodation is to allow the man to stay in the home and take the woman to a shelter, where she might even benefit from counselling. The oft-heard excuse that it is simply "easier" to take the man from his home is simply discriminatory.

The other pragmatic consideration sometimes mentioned is that police are understandably reluctant to separate children from their primary care-givers (usually their mothers), even temporarily. But to begin with, the presence of children was not a factor in enough cases to explain the large disparity in detention rates between male and female suspects. ${ }^{53}$ More fundamentally, as with the previous rationalization, this one is based on myths and stereotypes. To suppose that fathers who are victims of violence are incapable of looking after their children even for a day or a weekend while the allegedly violent mothers are in custody is insupportable as a general proposition. Much is made in the literature on family violence about the dire effects upon their children of violence between parents, which is why the presence of children is considered to be a major aggravating factor in sentencing for this kind of crime. To spare violent mothers the natural consequences of their behaviour - being taken into custody - in order that they be able to remain with their children, would be sending precisely the wrong message to their children. In short, none of the obvious explanations for the much harsher treatment of men with regard to being taken into custody is satisfactory.

Given what was shown in Part $A$ about police practice with respect to partner violence, none of the above should be particularly surprising. The main purpose of Part $B$ of the present study, however, is to determine how prosecutors (and, to a lesser extent, judges) respond to the kinds of cases they are presented by the police. Given the profile of these cases as revealed above, do prosecutors tend to mitigate the prior disparities in treatment between men and women, do they tend to process these files through the courts neutrally, or do they tend to exacerbate the pre-existing disparities in treatment? If prosecutors processed the cases they receive from the police neutrally, one would expect them to obtain the same proportion of convictions for male and female accuseds, other things being equal. To test this, the crosstabulation in Table 3.6 was performed to see whether a finding of guilt is associated with the

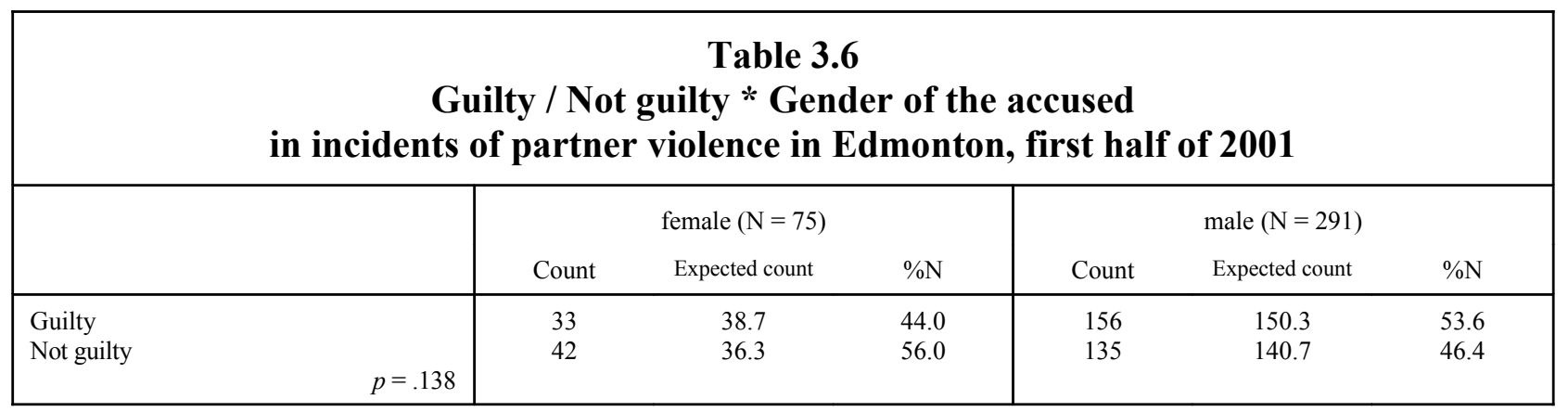

\footnotetext{
${ }^{53}$ Children were present at the time of the incident in 7 of the 29 cases where women were taken into custody, and in 69 of the 176 cases where men were taken into custody $(24.1 \%$ vs. 39.2\%). According to Table 3.1.3, children were present in $32.0 \%$ of cases where women were charged, and in $37.5 \%$ of cases where men were charged. This suggests that the presence of children tends to modestly reduce the likelihood of women being taken into custody, but has no appreciable effect on the likelihood of men being taken into custody. So while the presence of children might have some explanatory (as opposed to justificatory) influence on pre-trial detention, the differences are too small to account fully for the large overall disparities in pre-trial detention between male and female suspects.
} 
gender of the accused. ${ }^{54}$ Note to begin with that $51.6 \%$ of all cases where charges were laid resulted in a finding of guilt on at least one count. This is consistent with the findings of Ministry of the Attorney General (1999: 25, Figure 12), which found that 50\% of all decided cases had a finding of guilt in the B.C. sample. This suggests that the ECPO sample is broadly representative of the kinds of cases deal with by Canadian prosecutors.

Table 3.6 shows that men were more likely than women to be found guilty $(53.6 \% v s$. $44.0 \%)$, although the association is not statistically significant $(p=.138)$. While the disparity noted here is not large, it does favour women when the opposite might be expected. The reason one might expect a higher proportion of the women in the ECPO sample to have been found guilty is that they were more likely to have been charged with more-serious offences. In those cases, the use of weapons and the presence of major injuries would presumably have provided better objective evidence of an offence than the mere word of the putative victim alone, in cases where there was no injury or weapon used. Moreover, one might expect victims of major assaults, as well as prosecutors dealing with those cases, to be more highly motivated to seek justice and therefore to pursue them more vigorously. Nevertheless, the ECPO data confound any such expectations. The cross-tabulation in Table 3.6.1 shows a lack of significant association between a finding of guilt and the level of injury sustained by the victim $(p=.401)$.

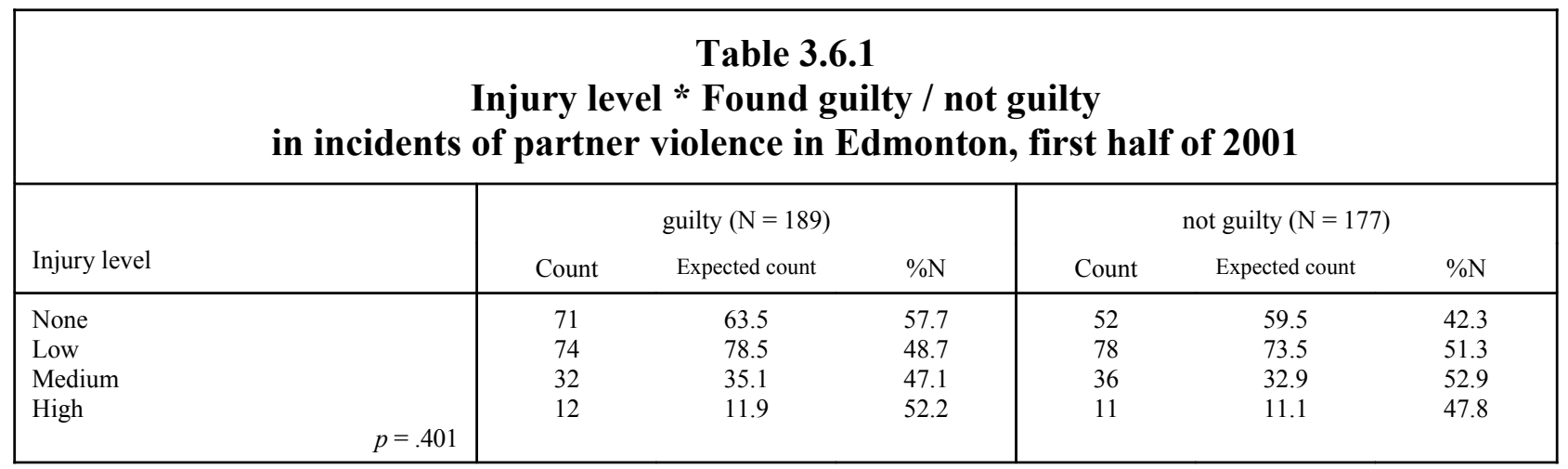

Curiously, the greatest likelihood of obtaining a conviction was with no-injury cases. Perhaps this is because no-injury cases are unlikely to result in significant penalties, so the accused was more prepared to plead guilty or take a plea-bargain in those cases, as opposed to incurring the inconvenience and expense of going to trial. In any event, more detail can be obtained by combining the operations in Table 3.6 and Table 3.6.1. The cross-tabulation in Table 3.6.2 shows that a finding of guilt in cases at each injury level is not associated with the gender of the accused $(p=.301)$. For comparison purposes, the charging data from Table 3.2 have been incorporated into Table 3.6.2. Both men and women who were charged in no-injury cases were more likely to have been found guilty of at least one charge than either men or women charged in low- and medium-injury cases. On the men's side, found-guilty ratios decline from $57.9 \%$ in the no-injury category to $46.9 \%$ in the medium-injury category, before rising dramatically to $71.4 \%$ in high-injury cases. On the women's side, the found-guilty ratios fluctuate from $56.3 \%$ in no-injury cases, down to $41.9 \%$ in low-injury cases, and back up to $47.4 \%$ in medium-injury cases, before dropping off dramatically in high-injury cases to $22.2 \%$.

\footnotetext{
${ }^{54}$ The 'found guilty' category includes those who were convicted at trail, or who pled guilty to at least one offence.
} 


\begin{tabular}{|c|c|c|c|c|c|c|c|}
\hline \multicolumn{8}{|c|}{$\begin{array}{c}\text { Table 3.6.2 } \\
\text { Injury level * Gender of those found guilty } \\
\text { in incidents of partner violence in Edmonton, first half of } 2001\end{array}$} \\
\hline & & \multicolumn{3}{|c|}{ female $(\mathrm{N}=51)$} & \multicolumn{3}{|c|}{ male $(\mathrm{N}=156)$} \\
\hline & & Count & Expected count & $\% \mathrm{~N}$ & Count & Expected count & $\% \mathrm{~N}$ \\
\hline None & $\begin{array}{l}\text { Charged } \\
\text { Guilty } \\
\% \text { guilty }\end{array}$ & $\begin{array}{c}16 \\
9 \\
56.3\end{array}$ & $\begin{array}{l}25.2 \\
12.4\end{array}$ & $\begin{array}{l}21.3 \\
27.3\end{array}$ & $\begin{array}{c}107 \\
62 \\
57.9\end{array}$ & $\begin{array}{l}97.8 \\
58.6\end{array}$ & $\begin{array}{l}36.8 \\
39.7\end{array}$ \\
\hline Low & $\begin{array}{l}\text { Charged } \\
\text { Guilty } \\
\% \text { guilty }\end{array}$ & $\begin{array}{c}31 \\
13 \\
41.9\end{array}$ & $\begin{array}{l}31.1 \\
12.9\end{array}$ & $\begin{array}{l}41.3 \\
39.4\end{array}$ & $\begin{array}{c}121 \\
61 \\
50.4\end{array}$ & $\begin{array}{c}120.9 \\
61.1\end{array}$ & $\begin{array}{l}41.6 \\
39.1\end{array}$ \\
\hline Medium & $\begin{array}{l}\text { Charged } \\
\text { Guilty } \\
\text { \% guilty }\end{array}$ & $\begin{array}{c}19 \\
9 \\
47.4\end{array}$ & $\begin{array}{c}13.9 \\
5.6\end{array}$ & $\begin{array}{l}25.3 \\
27.3\end{array}$ & $\begin{array}{c}49 \\
23 \\
46.9\end{array}$ & $\begin{array}{l}54.1 \\
26.4\end{array}$ & $\begin{array}{l}16.8 \\
14.7\end{array}$ \\
\hline High & $\begin{array}{l}\text { Charged } \\
\text { Guilty } \\
\text { \% guilty } \\
\qquad p=.301\end{array}$ & $\begin{array}{c}9 \\
2 \\
22.2\end{array}$ & $\begin{array}{l}4.7 \\
2.1\end{array}$ & $\begin{array}{c}12.0 \\
6.1\end{array}$ & $\begin{array}{c}14 \\
10 \\
71.4\end{array}$ & $\begin{array}{c}18.3 \\
9.9\end{array}$ & $\begin{array}{l}4.8 \\
6.4\end{array}$ \\
\hline
\end{tabular}

These patterns are difficult to explain, except perhaps as a product of a categorization scheme which is too fine-grained for the sample size. When no-injury and low-injury cases are combined into 'minor injury' cases, and medium-injury and high-injury cases into 'major injury' cases, the found-guilty ratios for men remain roughly level: $54.0 \%$ for minor-injury cases and $52.4 \%$ for major-injury cases.$^{55}$ In other words, the injury level of the victim is neither positively nor negatively associated with the likelihood of a guilty finding for male accuseds. In contrast, the found-guilty ratio for female accuseds falls from an already lower $46.8 \%$ in minor-injury cases to a dramatically lower $39.3 \%$ in major-injury cases. In other words, women who were charged in major-injury offences were less likely to be found guilty than women charged in minor-injury offences, and were also less likely to be found guilty than men in any injury-level category. That result accounts for why women were found guilty at lower rates than men overall. It also accounts for why injury-level to the victim is significantly and positively associated with female accuseds in the full sample, but not in the sub-sample of those found guilty.

Clearly, something is at play here which upsets the natural assumption that the level of injury would be positively associated with the probability of a finding of guilt. As suggested earlier, part of the explanation might be that those charged in no-injury cases were more inclined to cop a plea rather than incur the expense of a trial. But that would not explain the gender disparities and opposite tendencies in the findings of guilt between men and women at the higher injury levels. Another hypothesis is that uncooperative witnesses (typically the person identified as the victim) play a large part in determining whether a finding of guilt is obtained in any given case. As will become apparent, uncooperative witnesses posed perhaps the most pervasive problem for prosecutors in partner-violence cases. The question, then, is whether the likelihood of encountering an uncooperative witness is associated with either the level of the injury suffered in the incident or the gender of the victim.

\footnotetext{
${ }^{55}$ The found-guilty ratios for men would be exactly level if the 2 manslaughter convictions were included in the major-injury category. Note also that $(189 / 366=) 51.6 \%$ of the ECPO sample resulted in a finding of guilt, which compares favourably with the $47 \%$ figure that obtained in the B.C. data (Ministry of the Attorney General 1999: 9).
} 
Since prosecutors almost always sought a finding of guilt when a witness was prepared to testify, ${ }^{56}$ the sub-sample of cases in which all charges were withdrawn by the prosecutor corresponds highly with those cases in which witnesses did not show up for trial, refused to testify, changed their story, or presented other difficulties such that a reasonable likelihood of conviction did not obtain. Consideration of the sub-sample of cases in which all charges were withdrawn by the prosecutor therefore provides a reasonably reliable test of the hypothesis that witness problems are associated with gender. The cross-tabulation in Table 3.6.3 shows this association. Note to begin with that a substantial 147 of 366 cases in the ECPO sample (40.2\%) were cases where all charges were withdrawn, confirming that witness problems were indeed a large problem.

\begin{tabular}{|c|c|c|c|c|c|c|c|}
\hline \multicolumn{8}{|c|}{$\begin{array}{l}\text { Table } 3.6 .3 \\
\text { Charges withdrawn at each injury level * Gender of the accused } \\
\text { in incidents of partner violence in Edmonton, first half of } 2001\end{array}$} \\
\hline \multirow[b]{2}{*}{ Injury level } & & \multicolumn{3}{|c|}{ female $(\mathrm{N}=39)$} & \multicolumn{3}{|c|}{ male $(\mathrm{N}=108)$} \\
\hline & & Count & Expected count & $\% \mathrm{~N}$ & Count & Expected count & $\% \mathrm{~N}$ \\
\hline None & $\begin{array}{l}\text { Charged } \\
\text { Withdrawn } \\
\text { \% withdrawn }\end{array}$ & $\begin{array}{c}16 \\
6 \\
37.5\end{array}$ & $\begin{array}{l}25.2 \\
10.6\end{array}$ & $\begin{array}{l}21.3 \\
15.0\end{array}$ & $\begin{array}{c}107 \\
34 \\
31.8\end{array}$ & $\begin{array}{l}97.8 \\
29.4\end{array}$ & $\begin{array}{l}36.8 \\
85.0\end{array}$ \\
\hline Low & $\begin{array}{l}\text { Charged } \\
\text { Withdrawn } \\
\text { \% withdrawn }\end{array}$ & $\begin{array}{c}31 \\
16 \\
51.6\end{array}$ & $\begin{array}{l}31.1 \\
18.0\end{array}$ & $\begin{array}{l}41.3 \\
23.5\end{array}$ & $\begin{array}{c}121 \\
52 \\
43.0\end{array}$ & $\begin{array}{c}120.9 \\
50.0\end{array}$ & $\begin{array}{l}41.6 \\
76.5\end{array}$ \\
\hline Medium & $\begin{array}{l}\text { Charged } \\
\text { Withdrawn } \\
\% \text { withdrawn }\end{array}$ & $\begin{array}{c}19 \\
10 \\
52.6\end{array}$ & $\begin{array}{c}13.9 \\
7.7\end{array}$ & $\begin{array}{l}25.3 \\
34.5\end{array}$ & $\begin{array}{c}49 \\
19 \\
38.8\end{array}$ & $\begin{array}{l}54.1 \\
21.3\end{array}$ & $\begin{array}{l}16.8 \\
65.5\end{array}$ \\
\hline High & $\begin{array}{l}\text { Charged } \\
\text { Withdrawn } \\
\text { \% withdrawn } \\
\qquad p=.003\end{array}$ & $\begin{array}{c}9 \\
7 \\
77.8\end{array}$ & $\begin{array}{l}4.7 \\
2.7\end{array}$ & $\begin{array}{l}12.0 \\
70.0\end{array}$ & $\begin{array}{c}14 \\
3 \\
21.4\end{array}$ & $\begin{array}{c}18.3 \\
7.3\end{array}$ & $\begin{array}{c}4.8 \\
30.0\end{array}$ \\
\hline
\end{tabular}

The probability of a charge being withdrawn is associated with gender to a statistically significant degree $(p=.003)$. That is, men were less likely than women to benefit from withdrawn charges at every level of injury. Indeed, the disparity between the rate at which men and women benefited from withdrawn charges increased with the level of the injury to the victim. This is because men were steadily less likely to benefit from withdrawn charges as the level of injury they had inflicted on their putative victims increased - as one would expect while women were steadily more likely to benefit from withdrawn charges as the level of injury they had inflicted on their putative victims increased. This remarkable result warrants some discussion. The hypothesis of concern to the present study is that prosecutors were pursuing cases involving male accuseds more tenaciously than they were pursuing cases involving female accuseds, all other things being equal. (See illustrative cases A, D, G, and "A Day in Provincial Court," Appendix B, for anecdotal support for this hypothesis.) While the data in Table 3.6.3 do not prove this hypothesis, the finding is so dramatic that quite a radical alternative account would have to be advanced in order to provide an innocent explanation for these data. One such radical thesis is potentially available.

\footnotetext{
${ }^{56}$ Though anecdotal evidence suggests that prosecutors, and even judges (see "A Day in Provincial Court," Appendix B), sometimes actively try to dissuade male complainants from pursuing charges against a woman.
} 
This is not the place to engage in an extended critique of the theoretical underpinnings of the "battered woman syndrome," topic. One of the two main planks in the theory of the battered woman's syndrome is that women "learn helplessness" as a result of early failed attempts to escape from their "cycle of abuse" (Walker 1979). Feeling trapped in an abusive relationship, many women (it is claimed) refuse whatever outside help may be available to them, including the aid of the police and prosecutors. Expanding on this theme, it is often claimed in the literature on wife abuse that women are particularly reluctant to testify against their partners due to such factors as economic or emotional dependence or a fear of retaliation if they testify. Since the fear of retaliation would presumably arise most in those relationships characterized by the most severe and repetitive violence, the data in Table 3.6.3 are relevant. What they show is, first, that women are more willing to testify against their partners (not less willing) the more seriously they have been injured by them. Second, women are more willing than men to testify against their partners, regardless of the level of injury suffered. (Indeed, as was shown in Table 1.5, women were 4 times as likely to report their victimization to the police in the first place.) Most remarkably, all of the charges were withdrawn against women in $77.8 \%$ of cases in which they were charged with offences involving high-level injuries to their partners. All of the evidence indicates that abused men fit the theory of the "battered woman" better than abused women do! ${ }^{58}$

The data in the ECPO sample do not allow one to determine why male victims of partner violence were more likely than female victims to have become uncooperative witnesses, nor why they were more likely to have done so as the seriousness of the violence they suffered increased. But since the data tends to refute the "learned helplessness" theory for women, it should not be presumed to be operating in the case of men, either. Rather, a different dynamic was almost certainly more prevalent among both men and women who had become uncooperative witnesses.

\footnotetext{
${ }^{57}$ For critiques of the theory of the battered woman, see Paciocco (1999) and Morton and Knopff (2000).

${ }^{58}$ Much of the readily available publicity on partner violence implies that men are relatively rarely abused; and that even when they are, the dynamics of abuse against men are so different that what is claimed about abused women cannot be extended to abused men. Our Community Response to Domestic Violence, by the "Domestic Violence Action Team" for the City of Lethbridge, Alberta, is a recent example. (See Appendix $C$ for a brief critique.) It states: "The community recognizes that men can also be victims of family violence but the wording in this manual focuses on women because the majority of cases are men abusing women and, because men are bigger and stronger, male abuse of women has more serious consequences" (p. 2). And with that, violence against men is presumed to be safely ignored. In a similar vein, Canada's Supreme Court Justice Madame L'Heureux-Dube has said in obiter dicta: "To assume that men who are victims of spousal abuse are affected by the abuse in the same way [as women], without benefit of the research and expert opinion evidence which has informed the courts of the existence and details of 'battered woman syndrome' would be imprudent": R. v. Mallot (1998) 121 C.C.C. (3d) 456 at 473. (Question: if most of the "research and expert opinion evidence" on the "battered woman syndrome" is based on studies of white women, would it also be "imprudent" to extend the defence to women of colour?) "Imprudent" or not, sections 15 and 28 of the Canadian Charter of Rights and Freedoms are supposed to guarantee the equal protection of the law for men and women. In the absence of conclusive evidence showing that men and women are different in some respect, therefore, the legally required presumption is that they be treated similarly. Madame Justice L'Heureux-Dube's suggestion that the "battered woman" defence not be extended to abused men without further research should be abhorrent to any fair-minded person truly committed to equality under the law. This is particularly so when the reason for the lack of research in relation to abused men is that the phenomenon has been dismissed out of hand at the start by so many public funding agencies. (Even so, the Honourable Madame Justice might have benefited from reading Gregorash (1990) before delivering her obiter dicta.) From a judge who fancies herself a staunch critic of the "myths and stereotypes" surrounding gender discrimination, as well as a staunch defender of gender equality, Justice L'Heureux-Dube's obiter dicta in Mallot could hardly be more disappointing.
} 
Based on having read over 400 "spousal abuse" files from the ECPO, and without pretending to be conclusive, the researcher proposes the following hypothesis.

Uncooperative witnesses fell largely into two categories: (i) those who had decided to sever all ties with the accused, and simply disappeared; and (ii) those who were involved in relationships that were dysfunctional and characterized by high levels of dependency or codependency. Among the latter category, abused men were at least as prevalent as abused women, as one would expect; after all, emotional dependence and related personality problems afflict both genders about equally. ${ }^{59}$ In addition, several social-psychological forces make men vulnerable to partner abuse in ways that women are not. From an early age, boys are strongly socialized not to hit girls, even in self-defence or retaliation; they are expected to "take" various forms of abuse "like a man." Men who have internalized these lessons are in greater jeopardy when they find themselves in abusive relationships. Indeed, men who have had experience with the law-enforcement system undoubtedly realize that any aggression against their partner, even in self-defence, will be seen as unacceptable. Some men therefore find themselves between the proverbial rock and a hard place: when called in aid of a man, the police are more likely to take no action on the belief that he can "look after himself;" but if he does look after himself, then he stands a good chance of being charged with an offence. The culmination of all of this is that it is embarrassing and unmanly for men to complain about partner violence, and presumably even more embarrassing and unmanly to testify in court against their partners about such abuse. ${ }^{60}$ It should therefore be unsurprising if men, more than women, chose to opt out of the system, in either of the two ways indicated above. That is, pre-existing vulnerability is hypothesized to play a significantly greater role for abused men than abused women, and might explain why men are less likely to report it to the police and more likely to become uncooperative witnesses for the prosecution. More non-ideological, gender-neutral research concerning the motivations and psychological effects of partner violence is evidently needed to explore these suggestions.

However these things might be, gender is significantly associated with the withdrawal of all charges and, overall, charges against women were more likely to have been withdrawn than charges against men (52.0\% vs. 37.1\%). But even if a greater reluctance on the part of men to testify is behind this disparity, and even if this disparity completely accounts for the lesser likelihood of women being found guilty, all of this does not mean that prosecutors process files neutrally as between the genders. That is because the motivation of the witnesses is not completely exogenous to the prosecutor's decision-making. In other words, prosecutors can influence how reluctant or how willing a complainant is to pursue a case against their partner using several means available to them: they can be more or less persuasive; they can threaten to lay a mischief charge against those who indicate an intention to change their stories; they can issue a subpoena; and if the witness fails to show up for trial they can seek an adjournment with

\footnotetext{
${ }^{59}$ The case of Ray Snyder is a clear illustration of a battered and emotionally dependent man. "Although he wanted to turn their friendship [with Karla Moen] into a romance - something the younger woman rejected - Snyder knew she was trouble. Months before his death he told a neighbour that 'if Moen ever quit drinking, she would leave him, and that if she kept drinking, she would kill him'." (Kent 2002). She stabbed him to death. Yet this case was not reported as a case of a "battered man;" Moen's trial and sentencing received very little attention in the local media.

${ }^{60}$ In contrast to a reluctance to complain about abuse or testify about a partner's abusive behaviour which is based on an acquired fear of retaliation (i.e. "learned helplessness"), one might refer to a reluctance to complain or testify which is based on dependency or socialization as "pre-existing vulnerability." Both would tend to be associated with higher levels of abuse: the first because higher levels of abuse cause the fear of testifying, and the second because the pre-existing aversion to testifying allows the abuser to get away with increasingly abusive behaviour.
} 
a subpoena in aid. Conversely, they can actively discourage witnesses by stonewalling and throwing cold water on the complainant - e.g. by throwing up defeatist arguments - if they do not wish to proceed with a charge, or if they prefer to deal with the case by plea bargain rather than trial. ${ }^{61}$ It would therefore be hasty to assume that imbalanced prosecutor discretion has no effect on the likelihood of a finding of guilt or witness problems. Data from the ECPO do not allow for a clear test between the male-partner-reluctance and the prosecutor-reluctance hypotheses, but a few salient points can be made.

One indication that imbalanced prosecutor discretion might be present is the fact that women benefit more than men from withdrawn charges even in the no-injury cases. Earlier findings indicated that police lay charges against men in many minor cases which would not have induced action by police at all were the accused a woman. One would expect, therefore, that more of the no-injury cases involving charged men would result in withdrawn charges by the prosecutor as not being in the public's interest to pursue. The fact that charges against men in this category were less likely to have been withdrawn suggests that the prosecutors share or even exacerbate whatever initial harshness toward men the police might exhibit in the laying of charges in the first place. This is consistent with what was found regarding prosecutor reluctance to pursue charges against women in the B.C. data (Ministry of the Attorney General 1999). For a particularly dramatic contrast, compare illustrative cases A and D, Appendix B. In the former, charges were dropped against the woman even though every indication was that she would have been convicted at trial; whereas in case $\mathrm{D}$, it is perplexing how the proceedings against the man ever got to trial, given the overwhelming evidence of his innocence based on the known history of the woman's psychiatric problems. As is more generally the case, the most egregious examples of dubious leniency involved women who were charged, whereas the most egregious examples of questionable prosecutorial zealousness involved men who were charged.

In many cases where the female complainant appeared to be uncooperative, this was noted in the police report or elsewhere in the prosecutor's file, and a further note or annotation frequently appeared indicating what the prosecutor had done to secure the complainant's true testimony. Similarly, when the prosecutor sought an adjournment due to the non-appearance of a witness, this was recorded on the file. Copies of subpoenas were also in the prosecutor's files. While data on the efforts of prosecutors to secure the testimony of witnesses was not consistently available, nor collected, the researcher's impression - it is admittedly no more than that - is that prosecutors pursued the testimony of female complainants distinctly more vigorously than that of male complainants, when complainants were proving to be uncooperative. Given the greater inherent reluctance of men to testify against their partners to begin with, prosecutors should in fact try to compensate by pursuing male complainants more vigorously.

To test the hypothesis that prosecutors were relatively lenient with women who were charged with partner violence, a third subset of cases was considered, namely those in which a plea was bargained. With certain caveats that will be discussed presently, plea-bargain cases

\footnotetext{
${ }^{61}$ Given the imbalanced charging practices of the police demonstrated previously, men are often left to file their own charges (referred to as a "private information") if they want action to be taken against their partners. Prosecutors tend to be extremely reluctant to proceed on private informations, perhaps assuming that if the police do not think there is merit to the complaint then they should not waste their time on it, either. Part of the purpose of this study is to show that the prosecutors' prejudice against private informations from abused men is unwarranted, and that they should in fact compensate for lack of action taken by the police by more actively pursuing these files.
} 
provide the best available objective evidence of the way in which prosecutors use their discretion, since the outcome of a plea-bargain is heavily influenced by the stance a prosecutor takes toward a case. Plea-bargains were identified as those cases in which one charge was withdrawn and another was pled guilty to. The cross-tabulation in Table 3.7 shows that the striking of a plea-bargain is not associated with the gender of the accused $(p=.532$, although too many cells in this table have expected values of less than 5 to make this a reliable measure). In other words, men and women in the ECPO sample were equally likely to have struck a bargain with the prosecutor.

\begin{tabular}{|c|c|c|c|c|c|c|c|}
\hline \multicolumn{8}{|c|}{$\begin{array}{c}\text { Table } 3.7 \\
\text { Injury level * Gender of those who plea-bargained } \\
\text { in incidents of partner violence in Edmonton, first half of } 2001\end{array}$} \\
\hline \multirow[b]{2}{*}{ Injury level } & & \multicolumn{3}{|c|}{ female $(\mathrm{N}=13)$} & \multicolumn{3}{|c|}{ male $(\mathrm{N}=52)$} \\
\hline & & Count & Expected count & $\% \mathrm{~N}$ & Count & Expected count & $\% \mathrm{~N}$ \\
\hline None & $\begin{array}{l}\text { Charged } \\
\text { Plea-bargained } \\
\text { \% plea-bargained }\end{array}$ & $\begin{array}{c}16 \\
2 \\
9.5\end{array}$ & $\begin{array}{c}25.2 \\
4.2\end{array}$ & $\begin{array}{l}21.3 \\
15.4\end{array}$ & $\begin{array}{c}107 \\
19\end{array}$ & $\begin{array}{l}97.8 \\
29.4\end{array}$ & $\begin{array}{l}36.8 \\
85.0\end{array}$ \\
\hline Low & $\begin{array}{l}\text { Charged } \\
\text { Plea-bargained } \\
\text { \% plea-bargained }\end{array}$ & $\begin{array}{c}31 \\
6 \\
24.0\end{array}$ & $\begin{array}{c}31.1 \\
5.0\end{array}$ & $\begin{array}{l}41.3 \\
46.2\end{array}$ & $\begin{array}{l}121 \\
43.0\end{array}$ & $\begin{array}{c}120.9 \\
50.0\end{array}$ & $\begin{array}{l}41.6 \\
76.5\end{array}$ \\
\hline Medium & $\begin{array}{l}\text { Charged } \\
\text { Plea-bargained } \\
\text { \% plea-bargained }\end{array}$ & $\begin{array}{c}19 \\
3 \\
25.0\end{array}$ & $\begin{array}{c}13.9 \\
2.4\end{array}$ & $\begin{array}{l}25.3 \\
23.1\end{array}$ & $\begin{array}{c}49 \\
19 \\
38.8\end{array}$ & $\begin{array}{l}54.1 \\
21.3\end{array}$ & $\begin{array}{l}16.8 \\
65.5\end{array}$ \\
\hline High & $\begin{array}{l}\text { Charged } \\
\text { Plea-bargained } \\
\% \text { plea-bargained } \\
\qquad p=.532\end{array}$ & $\begin{array}{c}9 \\
2 \\
28.6\end{array}$ & $\begin{array}{l}4.7 \\
1.4\end{array}$ & $\begin{array}{l}12.0 \\
15.4\end{array}$ & $\begin{array}{c}14 \\
3 \\
21.4\end{array}$ & $\begin{array}{c}18.3 \\
7.3\end{array}$ & $\begin{array}{c}4.8 \\
30.0\end{array}$ \\
\hline
\end{tabular}

The real question, though, is whether the pleas that were struck were more or less favourable depending on the gender of the accused. In order to test this, it is necessary to look at the terms of the plea-bargains. For present purposes, a fairly crude measure of the terms of pleabargains is sufficient. The cross-tabulation in Table 3.7.1 shows that 'any term' ${ }^{\prime 2}$ is significantly associated with gender among the plea-bargain cases $(p<.001)$. That is, men who agreed to a

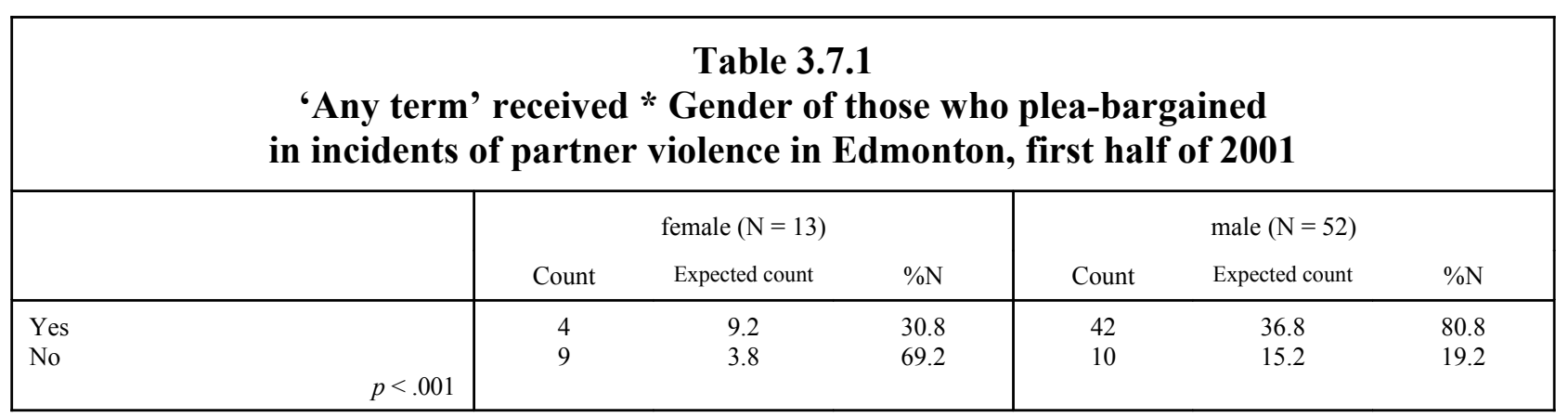

\footnotetext{
${ }^{62}$ To perform some of the tests in the remainder of Part B, it was necessary to combine variables. Thus 'any term' is 'yes' when any of 'jail', 'probation', or 'conditional sentence' is $>0$. Similarly, 'any personal-injury prior record' is 'yes' when the value in any personal-injury prior-record offence is $>0$; and 'non-personal-injury prior record' is 'high' when the value for 'non-personal-injury prior record' is $>2$ (otherwise it is 'low'). Finally, 'any prior record' is 'yes' when either 'any personal-injury prior record' is 'yes' or 'non-personal-injury prior record' is $>0$.
} 
plea-bargain were significantly more likely that women to have received a period of jail, probation, or a conditional sentence - which are the more serious penalties available to the justice system. This finding is especially surprising given that the women in the ECPO sample were significantly more likely to have caused a serious injury, were significantly more likely to have used a weapon, were significantly more likely to have been charged with certain categories of serious offence, were equally likely to have been intoxicated and to have had children present at the time of the incident, and yet were significantly less likely to have received pre-trial custody. Given all of that, one might expect that experienced, perceptive, and fair-minded prosecutors would be inclined to have bargained more favourable pleas with the men than the women, overall.

Several binary logistic regressions based on the plea-bargain sub-sample were used to further test this result. Since having a prior criminal record, especially a prior record for a personal-injury offence, is generally taken to be an important factor in setting penalties, various measures of prior record were included in these models.

Model D: $\quad$ dependent variable $=$ any term

$\begin{array}{lll}\text { covariates } & \text { gender } & p<.001 \\ & \text { injury level } & p=.189\end{array}$

Model E:

$$
\begin{array}{lll}
\text { dependent variable }= & \text { any term } & \\
\text { covariates } & \text { gender } & p=.001 \\
& \text { any prior record } & p=.216
\end{array}
$$

$\begin{array}{lll}\text { Model F: } & \text { dependent variable }= & \text { any term } \\ \text { covariates } & \text { gender } & p=.001 \\ & \text { any prior record } & p=.157 \\ & \text { intoxication } & p=.275 \\ & \text { presence of children } & p=.924\end{array}$

$\begin{array}{lll}\text { Model G: } & \text { dependent variable }= & \text { any term } \\ \text { covariates } & \text { gender } & p=.002 \\ & \text { any prior record } & p=.114 \\ & \text { non-personal-injury prior record } & p=.237 \\ & \text { any personal-injury prior record } & p=.633\end{array}$

What these models show is that, among the plea-bargained cases, gender is the only variable that is associated, at statistically significant levels, with receiving 'any term' as a penalty for partner violence. In other words, being male is more likely to result in receiving a more severe penalty on a plea-bargain than any other factor investigated in this study, including the level of injury to the victim. This is quite remarkable, since gender is the only factor which should be irrelevant to the outcome of plea-bargains. It seem that prosecutors are driving a much harder bargain with the men who are charged with partner violence than with the women, despite the generally more violent profile of the women in this sample. (Illustrative cases E and H, and "A Day in Provincial Court," Appendix B, provide anecdotal support to the conclusion advanced here.) 
Of course, it takes two sides to bargain and to agree to a plea, so the finding that women benefit significantly more than men from plea-bargains does not necessarily prove that the prosecutor is principally at fault for this outcome. Part of the explanation might be that women, through their experienced counsel, probably know that they have a strong hand to play when negotiating plea-bargains with prosecutors. They probably know, in other words, that they are less likely to be found guilty than men for various reasons (Table 3.6ff); and even if they are found guilty, they are likely to receive a lighter sentence than men (as will be shown below). Thus they have little incentive to jump at a plea-bargain except on favourable terms. The problem with this explanation is that it attempts to excuse prosecutorial bias against men by reference to systemic bias against men. If the actors in the justice system know that men are treated much more harshly that women generally, then their responsibility is to narrow the gap rather than to perpetuate it.

The final stage in the criminal justice system is the sentencing of those found guilty. Since so many variables factor into sentencing decisions, it is helpful to compare the proportion of men and women in the full ECPO sample with the proportion of men and women in the 'found guilty' sub-sample for each variable. These comparisons are set out in Table 3.8.

\begin{tabular}{|c|c|c|c|c|c|c|c|c|c|}
\hline \multicolumn{10}{|c|}{$\begin{array}{c}\text { Table } 3.8 \\
\text { Comparison of the full ECPO sample with the 'found guilty' sub-sample }\end{array}$} \\
\hline & & \multicolumn{4}{|c|}{ full sample $(\mathrm{N}=366)$} & \multicolumn{4}{|c|}{ found guilty $(\mathrm{N}=189)$} \\
\hline & & \multicolumn{2}{|c|}{ female $(\mathrm{N}=75)$} & \multicolumn{2}{|c|}{ male $(\mathrm{N}=291)$} & \multicolumn{2}{|c|}{ female $(\mathrm{N}=33)$} & \multicolumn{2}{|c|}{ male $(\mathrm{N}=156)$} \\
\hline & & count & $\% \mathrm{~N}$ & count & $\% \mathrm{~N}$ & count & $\% \mathrm{~N}$ & count & $\% \mathrm{~N}$ \\
\hline \multicolumn{2}{|c|}{ 1. Substance abuse } & 37 & 49.3 & 144 & 49.5 & 19 & 57.6 & 75 & 48.1 \\
\hline \multicolumn{2}{|c|}{ 2. Children present } & 24 & 32.0 & 109 & 37.5 & 13 & 39.4 & 47 & 30.1 \\
\hline \multicolumn{2}{|c|}{ 3. Taken into custody } & 29 & 38.7 & 176 & 60.5 & 17 & 51.5 & 103 & 66.0 \\
\hline \multirow[t]{3}{*}{ 4. Marital status } & married & 18 & 24.0 & 72 & 24.7 & 9 & 27.3 & 39 & 25.0 \\
\hline & cohabiting & 39 & 52.0 & 164 & 56.4 & 16 & 48.5 & 85 & 55.5 \\
\hline & separated & 18 & 24.0 & 55 & 18.9 & 8 & 24.2 & 32 & 20.5 \\
\hline \multirow{4}{*}{ 5. Injury level } & none & 16 & 21.3 & 107 & 36.8 & 9 & 27.3 & 62 & 39.7 \\
\hline & low & 31 & 41.3 & 121 & 41.6 & 13 & 39.4 & 61 & 39.1 \\
\hline & medium & 19 & 25.3 & 49 & 16.8 & 9 & 27.3 & 23 & 14.7 \\
\hline & high & 9 & 12.0 & 14 & 4.8 & 2 & 6.1 & 10 & 6.4 \\
\hline \multirow[t]{2}{*}{ 6. Weapon used } & minor & 52 & 69.3 & 271 & 93.1 & 25 & 75.8 & 143 & 91.7 \\
\hline & major & 23 & 30.7 & 20 & 69. & 8 & 24.2 & 13 & 8.3 \\
\hline \multirow[t]{3}{*}{ 7. Prior record } & non-personal-injury & 21 & 28.0 & 144 & 49.5 & 9 & 27.3 & 66 & 42.3 \\
\hline & any-personal-injury & 18 & 24.0 & 129 & 44.3 & 10 & 30.3 & 65 & 41.7 \\
\hline & any & 39 & 52.0 & 222 & 76.3 & 17 & 51.5 & 119 & 76.3 \\
\hline
\end{tabular}

The relevant comparisons for present purposes are between the proportion of women and men found guilty for each of the 7 variables. ${ }^{63}$ Among those found guilty, women were more

\footnotetext{
${ }^{63}$ A different set of interesting questions arises from comparisons between the proportions of women and men in the full sample and the proportions of women and men in the found-guilty sub-sample in Table 3.8. Note that the proportion of women in the found-guilty sub-sample is appreciably higher than the proportion of women in the full sample (whereas the reverse is the case for men) with respect to the following factors: substance abuse, children present, and personal-injury prior record. These factors seem to be positively associated with a finding of guilt for women, or negatively associated with a finding of guilt for men, or both. One can only speculate why; but (e.g.) if women are stereotypically considered to be necessary caregivers to the children then one would expect police to be more reluctant to lay charges against women than men when children are present. Consequently, when charges are laid against women when children are present, they would likely be much clearer cases of guilt than for similarly situated men. It is beyond the scope of this study to investigate these issues further.
} 
likely than men to have been intoxicated at the time of the incident $(57.6 \% v s .48 .1 \%)$. Since intoxication is an aggravating factor in the commission of an offence, one would expect women to have received harsher sentences, all other things being equal. Similarly, since the presence of children at the time of the incident is an aggravating factor, guilty women should again receive harsher sentences than guilty men, because children were more likely to be present in incidents where women were found guilty $(39.4 \%$ vs. 30.1\%). While being taken into custody after being charged is obviously not a mitigating factor in the legal sense, it should nevertheless tend to reduce the harshness of any sentence for those found guilty since credit is given in sentencing for "time served." Since guilty men were more likely than guilty women to have been taken into custody $(66.0 \%$ vs. $51.4 \%)$ and to have been detained until the time of the trial $(16.5 \% v s .2 .7 \%)$, one should again expect the women in the ECPO sample to have received harsher sentences, all other things being equal.

Marital status is also not directly an aggravating or mitigating factor; but if it is indirectly relevant to sentencing, then harsher sentences would likely attach to perpetrators who were separated from their victims at the time of the incident, for two reasons. First, perpetrating an offence against an estranged partner demonstrates a greater determination to commit the offence, since one has to go out of one's way to engage the victim. Second, separated couples are more likely to be subject to restraining orders or no-contact orders, so committing an offence against an estranged partner will more likely entail additional charges. As with the other factors so far considered, women who were found guilty were more likely than men to have been separated from their partners at the time of the offence $(24.2 \% v s .20 .5 \%)$, and so should warrant harsher sentences, all other things being equal. Higher-injury offences generally warrant harsher sentences than lower-injury offences, also. Men and women who were found guilty were about equally likely to have committed low-injury and high-injury offences; but women were more likely to have committed medium-injury offences while men were more likely to have committed no-injury offences. Thus, overall, the women who were found guilty committed the more injurious offences than the men, which should lead to harsher sentences for the women, all other things being equal. Similarly with use of a weapon: $24.2 \%$ of the guilty women, but only $8.3 \%$ of the guilty men, had used a major weapon in the commission of their offence. So again, other things being equal, the women in this sample should have received harsher sentences.

\begin{tabular}{|c|c|c|c|c|c|c|c|}
\hline \multicolumn{8}{|c|}{$\begin{array}{l}\text { Table } 3.8 .1 \\
\text { Prior criminal record * Gender of those found guilty } \\
\text { in incidents of partner violence in Edmonton, first half of } 2001\end{array}$} \\
\hline \multirow{2}{*}{\multicolumn{2}{|c|}{ Type of prior record }} & \multicolumn{3}{|c|}{ female $(\mathrm{N}=33)$} & \multicolumn{3}{|c|}{ male $(\mathrm{N}=156)$} \\
\hline & & Count & Expected count & $\% \mathrm{~N}$ & Count & Expected count & $\% \mathrm{~N}$ \\
\hline 1. Unrelated offence & $\begin{array}{l}\text { Many } \\
\text { Few } p=.109\end{array}$ & $\begin{array}{c}9 \\
24\end{array}$ & $\begin{array}{l}13.1 \\
19.9\end{array}$ & $\begin{array}{l}27.3 \\
72.7\end{array}$ & $\begin{array}{l}66 \\
90\end{array}$ & $\begin{array}{l}61.9 \\
94.1\end{array}$ & $\begin{array}{l}42.3 \\
57.7\end{array}$ \\
\hline 2. Personal-injury offence & $\begin{array}{ll} & \\
\text { Yes } & \\
\text { No } & \\
& p=.225\end{array}$ & $\begin{array}{l}10 \\
23\end{array}$ & $\begin{array}{l}13.1 \\
19.9\end{array}$ & $\begin{array}{l}30.3 \\
69.7\end{array}$ & $\begin{array}{l}65 \\
91\end{array}$ & $\begin{array}{l}61.9 \\
94.1\end{array}$ & $\begin{array}{l}41.7 \\
58.3\end{array}$ \\
\hline 3. Any prior record & $\begin{array}{l}\text { Yes } \\
\text { No } p=.004\end{array}$ & $\begin{array}{l}17 \\
16\end{array}$ & $\begin{array}{c}23.7 \\
9.3\end{array}$ & $\begin{array}{l}51.5 \\
48.5\end{array}$ & $\begin{array}{c}119 \\
37\end{array}$ & $\begin{array}{l}112.3 \\
43.7\end{array}$ & $\begin{array}{l}76.3 \\
23.7\end{array}$ \\
\hline
\end{tabular}


The only variables considered in this study which suggest that the men who were found guilty should receive harsher sentences than the women who were found guilty are measures of prior criminal record. Yet the cross-tabulations in Table 3.8.1 show that this disparity was statistically significant only for the 'any record' variable $(p=.004){ }^{64}$ It could be argued that 'prior criminal record' is a tainted variable which should not be used in the analysis of sentencing outcomes. If men receive harsher treatment from the law-enforcement authorities at every stage in the process, then one would expect them to have worse criminal records even if they have not committed any more violence against their partners. Earlier systemic bias should not be brought in to justify subsequent harshness in sentencing. On this theory, cross-tabulations were done to test for the association of sentencing outcomes with gender. Table 3.9 shows that guilty men were significantly more likely to receive a harsher sentence than guilty women. This is true whether jail terms $(p=.014)$, terms of probation or conditional sentences $(p=.055)$, or 'any term' $(p<.001)$ is used to measure the harshness of the sentence imposed.

\begin{tabular}{|c|c|c|c|c|c|c|c|}
\hline \multicolumn{8}{|c|}{$\begin{array}{c}\text { Table } 3.9 \\
\text { Sentencing outcome * Gender of those found guilty } \\
\text { in incidents of partner violence in Edmonton, first half of } 2001\end{array}$} \\
\hline \multirow{2}{*}{\multicolumn{2}{|c|}{ Type of penalty }} & \multicolumn{3}{|c|}{ female $(\mathrm{N}=33)$} & \multicolumn{3}{|c|}{ male $(\mathrm{N}=156)$} \\
\hline & & Count & Expected count & $\% \mathrm{~N}$ & Count & Expected count & $\% \mathrm{~N}$ \\
\hline 1. Jail term & $\begin{array}{l}\text { Yes } \\
\text { No } \quad p=.014\end{array}$ & $\begin{array}{c}2 \\
31\end{array}$ & $\begin{array}{c}7.3 \\
25.7\end{array}$ & $\begin{array}{c}6.1 \\
93.9\end{array}$ & $\begin{array}{l}40 \\
149\end{array}$ & $\begin{array}{l}34.7 \\
121.3\end{array}$ & $\begin{array}{l}25.6 \\
74.4\end{array}$ \\
\hline $\begin{array}{l}\text { 2. Probation } \\
\text { or conditional sentence }\end{array}$ & $\begin{array}{l}\text { Yes } \\
\text { No } \\
\quad p=.055\end{array}$ & $\begin{array}{l}15 \\
18\end{array}$ & $\begin{array}{l}19.9 \\
13.1\end{array}$ & $\begin{array}{l}45.5 \\
54.5\end{array}$ & $\begin{array}{l}99 \\
90\end{array}$ & $\begin{array}{l}94.1 \\
61.9\end{array}$ & $\begin{array}{l}63.5 \\
36.5\end{array}$ \\
\hline 3. Any term & $\begin{array}{l}\text { Yes } \\
\text { No } p<.001\end{array}$ & $\begin{array}{l}17 \\
16\end{array}$ & $\begin{array}{c}25.0 \\
8\end{array}$ & $\begin{array}{l}51.5 \\
48.5\end{array}$ & $\begin{array}{l}126 \\
63\end{array}$ & $\begin{array}{l}118.0 \\
38\end{array}$ & $\begin{array}{l}80.8 \\
19.2\end{array}$ \\
\hline
\end{tabular}

As Table 3.8 shows, every factor that was examined in this study other than prior criminal record suggests that the women who were found guilty should have received harsher sentences than the men, on the whole. It would therefore be surprising if the prior criminal record of those found guilty of violence against their partners had such an overwhelming effect on sentencing as to account for this disparity in treatment. Nevertheless, to test this, and to test the relationship between various sentencing outcomes and other variables of interest, three series of binary logistic regressions were performed on the data in the found-guilty sub-sample. The first series (Models F - R) shows how several variables are associated with 'any jail'.

$\begin{array}{lll}\text { Model F: } & \begin{array}{l}\text { dependent variable }= \\ \text { covariate }\end{array} & \begin{array}{l}\text { any jail } \\ \text { gender }\end{array} \\ \text { Model G: } & \begin{array}{l}\text { dependent variable }= \\ \text { covariate }\end{array} & \begin{array}{l}\text { any jail } \\ \text { injury level }\end{array} \\ & & p=.026\end{array}$

\footnotetext{
${ }^{64}$ Overall, $(42 / 366=) 11.5 \%$ of the cases in the ECPO sample resulted in a jail sentence being imposed. The corresponding figure in the B.C. data is $13 \%$. Likewise, $(114 / 366=) 31.2 \%$ of the cases in the ECPO sample resulted in a term of probation or a conditional sentence. The corresponding figure in the B.C. data is $27 \%$ (Ministry of the Attorney General 1999: 29). This tends to confirm that the ECPO sample is broadly representative and valid.
} 


\begin{tabular}{|c|c|c|c|}
\hline Model H: & $\begin{array}{l}\text { dependent variable }= \\
\text { covariate }\end{array}$ & $\begin{array}{l}\text { any jail } \\
\text { children present }\end{array}$ & \\
\hline Model I: & $\begin{array}{l}\text { dependent variable }= \\
\text { covariate }\end{array}$ & $\begin{array}{l}\text { any jail } \\
\text { substance abuse }\end{array}$ & \\
\hline Model J: & $\begin{array}{l}\text { dependent variable }= \\
\text { covariate }\end{array}$ & $\begin{array}{l}\text { any jail } \\
\text { any prior record }\end{array}$ & \\
\hline Model K: & $\begin{array}{l}\text { dependent variable }= \\
\text { covariate }\end{array}$ & $\begin{array}{l}\text { any jail } \\
\text { non-personal-injury prior record }\end{array}$ & $p=.004$ \\
\hline Model L: & $\begin{array}{l}\text { dependent variable }= \\
\text { covariate }\end{array}$ & $\begin{array}{l}\text { any jail } \\
\text { any personal-injury prior record }\end{array}$ & $p=.004$ \\
\hline Model M: & $\begin{array}{l}\text { dependent variable }= \\
\text { covariates }\end{array}$ & $\begin{array}{l}\text { any jail } \\
\text { gender } \\
\text { any prior record }\end{array}$ & $\begin{array}{l}p=.071 \\
p=.003\end{array}$ \\
\hline Model N: & $\begin{array}{l}\text { dependent variable }= \\
\text { covariates }\end{array}$ & $\begin{array}{l}\text { any jail } \\
\text { gender } \\
\text { any personal-injury prior record }\end{array}$ & $\begin{array}{l}p=.035 \\
p=.006\end{array}$ \\
\hline Model O: & $\begin{array}{l}\text { dependent variable }= \\
\text { covariates }\end{array}$ & $\begin{array}{l}\text { any jail } \\
\text { gender } \\
\text { non-personal-injury prior record }\end{array}$ & $\begin{array}{l}p=.039 \\
p=.007\end{array}$ \\
\hline Model P: & $\begin{array}{l}\text { dependent variable }= \\
\text { covariates }\end{array}$ & $\begin{array}{l}\text { any jail } \\
\text { gender } \\
\text { any personal-injury prior record } \\
\text { non-personal-injury prior record }\end{array}$ & $\begin{array}{l}p=.039 \\
p=.033 \\
p=.041\end{array}$ \\
\hline Model Q: & $\begin{array}{l}\text { dependent variable }= \\
\text { covariates }\end{array}$ & $\begin{array}{l}\text { any jail } \\
\text { gender } \\
\text { any personal-injury prior record } \\
\text { non-personal-injury prior record } \\
\text { level of injury }\end{array}$ & $\begin{array}{l}p=.023 \\
p=.039 \\
p=.073 \\
p=.011\end{array}$ \\
\hline Model R: & $\begin{array}{l}\text { dependent variable }= \\
\text { covariates }\end{array}$ & $\begin{array}{l}\text { any jail } \\
\text { gender } \\
\text { any prior record } \\
\text { level of injury }\end{array}$ & $\begin{array}{l}p=.033 \\
p=.003 \\
p=.009\end{array}$ \\
\hline
\end{tabular}

While gender is less significant in this series than measures of prior record and injury level (as one would expect), it is still associated with jail-term outcomes to a statistically significant degree in every model except $\mathbf{M}$, where it is only marginally insignificant. That is, even when prior criminal records and levels of injury are taken into account, gender remains associated at a statistically significant level with receiving a jail term for a partner-violence 
offence. Specifically, being a man increases the likelihood of receiving jail; being a woman reduces it.

A similar series of binary logistic regressions was performed on the 'any probation' outcome from the found-guilty sub-sample (Models $\mathbf{S}-\mathbf{E E}$ ). In the second series, gender is again statistically significant in every model, although only marginally so on its own (Model S). Also of interest is that having a high number $(>2)$ of prior convictions for non-personal-injury offences is not statistically associated with 'any probation', though other measures of prior criminal record remain significant.

\begin{tabular}{|c|c|c|c|}
\hline Model S: & $\begin{array}{l}\text { dependent variable }= \\
\text { covariate }\end{array}$ & $\begin{array}{l}\text { any probation } \\
\text { gender }\end{array}$ & $p=.058$ \\
\hline Model T: & $\begin{array}{l}\text { dependent variable }= \\
\text { covariate }\end{array}$ & $\begin{array}{l}\text { any probation } \\
\text { injury level }\end{array}$ & $p=.011$ \\
\hline Model U: & $\begin{array}{l}\text { dependent variable }= \\
\text { covariate }\end{array}$ & $\begin{array}{l}\text { any probation } \\
\text { children present }\end{array}$ & $p=.131$ \\
\hline Model V: & $\begin{array}{l}\text { dependent variable }= \\
\text { covariate }\end{array}$ & $\begin{array}{l}\text { any probation } \\
\text { substance abuse }\end{array}$ & $p=.699$ \\
\hline Model W: & $\begin{array}{l}\text { dependent variable }= \\
\text { covariate }\end{array}$ & $\begin{array}{l}\text { any probation } \\
\text { any prior record }\end{array}$ & $p=.009$ \\
\hline
\end{tabular}

Model X: $\quad$ dependent variable $=$ any probation

covariate non-personal-injury prior record $\quad p=.199$

Model Y: $\quad$ dependent variable $=$ any probation

covariate any personal-injury prior record $\quad p=.013$

Model Z: $\quad$ dependent variable $=$ any probation

$\begin{array}{lll}\text { covariates } & \text { gender } & p=.010 \\ & \text { any prior record } & p=.002\end{array}$

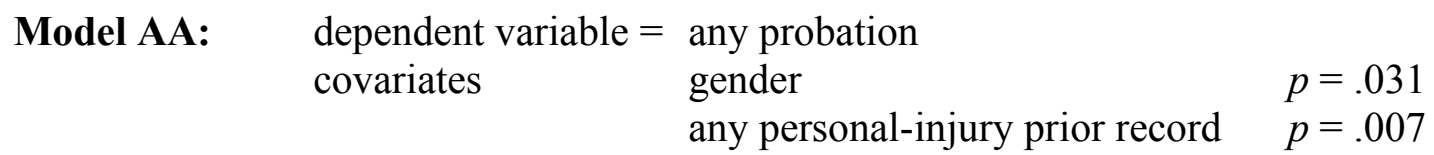

$\begin{array}{lll}\text { Model BB: } & \begin{array}{l}\text { dependent variable }= \\ \text { covariates }\end{array} & \text { any probation } \\ & \text { gender } & p=.038 \\ & \text { non-personal-injury prior record } & p=.125\end{array}$

Model CC: $\quad$ dependent variable $=$ any probation

covariates

gender

$p=.026$

any personal-injury prior record $\quad p=.019$

non-personal-injury prior record $\quad p=.453$ 
Model DD:

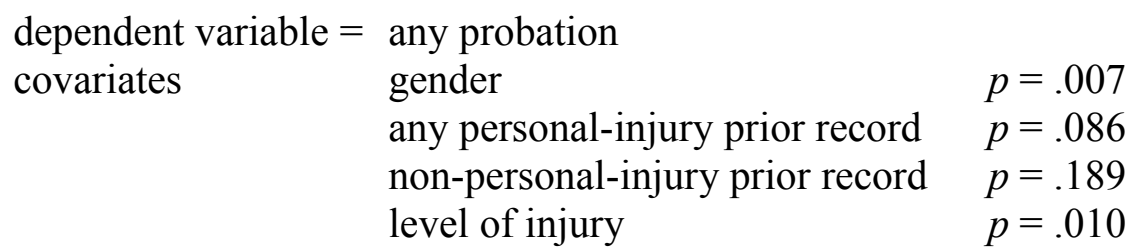

Model EE:

dependent variable $=$
covariates

any probation

gender

any prior record

$p=.002$

level of injury

$p=.001$

$p=.003$

The third series of binary logistic regressions was performed on the 'any term' outcome from the found-guilty sub-sample (Models FF - SS). This series tends to confirm the finding of Table 3.9 that 'any term' is the sentencing outcome that is most significantly associated with gender. Gender is, in fact, the variable that best predicts the likelihood of receiving 'any term' more so than the level of injury sustained by the victim or the prior record of the offender.

Model FF: $\quad$ dependent variable $=$ any term

covariate gender $p=.001$

Model GG: $\quad$ dependent variable $=$ any term

covariate injury level $\quad p=.032$

Model HH: dependent variable $=$ any term

covariate children present $\quad p=.789$

Model II: $\quad$ dependent variable $=$ any term

covariate substance abuse $\quad p=.525$

Model JJ: $\quad$ dependent variable $=$ any term

covariate any prior record $\quad p=.474$

Model KK: $\quad$ dependent variable $=$ any term

covariate non-personal-injury prior record $p=.436$

Model LL: dependent variable $=$ any term

covariate any personal-injury prior record $\quad p=.546$

Model MM: $\quad$ dependent variable $=$ any term

$\begin{array}{lll}\text { covariates } & \text { gender } & p<.001 \\ & \text { any prior record } & p=.130\end{array}$

Model NN: $\quad$ dependent variable $=$ any term

$\begin{array}{lll}\text { covariates } & \text { gender } & p=.001 \\ & \text { any personal-injury prior record } & p=.338\end{array}$

Model OO: dependent variable $=$ any term

covariates gender $p=.001$

non-personal-injury prior record $\quad p=.701$ 


\begin{tabular}{|c|c|c|c|}
\hline Model PP: & $\begin{array}{l}\text { dependent variable }= \\
\text { covariates }\end{array}$ & $\begin{array}{l}\text { any term } \\
\text { gender } \\
\text { any personal-injury prior record } \\
\text { non-personal-injury prior record }\end{array}$ & $\begin{array}{l}p=.001 \\
p=.249 \\
p=.455\end{array}$ \\
\hline Model QQ: & $\begin{array}{l}\text { dependent variable }= \\
\text { covariates }\end{array}$ & $\begin{array}{l}\text { any term } \\
\text { gender } \\
\text { any personal-injury prior record } \\
\text { non-personal-injury prior record } \\
\text { level of injury }\end{array}$ & $\begin{array}{l}p<.001 \\
p=.550 \\
p=.847 \\
p=.015\end{array}$ \\
\hline Model RR: & $\begin{array}{l}\text { dependent variable }= \\
\text { covariates }\end{array}$ & $\begin{array}{l}\text { any term } \\
\text { gender } \\
\text { any prior record } \\
\text { level of injury }\end{array}$ & $\begin{array}{l}p<.001 \\
p=.056 \\
p=.007\end{array}$ \\
\hline Model SS: & $\begin{array}{l}\text { dependent variable }= \\
\text { covariates }\end{array}$ & $\begin{array}{l}\text { any term } \\
\text { gender } \\
\text { injury level } \\
\text { any prior record } \\
\text { substance abuse } \\
\text { children present }\end{array}$ & $\begin{array}{l}.001 \\
.009 \\
.051 \\
.524 \\
.893\end{array}$ \\
\hline
\end{tabular}

The implication of this series of binary logistic regressions bears emphasis: being male is more likely to result in harsher sentences for partner violence than even the level of injury inflicted upon the victim - and even when the prior criminal record of the offender and other aggravating factors such as the presence of children or intoxication at the time of the incident are taken into account. Being male also tends to increase in significance as the number of other variables included in the model increases. This would be the case if the other variables are not independent of gender, but rather have a disparate effect on sentencing outcomes for men and women. Take the presence of children as an example. When men are sentenced for partnerviolence incidents, the presence of children at the time of the incident is typically raised as an aggravating factor, leading to a harsher sentence. On the other hand, traditionalist thinking, which holds that the children should not be punished by being deprived of their primary caregivers for the crimes of their mothers, may lead to more lenient sentences for women when children are present at the time of their partner-violence offences. This kind of interaction between variables may well be at play in affecting the sentencing outcomes of the present study.

It is apparent from the analyses of Part $B$ that prosecutors and judges were not acting so as to mitigate the harsher treatment men in the ECPO sample received at the hands of the police. Indeed, there is strong evidence here that prosecutors and judges tended to exacerbate preexisting disparities in treatment in several ways: by being more reluctant to see charges against men withdrawn; by driving harder plea-bargains with the men than the women; and by seeking or imposing harsher sentences upon the men than the women. Of course, it is not possible to disentangle the contributions of the prosecutors from that of the judges who are ultimately responsible for awarding sentences - or even from defence counsel who might also consciously or unconsciously expect a "female discount" in sentencing. Nevertheless, it would certainly be 
inappropriate to blame the victims - in this case, the male victims of female violence - for the fact that the women in the ECPO sample received significantly more lenient treatment at every step in the prosecutorial and judicial process.

The results of this investigation are especially robust for at least two reasons. First, the analyses in Part A and Part B, insofar as they overlap, arrive at the same conclusion on the basis of two quite different data sources. Second, although it is usually possible to suggest an innocent explanation for any individual finding in this study, it is very difficult to find a consistent set of innocent explanations for all of the findings taken together. This is because an innocent explanation for one finding tends to militate against an innocent explanation for a different finding. For example, when it was initially noted that the men in the ECPO sample were more likely than the women to be found guilty, the suggestion was made that this might be because men were charged in proportionately more of the no-injury cases, where it might have been convenient to enter into favourable plea-bargains rather than take the matter to trial. However, later analyses showed that men were more likely to have been found guilty in offences involving all levels of injury, and that men did not receive as favourable treatment as women in the pleabargains they had obtained. Indeed, what makes innocent explanations for any individual finding of discriminatory treatment in this study most implausible is the fact that discrimination against men was found to be so pervasive elsewhere. It defies logic and human nature to suppose that, while men were treated more harshly than women at almost every other stage in the lawenforcement system, they were treated more favourably than women in any one stage.

\section{Conclusions and Recommendations}

The results of this investigation indicate that men who are involved in disputes with their partners, whether as alleged victims or as alleged offenders or both, are disadvantaged and treated less favourably than women by the law-enforcement system at almost every step. Men are much less likely to report their victimization to the authorities to begin with, either because they consider it unmanly to do so or because they believe the authorities will not take their complaints very seriously, anyway. When men do report their victimization, or when it is reported for them by third parties, the police are less likely to lay charges against their partners than they would be to lay charges against comparable male suspects. In fact, the police seem reluctant to lay charges against women in partner violence cases unless a relatively serious offence has been committed or other aggravating factors are present. The result is that, even though the charging ratios by the Edmonton police in the period under scrutiny are higher against women than in many other jurisdictions in Canada in the past, they still diverge greatly from what the sociological data on partner violence indicates would reflect reality. The categories of female-only assaults and mutual aggression seem especially under-represented in the police charging data.

After laying charges, police are significantly more likely to take a man into custody than a woman, even when factors such as the level of injury inflicted and prior criminal record are taken into account. Nor do prosecutors tend to mitigate this disparately harsh treatment of men. On the contrary, prosecutors appear to pursue cases involving male suspects more vigorously than those involving female suspects. Thus men are more likely to be found guilty and are less likely to benefit from withdrawn charges, even though they are suspects in proportionately more

of the no-injury cases. Men are also less likely to benefit from favourable plea bargains, despite 
the fact that they have committed, on average, less grievous offences. And men are significantly more likely to receive harsher sentences than women, even when all other relevant factors are taken into account. Indeed, gender is often the most significant factor in predicting how the lawenforcement system responds to incidents of partner violence.

This pattern of unfavourable outcomes bears all of the classic signs of a self-reinforcing system of discrimination against men, a system that is supported by ideological myths and stereotypes. Public-awareness campaigns based on information from official sources typically promote the awareness of and remedies for female victims only; so men who are victimized often do not even realize that help (such as it is) is available to them, and many of their cases do not come to the attention of the authorities. Many men who have had experience with the lawenforcement system, or know others who have had such experience, come to mistrust the fairness of that system and refuse to engage it when they are themselves the victims of abuse. They can be forgiven for wondering why they should subject themselves to all of the embarrassment associated with pursuing charges against a violent female partner when the justice system does not seem inclined to take it seriously anyway. This reluctance on the part of male victims, in turn, reinforces stereotypical attitudes of police and prosecutors, who figure either that the man can look after himself or that he is not really interested in pursuing his complaint anyway. Since relatively few cases involving violent women reach the courts, judges acquire the mistaken impression that violence against men is not a serious social problem, and excuse their leniency toward women with the sexist assumption that children should not be punished for the crimes of their mothers. Prosecutors, seeing how judges routinely slap women on the wrist for even fairly major assaults, lose incentive to fight these cases aggressively in the courts, and offer favourable plea-bargains to the women instead. And the police, seeing that prosecutors do not appear to pursue cases against women as vigorously as cases against men, in turn decide not to lay charges against women except in the clearest of cases. Up and down the system, everyone quickly adjusts to the political myth that family violence is only about protecting "women and children" from abusive male partners. Breaking this cycle of bias can only be achieved through system-wide, concerted, and conscious efforts.

\section{Recommendations for Government Agencies}

The first rule of good governance, like the first rule of medicine, is to do no harm. All branches of government that concern themselves with domestic violence in a legal, supportproviding, or educative capacity must therefore, first and foremost, eradicate all of the one-sided, propagandistic publicity and pseudo-research on this subject. While much of the extant literature continues to reflect, to one degree or another, the orientation that women are overwhelmingly the victims of family violence, a perfect example of the kind of document which does considerably more harm than good by perpetuating grossly inaccurate myths and stereotypes is the City of Lethbridge's Our Community Response to Domestic Violence. A comprehensive critique of this document is beyond the scope of this paper, though Appendix $C$ summarizes some of the most salient reasons why governments at all levels must move quickly and unambiguously to disown that kind of advocacy, and to insist that it not be used in the educating or training of any workers in this field, including counsellors, police, prosecutors, and judges.

Beyond eradicating harmful misinformation, government agencies must make sure that they provide valid, useful information to their departments that deal with family violence. This 
means diverting research funds to projects which are genuinely scholarly (as opposed to merely ideological advocacy) and which are expressly gender inclusive. The present research is only a first, unfunded step in that direction - but no less important for that. Sufficient research funding would permit a study such as the present one to be conducted on a larger scale, taking into account more variables and using a larger sample of cases. This would improve the scope and power of the statistical analyses.

This ground-breaking study has identified several important areas in which further gender-inclusive research into the nature of and legal-system's response to partner violence remains to be done. In addition, government workers in this area would benefit from related research on the possibly counterproductive aspects of "zero tolerance" policies, and on the positive aspects of healing policies similar to those already applied in child-assault cases. Most especially, research is required on the way in which the criminal justice system with respect to partner violence may influence the outcomes of family courts. The disparately harsh treatment of men noted at every step in this study has potentially serious negative effects on the fairness of custody and access orders in particular. Finally, further research is required on the abuse of laws and government resources through false accusations, including the fraudulent use of shelters and ex parte court orders. (Indeed, the bias against men in the criminal-justice system which is evident from this study is expected to be part of a broader bias against men in the legal system generally. The biases in the criminal-justice system reinforce and exacerbate the biases in the family courts.) Since the behaviour of the actors in the system can be expected to change as greater awareness of the systemic biases currently prevailing come to light, on-going research is needed to mark the progress expected to be made toward gender neutrality. ${ }^{65}$

Of course, proportionate government funding of support services for abused men and their children is also required. It is beyond the scope of this paper to outline the many ways in which abused men are short-changed in the provision of these services, but it is important to note that in the case of abused women, public-service providers offer useful entry points for the collection of data for further research. Until abused men receive the same level of services, it will be difficult to determine the exact nature and extent of the specific problems men face when they find themselves victims in deteriorating or dysfunctional relationships. ${ }^{66}$ Because the lives of men and woman are so intimately intertwined, help for men in need can be expected to improve the lives of the women they live with, too.

\footnotetext{
${ }^{65}$ This study provides only a "snapshot" of the situation at a particular time rather than a longitudinal overview of how law-enforcement practices may have changed over time. In the Fall of 2001, i.e. just after the cases in the sample for the present study were closed, the Edmonton Crown Prosecutor's Office was reorganized so that two special prosecutors are now assigned to deal with all domestic abuse cases. Thus greater consistency in the handling of partner-violence cases is to be expected, perhaps including greater gender neutrality. This study therefore provides a useful "base point" for future comparisons.

${ }^{66}$ Some years ago this researcher attended a lecture in Edmonton by Dr. Suzanne Steinmetz, a top American researcher in the area of family violence. She quoted the mayor of a resort in Florida in the mid-1970s, who when confronted by statistics on the prevalence of rape in that town said: "Before we set up this hotline and crisis center last year, we didn't have a problem with rape." The same mentality is displayed by the many public agencies which continue to assiduously suppress any attention to partner abuse of men, despite the scholarly evidence available showing it is a significant problem.
} 


\section{Recommendations for the Judiciary}

Judges ultimately establish the tone of the criminal-justice system by the manner in which they hear and dispose of the cases before them. Any perception that judges are not gender blind is therefore fatal to fairness in this area of the law. Moreover, it is the solemn duty of the judiciary to uphold the Constitution of Canada, and in particular to guarantee the provisions articulated in the Charter of Rights and Freedoms. Of special importance to the present discussion is the following:

15. Every individual is equal before and under the law and has the right to the equal protection and benefit of the law without discrimination and, in particular, without discrimination based on race, national or ethnic origin, colour, religion, sex, age or mental or physical disability.

Abused men are constitutionally entitled to the same protections and the same benefits of the law as abused women, which means that judges must apply the same standards in their rulings for one gender as the other. They must be as willing to hear a case against a woman as against a man. (See the first case in "A Day in Provincial Court," Appendix B, for some indication that judges may be less willing to hear cases involving women charged with domestic assaults.) Most critically, giving a "female discount" in sentencing amounts to an unconstitutional devaluation of the suffering of male victims by the very judiciary which is supposed to guarantee these men equal dignity and respect as individuals. The clear disparities in sentencing treatment of men and women who have been convicted of partner violence needs to be brought to the attention of the judiciary, together with a reminder of their constitutional responsibility to administer justice "blindly" with respect to gender.

The over-riding importance of gender equality to the Constitution of Canada can be seen from the fact that this right is reiterated elsewhere, affording men and women equal rights absolutely and notwithstanding anything else in the Constitution. Consider the combined effect of these other two sections of the Charter:

7. Everyone has the right to life, liberty, and security of the person and the right not to be deprived thereof except in accordance with the principles of fundamental justice.

28. Notwithstanding anything in this Charter, the rights and freedoms referred to in it are guaranteed equally to male and female persons.

To impose harsher sentences upon male offenders than upon comparable female offenders is to deprive men of their right to liberty and security of person to a greater extent than women. That is to say, it deprives men of their s. 7 rights in contravention of s. 28. Furthermore, inasmuch as punishment is intended to have a deterrent effect, the practice of "female discounting" in sentencing violates the s. 7 security-of-the-person rights of male victims of partner violence, too. After all, women who are not properly deterred pose a greater risk to their partners. This is true whether the judicial practice of "female discounting" in sentencing is conscious or systemic. Clearly, the Constitution of Canada requires the utmost impartiality as between men and women in the administration of justice. 
Judges, too, should be alive to the interaction between the criminal and family-law implications of their decisions. Especially in the context of a disintegrating or dissolved relationship where custody and access to children is an on-going dispute, judges should be aware of the possibilities for exaggerated and false allegations, to which men in particular are vulnerable given police charging practices. In the interest of maintaining maximum contact between the child and both parents, harsh sentences should be avoided where possible in preference to counselling or mutual no-contact orders.

\section{Recommendations for Prosecutors}

Prosecutors play a pivotal role in the criminal-justice system. They, too, must proceed with the utmost impartiality as between men and women who are charged with an offence. When dealing with police, they must insist on equal diligence in all cases - e.g. in terms of the documentation of injuries, the laying of charges, the provision of follow-up reports, etc. As long as police continue to charge men and women at significantly disproportionate rates relative to what the sociological evidence suggests is warranted, prosecutors should exercise their discretion to screen cases in such a way as to mitigate this disparity. This discretion can be employed in two ways: First, prosecutors should consider seriously whether it is in the public interest to proceed against men where charges would not be - or had not been - laid against an equally aggressive woman. Some of the no-injury cases clearly fit this description. Second, prosecutors should seriously consider proceeding with private informations from men where police have declined to lay charges in the first instance, especially where the complaint likely would have resulted in a charge were the complainant female. Sensitivity to the inhibitions peculiar to abused men who may be required to testify against their partners must be shown.

Prosecutors sometimes express frustration when complainants, particularly female complainants, change their story or refuse to testify after the incident. In an attempt to get the charges dropped, the complainant will often say that it was really her fault, that the fighting was mutual and consensual, that she had unjustifiably provoked the accused, or that she had fabricated the assault claim. But the prosecutors' frustration may not be well founded in many cases involving minor acts of aggression, since the complainant's later retraction may well be closer to the truth than the version she supplied at the time of the incident when emotions were running high or leverage over the dispute was being sought from the authorities. If roughly half of all minor-act conflicts truly involve mutual aggression, as the sociological evidence suggests, and if only a small fraction of cases where charges are laid involve charges against both parties, as the evidence in the present study indicates, then there must be a significant number of cases of mutual aggression involving minor acts where only the man is charged. It is very much an open question in any particular case of minor aggression, then, whether the woman's later retraction is genuine. Certainly there is no reason for prosecutors to suppose that male victims who later turn into uncooperative witnesses are any more or less prone to the influence of their partners to change their stories.

When in court, prosecutors must show the same firm resolve to proceed with cases against women as men, even when judges show greater impatience for cases against women. On their own initiative, they must pursue witnesses - and adjournments, when witnesses fail to appear - in all cases with the same vigour. Given the clear evidence of significant disparities in sentencing between men and women, it would not be out of line for prosecutors to remind judges 
from time to time of their constitutional duty to administer justice impartially in this respect. A detailed examination of the case law should be undertaken to establish appropriate "benchmark" sentences for various partner-violence offences, which can be applied equally to all convicts.

Whenever discretionary actions are taken - withdrawing charges, arguing to sentence, and so on - prosecutors should briefly record the reasons for their decisions, since the recording of reasons tends to improve the objectivity of decisions. This would improve consistency of discretionary actions between cases, and may even provide better data upon which further studies of prosecutorial discretion in these cases can be tested.

An area that spans the responsibilities of prosecutors and police is the concern often expressed by fathers'-rights groups that false allegations of wife abuse are the weapon of choice, these days, of women seeking to obtain favourable divorce settlements or to cut off their exhusbands from access to their children. The topic is clearly an important one for lawenforcement officials at all levels to be aware of and to address. This is so not just because false accusations constitute criminal acts of mischief which divert badly needed time and resources from real crimes, but as well because they constitute the use of the state as a proxy assailant. False accusations of assault are themselves an assault (physically, when they result in the accused being manhandled into jail, including body searches) on the party thus accused. And yet awareness of this danger is not reflected in the standard publicity on partner abuse, including the literature of law-enforcement agents. It was unsurprising, then, that the ECPO files searched for this study contained little that would help to throw light on the extent of the problem. (Though a few files did in fact include notes from the investigating officer suggesting that the complainant was not credible for various reasons.) Falsely accused husbands may face as much official indifference as directly assaulted husbands. It is strongly urged, therefore, that efforts be made to (1) raise awareness of the problem at all levels of the justice system, and (2) keep records of actions taken to discover and deal with the problem.

\section{Recommendations for Police}

Police are the "gatekeepers" in the law-enforcement system. Almost everything that happens post-investigation depends critically upon the handling of the case by police. This means that police, too, must be scrupulously impartial and open-minded in handling of cases of partner violence. They must resist the kind of propaganda promoting ideological myths and stereotypes which was complained of under "Recommendations for Government Agencies" above. (See also Appendix C.) Evidently, a considerable amount of counter-conditioning sensitivity training to the issues of abuse of men - is needed at this point.

Police need to be made emphatically aware of the fact that roughly half of all incidents of partner violence involve mutual aggression, so that they can adjust their practice in dealing with these cases to more accurately reflect the actual phenomenon. In particular, they should genuinely and sincerely attempt to obtain both sides of the story before laying charges ${ }^{67}$ Where there is evidence of a mutual fight requiring charges, they should always lay charges against both parties, and let the courts determine who, if either, is guilty. Similarly, they should detain male

\footnotetext{
${ }^{67}$ As long as men are suspicious that police are biased against them, they are likely to "clam up" under questioning. It might be necessary, in order to get the suspects to talk more freely about what happened, to tell them that whatever they say before being advised of their Charter rights cannot be used in court against them.
} 
and female suspects on an equal basis. Since courts have no jurisdiction over persons not charged with an offence, or not taken into custody, they cannot fairly impose conditions in cases of mutual aggression when only one party is brought before them. Thus judges are only able to deal with half of the problem, and only men tend to be placed in legal jeopardy, in cases of mutual aggression. This problem needs to be rectified.

Police should be sensitive to the family-law implications of the actions they take in dealing with partner violence. They should be alive to the weapons of false allegations and denial of visitation, and lay charges in all cases where appropriate. (Denying court-ordered access of the children to the father is child abuse as much as it is ex-partner abuse. It needs to be recognized as such, and handled by the authorities as such.) When dealing with incidents that are in any way ambiguous, charges should be laid against neither party or both, and the courts should be left with the job of sorting out who is telling the truth.

Finally, police should collect and report more and better information about partner violence. In particular, along with other reasons given for not laying a charge, they should report when there was evidence the accusation was malicious. Also police should record who the caller or accuser was in each case: wife, husband, or third party. This will quickly reveal any pattern of taking one gender's complaints less seriously than the other's. Police should interview a sample of accused men, accused women, abused men, and abused women about how they feel they have been treated by police, and produce the results.

\section{Postscript}

Preliminary results from this study were released to the print media in September 2002, and generated a modest amount of publicity (see, e.g., Staples 2002). This researcher also appeared on three radio call-in shows at that time. The response from the general public has been uniformly supportive of the conclusions stated herein: $100 \%$ of the letters to the editor, and $100 \%$ of the callers to the radio shows, expressed wholehearted agreement. That includes support from retired police officers. As an articling student, this researcher has also had an opportunity to discuss his findings with many experienced, practising lawyers in the field of criminal and family law. Again, $100 \%$ of these private professionals expressed no surprise at all with the findings of this study. Indeed, the most common reaction was to say that anyone who had any experience with the system would probably consider a study such as this one to be superfluous.

The response of officialdom to date has been quite different. A spokesman for Alberta Justice, for example, expressed regret that this researcher had chosen to frame domestic violence as a "gender issue." The irony is thick, given that his own government department funds and supports the view that domestic violence is a gender issue (see Appendix $C$ for a particularly blatant current example of that). That spokesman also felt unconstrained to cast aspersions upon the academic integrity this researcher, saying that this study is the product of an ideologue who approached it with conclusions already in mind - even though he had never met the researcher, knew nothing about him, and almost certainly had not read the study itself. Regrettably, that kind of dishonest, shameful, ad hominem response to a serious academic study of an important social issue suggests that officialdom would rather circle the wagons than face their shortcomings squarely. 


\section{Appendix A \\ Codification and Limitations of ECPO Data}

What follows is a summary of the variables over which data was collected from the ECPO files (in italics), the possible values entered for each variable in brackets\}, and a discussion of the difficulties encountered in assigning values based on the information in the Crown files.

Variables relating to the accused and the circumstances of the offence

Gender of the accused \{male, female\}: The only complication in this category was the case or two involving "preoperative transsexuals." Since such an accused would have appeared to the law-enforcement system in her female identity, she was so classified.

Marital status \{married, cohabiting, separated or divorced\}: When couples were identified as married, this posed no codification problems. If marital status was not expressly noted in the police report, and the parties had different surnames, they were deemed to be "cohabiting." Common-law spouses and shorter-term cohabiting couples were not distinguished, and were classified as "cohabiting." Cases involving partners who had a history of repeatedly getting together and breaking up were classified as "cohabiting" unless it was clear that they had separate residences at the time of the incident. Cases where one of the parties had a no-contact order, but the couple had been making an unsuccessful attempt at reconciliation at the time of the incident, were classified as "separated."

Substance abuse by accused \{yes, no\}: Any evidence that the accused had consumed an intoxicating substance near the time of the incident resulted in "yes" being entered. To avoid inconsistency and subjective judgement as much as possible, "yes" was registered even in cases where the police reported that, although the accused had had a drink or two, he or she was "not intoxicated," or "alcohol was not a factor." (Only a few cases involved any intoxicant other than alcohol.) On the other hand, if the accused had failed to take prescribed medication for a psychiatric condition, then "yes" was also entered under the heading "substance abuse." If no mention was made of intoxication one way or the other, then "no" was entered.

Level of injury to the complainant \{none, low, medium, high\}: Categorizing injuries into only four levels posed one of the more difficult problems, and lead to a few disagreements between the researcher's judgement and that of the investigating officer. (The most dramatic difference of opinion appears in Case B, Appendix B.) "None" was entered where there was no physical contact - e.g. only threats were made - and also when the physical contact left only ephemeral traces - e.g. a grip on the arm or a slap to the face that left only a red mark. "Low" level injuries included minor bruises, abrasions, rug burns, scratches, hair-pulling, and reported soreness. "Medium" level injuries ranged from black eyes to less serious stab wounds, and included cases where the victim sustained many individually low-level injuries consistent with an extended (but not especially brutal) beating. "High" level injuries included the more serious stab wounds, broken or dislocated bones, internal injuries, or many individually medium-level injuries consistent with an extended and serious beating.

Weapon used by the accused \{none, household object, dangerous object, knife, gun\}: Where only physical force was used, "none" was entered. This included kicking incidents when shoes or boots might actually have been as likely to inflict harm as other "household objects." "Household object" was entered when some ordinary, readily available, and not inherently dangerous object was used - objects like dinner plates and coffee mugs, phones, lamps, and the like. "Dangerous object" was entered when the ad hoc weapon was inherently dangerous. This included vehicles, hammers, baseball bats, and the like. "Knife" included any sharp, piercing instrument, including scissors, kitchen knives, and glass shards. "Gun" is self-explanatory.

Children present $\{$ yes, no\}: If it was reported that children in the care of the couple were nearby when the incident occurred, "yes" was entered, even if they were not in the same room or were presumed to be sleeping. If children were not mentioned in the report, then "no" was entered. 
All prior-record categories $\{0-\propto\}$ : Criminal offences were divided into 9 categories, and a whole number was entered in each category corresponding to the number of prior convictions of the accused in that category. (The researcher found a number of cases where "no record" appeared on an accused in one file, while a record was produced in another file relating to the same accused in the same time period. Apparently, there are two ways to search for a prior record, and one method is more exhaustive than the other. Data in this category, while evidently not completely reliable, is reliable enough for the limited purposes of this study.) The 9 categories criminal offence that were codified were the following:

Unrelated: All offences that were apparently unrelated to personal-injury criminal offences fit into this category. These included thefts, break-and-enters, criminal driving offences, controlled-substance offences, etc.

Administrative offence: If the accused had failed to appear in court, or had breached probation relative to another partner violence charge, this was entered here. (In most cases, the nature of the underlying offence could not be determined, so most failures to appear and breaches of probation were classified as "unrelated" offences.)

Sexual offence: If the accused had a prior record for sexual interference or sexual assault, the number of prior convictions was entered here.

Uttering threats or criminal harassment: Any prior conviction for a Criminal Code s. 264(a) or s. 264(b) offence was entered here.

Assault: Any prior conviction for a Criminal Code s. 266 offence was entered here.

Assault causing bodily harm, or with a weapon: Any prior conviction for a Criminal Code s. 267(a) or s. 267(b) offence was entered here.

Aggravated assault: Any prior conviction for a Criminal Code s. 268 offence was entered here.

Unlawful confinement: Any prior conviction for a Criminal Code s. 279 offence was entered here.

Breach of a peace bond: Any prior imposition or breach of a peace bond was entered here.

\section{Variables relating to the response of the law-enforcement system}

Offences charged \{none, withdrawn, stayed, acquitted, pled guilty, convicted\}: Charges laid against those involved in partner disputes fell into the 15 categories listed below. If an accused was not charged with an offence, then "none" was entered under that variable. If the prosecutor stayed the charges, or if the accused pled guilty or was convicted, these outcomes were entered. Distinguishing between acquittals and cases of withdrawn charges posed a problem in the significant number of cases when witnesses failed to appear, claimed not to remember what had happened, gave inconsistent accounts or recanted their initial story, claimed the fight was consensual, and so on. In those cases, it was sometimes difficult to determine whether a case was dismissed because the prosecution had a fair opportunity to present its case and the judge acquitted, or because the prosecution had problems with a witness and would have withdrawn the charges due to "no reasonable likelihood of conviction" had he or she known that the witness would prove to be unreliable. Where there was a clear indication that the latter was the case, "withdrawn" was entered even though the accused may technically have been acquitted.

Weapons offence: This category includes improper use or storage of a weapon or ammunition.

Administrative offence: This category includes Criminal Code ss. 145, 733, and 811 offences.

Causing bodily harm by criminal negligence: This category includes Criminal Code s. 221.

Attempted murder: This category includes Criminal Code s. 239.

Overcoming resistance to the commission of a crime: This category includes Criminal Code s. 246.

Uttering threats or criminal harassment: This category includes Criminal Code s. 264(a) and s. 264(b).

Assault: This category includes Criminal Code s. 266.

Assault causing bodily harm, or with a weapon: This category includes Criminal Code s. 267(a) and s. 267(b).

Aggravated assault: This category includes Criminal Code s. 268.

Assaulting a police officer: This category includes Criminal Code s. 270.

Sexual assault: This category includes Criminal Code s. 271.

Unlawful confinement: This category includes Criminal Code s. 279.

Breaking and entering, with intent: This category includes Criminal Code s. 348.

Mischief: This category includes Criminal Code s. 430.

Entering into a peace bond: This category includes Criminal Code s. 810 . To impose a peace bond, a judge merely has to be "satisfied" that the complainant has reason to fear the respondent. One is not "found guilty" of a s. 810 "offence," nor does one "plead guilty" to it. Rather, a peace bond is either ordered against one, or one voluntarily agrees to the terms of a peace bond - but in either case, it is not a criminal conviction. However, violating the conditions of a peace bond is a Criminal Code s. 811 offence. These offences are lumped together with s. 145 and s. 733 offences, since they are similar in nature and generally bear the same level of penalty. 
Pre-trial restrictions \{none, short incarceration, jail to trial\}: "None" was entered in those cases when the accused was released at the time of the charge on a Promise to Appear. "Short incarceration" was entered when the accused was taken to the holding cells and released on bail soon after. "Jail to trial" was entered when the accused was denied bail. In the few cases where the accused was initially denied bail, but successfully appealed for release subsequently, "jail to trial" was entered unless it could be determined that the release was closer to the time of the arrest than to the trial. (Conditions of bail were not recorded.)

Jail sentence $\{0-\propto\}$ : A whole number representing the number of months of imprisonment was entered (rounded to the nearest month in cases when this was less than 1). Note: this number does not include "time served."

Conditional sentence $\{0-\propto\}$ : A whole number representing the number of months of a conditional sentence.

Probation $\{0-\propto\}$ : A whole number representing the number of months of probation.

Fine $\{\$ 0-\$ \propto\}$ : The dollar amount of any payments imposed, including fines, restitutionary awards, victim surcharges, and the like.

Other \& Another \{absolute discharge, conditional discharge, none, no-contact order, counselling, community service, weapons prohibition, submit to providing a DNA sample\}: These are miscellaneous categories for noting any other aspects of the sentence recorded in the prosecutors' files.

The fundamental problem with studies of this nature is that most of the information about the underlying events is gleaned from police reports, and unfortunately police reports are frequently based on the account of only one witness, namely the complainant, who is an interested party to the events. ${ }^{68}$ Often, police reports are an almost word-for-word recounting of the story as told by the complainant, which is an unreliable practice when there is little or no corroborating evidence of what had transpired by the time the police arrive. General knowledge of human nature leads one to suspect that, when emotions are running high following a physical encounter, the complaining parties will often embellish their story by exaggerating the actions of the accused and diminishing or even failing to mention at all their own role in the dispute (see Case $\mathrm{C}$ in Appendix B). The sociological data indicate that about half of all violent disputes involve mutual aggression, so the practice of taking one party's word as a true account of events is not safe investigative practice by the police in most cases. Part of the problem is that the law slants the playing field heavily in favour of the party making the complaint, and women are more likely to complain to authorities than men are. The party initially complained about, being a suspect in a criminal investigation, is well advised to say nothing to the police that could be used against them in court; most often, suspects heed this advice. The probable result is that many instances of mutual ("consensual") aggression end up being recorded by the police as an unmitigated assault on the woman only.

Since the primary focus of the analysis of the ECPO data is the differential exercise of prosecutorial discretion between male and female accuseds, it might be thought that the problem of unreliable (one-sided) police reports can be ignored. The question is whether prosecutors exercise their discretion even-handedly as between men and women who are charged with partner violence, given the information available to them. But this is simplistic. Prosecutors must be alive to the problem of unreliable police reports, and should exercise their independent judgment when handling files that contain little information beyond what the complainant asserted at the time of the incident. In particular, because of the very real possibility of false or

\footnotetext{
${ }^{68}$ The terms 'complainant' and 'victim' are used in police reports even in cases where the person referred to insists at the time of the incident that it was not the accused's fault and that she did not want to have him charged. (See, for example, Case E in Appendix B.)
} 
embellished accusations, it should not be assumed that whenever a complainant changes his or her story the later version of events is less accurate.

Another major difficulty with research relating to prosecutorial discretion is that the most important ways in which prosecutors influence law-enforcement outcomes are typically not amenable to objective codification. Prosecutors exercise their discretion mostly in rather subtle ways that leave behind no documentary evidence. They have influence over legal outcomes when deciding whether or not to withdraw or stay charges, what plea bargains to accept or reject, how vigorously to pursue witnesses in order to get a conviction, and through their submissions on sentencing. But while an impressionistic sense of how prosecutors exercise their discretion in these matters can be obtained from reading enough files, collecting hard statistical data to confirm these impressions is not a simple matter. Differences in the way prosecutors may exercise their discretion when dealing with male and female accuseds can only be inferred from certain outcomes; and there is a possibility that the outcomes can be explained in other ways.

Consider the decision whether to pursue charges to trial, or conversely to withdraw or stay them. What can be determined objectively is the frequency of charges being withdrawn or stayed for men and women who are charged with an offence; but differences in frequency can be explained in at least two ways. Perhaps prosecutors, influenced by stereotypical attitudes of chivalry toward the "weaker sex," pursue female offenders less vigorously; or conversely, perhaps male victims are more likely to be hostile witnesses, making the pursuit of female offenders more difficult for prosecutors and resulting in more withdrawn charges against them. In order to test these two hypotheses directly, the prosecutor's (honest) reasons for withdrawing charges would have to be recorded, which they typically are not. Furthermore, even if objective data were collected that showed male victims to be less willing to testify against their attackers, prosecutors also exercise discretion in how vigorously they pursue witnesses in order to convince them to testify in court. One would have to examine telephone records and monitor private conversations in order to determine whether prosecutors more vigorously pursued witnesses for one gender or the other - obviously a project of a different order from the present study.

Plea bargaining presents similar problems, since it is not a formalized process that leaves behind documentary evidence in most cases. In many cases, bargains are struck just prior to trial, depending on what witnesses appear in court that day. Nothing is recorded of the discussions that take place between prosecutor and defence counsel at these pre-trial conferences, so there is no way for a researcher, looking only at the files, to determine whether stereotypical thinking plays a direct part in the bargaining outcome. The best that can be done is to determine whether, overall, plea bargains for female offenders are more or less lenient than for similar male offenders - and again, there may be several alternative explanations for this. The same problem afflicts submissions on sentencing. These are oral and leave no documentary evidence in the file beyond the result, which is as much attributable to the judge and defence counsel as to the prosecutor.

Compared to the limitations imposed by the nature of the available information in prosecutors' files, limitations due to the accuracy of information are minor. Nevertheless, it should be recalled that many discrepancies within files, and between files and other sources of information, were observed in several areas. Information on the suspect's prior criminal record was sometimes inconsistent; the sentence imposed was sometimes incompletely recorded in the 
file by the prosecutor; and the computer-generated list of "spousal abuse" cases was not even completely accurate, as noted elsewhere. While files where the researcher positively identified these sorts of problems were generally eliminated from the sample, the existence of these errors in some files raises a question about the accuracy of the information in other files where no clear discrepancy was found. Finally, it is important to note that in those cases where the accused was charged with more than one count on a single Criminal Code section, only one count was entered, since entering multiple charges would have doubled or tripled the number of variables for the sake of capturing complete information in only a relatively few cases. Likewise, when more than two miscellaneous penalties were applied, only the most punitive were entered in the "Other" and "Another" categories. Substance-abuse and anger-management counselling were so commonly ordered that these were not even consistently recorded in the files.

Given more time and resources, the following kinds of information might have proven useful to collect and analyse. Many suspects had a history of being charged with offences without being found guilty of them; so perhaps the number of charges faced, rather than prior criminal record, might have been a more revealing variable if it could have been consistently collected. In the category of "injury to the complainant," a value indicating the risk of serious harm would prove helpful to deal with cases that involved inherently highly risky attacks which happened to result in only low-level injuries. (Choking to the point of losing consciousness, and attacks on pregnant women, are examples of acts in this class.) Recording the age of the accused would have helped to distinguish between suspects who had accumulated extensive criminal records over decades rather than in only a few years. Being able to separate out cases where the complainant was intoxicated, and where both parties had been charged, would have permitted further interesting analyses with respect to contributory or mitigating factors in assaults. In a number of cases, the accused had disabled the telephone at some point in the attack, thus increasing the risk to the victim, which might be reflected in the sentencing. And it obviously would have been helpful if reasons for withdrawing charges, and for dismissals, were more consistently recorded in the files and studied. 


\section{Appendix B \\ Illustrative Cases}

Case A: A female ex-partner with a prior criminal record was charged with 7 counts of violating no-contact orders (terms of probation and terms of peace bonds), after prowling around the complainant's home and causing mischief (making threats, slashing tires, etc.) on at least three separate dates. She was apprehended by police on each occasion. The complainant's written statement indicated that all of these infractions had been videotaped, and that independent witnesses would be available to testify. A trial date was set; yet the charges were dropped without any indication why in the file.

Case B: The suspect was a woman with a prior record for violating a no-contact order with respect to the same complainant only a month prior to the incident in the sample period. She had allegedly attacked her ex-partner's genitals with a knife. Police noted blood in several rooms in the house, and on the groin area of the victim's track-pants. The victim was attended by EMS at the scene, and taken to hospital for treatment. There was no follow-up report by the police. The injury was described on the police reporting form as "minor" and the accused was charged with assault with a weapon (s. 267(B)) - not with aggravated assault (s. 268), sexual assault (s. 272), or even aggravated sexual assault (s. 273). She was convicted of only a weapons offence (s. 88) and violating a no-contact order (s. 145), presumably because the victim failed to appear.

Case C: The female complainant reported to a local police station, providing a written statement about a recent incident with her husband. There was no mention in her statement of any assault she may have committed in the incident; according to her statement, he was the only aggressor. After a police investigation, it was determined that she had initiated the fight while he was driving (and therefore relatively defenceless), and that he had suffered the greater injuries. She was charged with the higher offence (s. 267(A) - assault causing bodily harm) in the end, but he was still charged with assault (s. 266) for what appeared to be clearly self-defence.

Case D: The female "complainant" provided a written statement to the defence lawyer which included the following information. She had told the investigating officers at the time of the incident that she was well known to the police in another part of the city where she previously lived, so they should consult with Officers $\mathrm{X}$ and $\mathrm{Y}$ to verify her story. Her story was that she had been diagnosed with a multiple-personality disorder. When she drinks, a man-hating personality comes out, which is what happened in this instance: she had attacked the accused, and he was merely defending himself. She had attacked this particular partner, who was described as very supportive, several times in the past as a result of drinking and not being on her medication. Despite this, the case against the man proceeded to trial; he was acquitted.

Case E: A woman was charged with assault with a weapon (s. 267(B)) after breaking a broom handle over her partner's head. No detailed report of the injuries was provided. She pled guilty to assault (s. 266), and was fined $\$ 250$.

Case F: A mutual fight resulted in the man receiving greater injuries. The woman had a more extensive prior record, yet the police recommended that she be released on a money bail, while recommending that he be denied bail - on the ground that he had a prior criminal record. 
Case G: A note on a police officer's business card, in the file of female accused, stated: "I know you are new to prosecution, but it is a courtesy to discuss the matter with the arresting officer before you withdraw charges for no apparent reason."

Case H: Sometimes disparities in treatment become apparent because of the chance juxtaposition of two strikingly similar cases. The following two files were found one after the other: (a) A woman who inflicted a high-level injury on her husband with a knife in the presence of their children was charged with aggravated assault (s. 268) and a weapons offence (s. 88), pled guilty to assault with a weapon (s. 267(B)), and was given a 24-month conditional sentence (with community service and counselling ordered). (b) A man who merely threatened his partner with a knife but caused no injuries was charged with a weapons offence (s. 88), breach of a term of probation (to abstain from alcohol consumption - s. 145), uttering threats (s. 264(A)), and assault with a weapon (s. 267(B)). He pled guilty to the latter three offences, and was given a 6-month jail term plus 24 months probation. (Both accuseds were taken into custody and denied bail.) The only factor supporting a higher sentence in the man's case was that he had two prior convictions for assault, possibly against the same victim. In contrast, the woman had four prior convictions on unrelated offences, including two prior convictions for failing to appear in court for earlier domestic violence charges of which she was evidently acquitted.

A Day in Provincial Court: The researcher attended Provincial Court one day to observe firsthand how domestic violence cases are handled. Coincidentally, two female-offender cases were on the docket that day. Prior to the commencement of proceedings, the prosecutor met with a police officer and the male victim in one of these cases. The male victim indicated that he was prepared to testify; indeed, he was eager to do so: he had brought with him audio-taped evidence of the conversations he had had with the accused immediately prior to the assault taking place, as well as other documentary evidence relating to the nature of the relationship between the parties. (He was told that none of this could be used, presumably due to pre-trial disclosure requirements. Given that the recordings had been mentioned in the victim's written statement in the prosecutor's files, it is a mystery why he had not obtained this evidence prior to trial, and disclosed it to the defence. Would such a casual approach to documentary evidence have been taken in the case of a male offender?, one wonders.) The police officer provided photographs of the male victim that were taken at the station immediately after the incident. The photographs revealed two black eyes and a 2-3 inch gash on the victim's wrist. The accused was charged merely with assault (s. 266), the allegation being that she held her husband down and restrained him while her boyfriend administered a beating upon him in the presence of their children.

When this case was called, the accused rose to make her way to join her defence counsel at the front of the courtroom. Almost immediately, and without prompting, the judge intervened to ask the prosecutor whether the case could not be disposed of by way of an agreement on a peace bond. The prosecutor indicated that the witnesses were present and wanting to testify; but if the judge insisted, then he would try again to reach an agreement. The parties then left the courtroom for about 45 minutes of consultation, and returned to announce an agreement on a peace bond. (The prosecutor told me later that the defence had brought the young daughter to court to testify on behalf of the mother, and this leverage had been used to convince the father not to force a trial. Apparently, the couple had separated following this violent incident, the mother receiving interim custody of the children.) 
The second case observed by the researcher that day involved a woman who had returned home one night in a drunken state. She was unable to find her cab fare, and got into an argument with the driver. After leaving the cab without paying, she scratched and dented his vehicle, then entered the home where her partner was caring for her deaf, 4-year-old son (from a previous relationship). For reasons that were not clear, she then became belligerent toward her partner, and was in the process of assaulting him when the police arrived, presumably in response to the cab-driver's complaint. Since the cab driver had appeared as a witness, but not the (now former) partner, the woman was convicted of a property-damage offence and ordered to make restitution, but was acquitted of the assault charge and merely given a stern lecture about being a better role model for her disabled son.

\section{A Case Study}

The following story illustrates very clearly that men, too, face problems in relation to reporting partner violence, and are inclined to cover it up when it happens. It also illustrates how observers tend to regard violence against men as justified in circumstances where equivalent violence against women would be deplored. The non-response of the authorities, even when the abuse is known to them, also deserves notice.

\section{Is There a Batterer in the U.S. Senate? by Glenn Sacks}

CNSNews.com Commentary, May 07, 2002

There is a batterer in the United States Senate.

This abuser's spouse has suffered repeated violent attacks, yet there has been no condemnation of this Senator's violence. Ironically, this Senator, who is one of the most controversial people in American public life today, has somehow escaped reproach for the one thing that both detractors and admirers should agree is genuinely inexcusable - domestic violence.

Who is this perpetrator of domestic violence? New York Senator Hillary Clinton.

The evidence against Ms. Clinton is strong. According to Hillary's admiring biographer Gail Sheehy, author of Hillary's Choice, one of the domestic assaults upon Bill Clinton occurred in 1993, when Hillary slashed Bill Clinton's face with her long fingernails, leaving a "mean claw mark along his jawline."

The incident was first explained as a "shaving accident" and a subsequent attempt was made to pin the blame on Socks the cat. Because of the gouge's size, neither explanation was accepted by observers. Dee Dee Myers, the White House spokeswoman at the time, later explained to Sheehy that it had been singer Barbara Streisand's visit to the White House that had sparked Hillary's jealous, violent rage.

According to Christopher Andersen, author of Bill and Hillary, Hillary also assaulted Bill on August 13, 1999, after the Monica Lewinsky revelations. Andersen writes:
"[T]he President... weeping, begged her forgiveness. Much of what transpired next between Bill and Hillary Clinton was plainly audible to Secret Service agents and household staff members down the hall. In the past, Hillary had thrown books and an ashtray at the President - both hitting their mark... Hillary rose to her feet and slapped him across the face - hard enough to leave a red mark that would be clearly visible to Secret Service agents when he left the room.

“' 'You stupid, stupid, stupid bastard,' Hillary shouted. Her words, delivered at the shrill, earsplitting level that had become familiar to White House personnel over the years, ricocheted down the corridor."

Sheehy's account of the incident is similar, adding that Hillary's friend Linda Bloodworth-Thomasen, who was staying with her husband in the private quarters nearby, "thought it was great that Hillary 'smacked him upside the head.'"

The U.S. Department of Justice's Office for Victims of Crime classifies these types of attacks scratching, slapping, hitting, throwing objects, and inflicting bruises or lacerations - as "physical abuse" and domestic violence.

Bill Clinton handled the incidents in a manner eerily reminiscent of the way many female victims of domestic violence did in the pre-feminist era. Ashamed, he tried to cover the incidents up, even ordering his representatives to publicly alibi his wife's violence. He probably blamed himself for "provoking" her, as if marital infidelity warrants physical assault. 
And he almost certainly never considered calling the police or formally charging his abuser.

The public's reaction has been of the "what did he do to set her off?" variety - a "blame the victim" mentality that would immediately be recognized and condemned were the genders of the perpetrator and victim reversed. Media coverage of the incidents has almost entirely consisted of jokes on late night TV and talk radio. In narrating these assaults, neither Sheehy nor Andersen mention 'domestic violence' or even write disapprovingly of Hillary's attacks. Needless to say, the reaction would be quite different were it the president's wife who appeared in public with lacerations on her face.

Nor were the incidents mentioned during Hillary's 2000 Senate campaign. In fact, it was former New York Mayor Rudy Giuliani who was publicly pilloried as a bad spouse for his failing marriage, while the fact that his electoral opponent was a known abuser merited little or no mention.

The Clinton incidents demonstrate that, despite the overwhelming body of research which shows that men and women initiate and engage in domestic violence equally, the public still largely holds the outdated and discredited view that domestic violence is synonymous with wife-beating.

Ironically, Senator Clinton herself has spoken out on domestic violence on many occasions, and has supported the Family Violence Prevention Fund's \$100 million anti-Domestic Violence campaign. The campaign's slogan is “There's No Excuse for Domestic Violence."

What's Senator Clinton's excuse?

Copyright 2002, Glenn J. Sacks

When even the most powerful man in the world feels powerless to defend himself against repeated spousal assaults, it is not difficult to imagine men lower down on the social scale feeling helpless, misunderstood, and unsupported by the authorities in their dealings with abusive female partners. 


\section{Appendix C \\ Critique of "Our Community Response to Domestic Violence"}

Recently, the "Domestic Violence Action Team" in the City of Lethbridge produced a 106-page "manual" entitled Our Community Response to Domestic Violence. ${ }^{69}$ This manual was sponsored by two separate divisions of Alberta Justice, the City of Lethbridge, Lethbridge Police Services, Lethbridge Family Services, YWCA Harbour House (a women's shelter), and the Chinook Health Region. It therefore has the imprimatur of official policy. Yet, merely to cite from the manual is to critique it - it is so patently biased, ideological, and counter-productive.

Among the 19 "Guiding Principles" of the manual (pp. 2-3) are these:

- The safety of women and children is of primary importance.

- All women and children who experience family violence shall immediately be offered a safe environment.

- The continued safety of women and children remains paramount and, upon completion of the criminal court process, all resources that were made available to assist them through the legal process shall continue to be available to them.

- Upon disclosure of family violence women shall be contacted by a Treatment Co-ordinator within 48 hours.

- Psycho-educational groups, treatment groups and individual counselling will be available to all women who have disclosed violence in their family.

- Women shall be provided with long-term support through the criminal legal process. Support shall include court preparation and may include assistance with civil restraining orders.

In case anyone should get the impression that the Domestic Violence Action Team is insensitive to the fact that men, too, experience domestic abuse, the final "guiding principle" is this:

- The community [sic: committee?] recognizes that men can also be victims of family violence but the wording of this manual focuses on women because the majority of cases are men abusing women and, because men are bigger and stronger, male abuse of women has more serious consequences.

And just in case this point is missed, it is repeated in bold print, preceded by an asterisk, and with exaggeration, on the following page:

- The vast majority of abuse occurs against women and children. The committee acknowledges that abuse against men does occur, however the dynamics may be different.

So the gender-exclusive focus of the manual is not inadvertent; it is deliberate.

The Domestic Violence Action Team's rationale for focusing exclusively on women and children is patently false and sexist. It is false that the "vast majority" of abuse occurs against women and children; in fact, men and children are equally likely to experience abuse in general; and in a not-insignificant minority of cases, men also experience serious violence from their partners. With the aid of weapons (as this study shows), women are quite capable of inflicting

\footnotetext{
${ }^{69}$ The document is undated, but the beginnings of the report are traced back to "the early summer of 1995" (p. 3). (The probable date of publication is 2001.) Authorship of the document is also unattributed to any individual(s).
} 
serious harm upon their partners. Nor is there any sound empirical evidence to support the suggest that the "dynamics may be different" between male abuse and female abuse. The evidence from the present study, though inconclusive, suggests quite the opposite, in fact. To dismiss that much abuse against men as being of no particular interest is to condemn the authors as ideological bigots. ${ }^{70}$

It is not that the Domestic Violence Action Team completely ignores men. Here are a few of the "guiding principles" that are directed to men:

- All abusers shall be held accountable for their actions.

- The process for abusers shall include mandatory arrest and court appearances.

- In addition to any other provisions imposed by the courts, there should be ordered a sufficient period of court supervised probation to monitor ongoing conduct and attendance in ordered treatment programs.

Based on the data in the present study, this is clearly overkill. Abuse is a wide-ranging phenomenon, from verbal and emotional abuse to murder. Women are just as capable and just as willing as men to inflict the more widely practised forms of "minor" abuse. A genuinely genderneutral "zero tolerance" policy for these incidents would dramatically increase the rates at women are charged and tried for domestic abuse offences. Instead, a "healing" approach to minor abuse incidents might have a more positive impact on both male and female abuse. With regard to probation, it is simply unrealistic to suggest that this is necessary in the majority of cases which do not involve serious injury.

Tipping its ideological hand, the Domestic Violence Action Team claims (at p. 4) that:

Woman abuse occurs because of the pervasive intent and desire of a male to assume power and control over his partner. This continual control places the woman in a position where she is terrified, uncertain, without choices about her life and ultimately unable to escape the situation, due to physical and/or sexual danger and emotional trauma. This reality is played out continually in a cycle that repeats itself over and over.... ${ }^{71}$

Perhaps the two manslaughter cases that were found but not analysed in the present study might have go some way to approaching this dire scenario, but it would be a very long stretch to say that the picture of domestic abuse painted above is anywhere near the norm. As indicated above, the supposedly exclusively male motive to "assume power and control over his partner" is a stereotypical and ideological assumption - a myth - rather than a reality in the vast majority of

\footnotetext{
${ }^{70}$ Anyone who suggested that the experience of blacks in Canada can be safely ignored because the vast majority of abuse occurs against whites, and because the dynamics of abuse against blacks may be different (for all that is known to the contrary), would be vilified for their abhorrent bigotry. There is no disparity between these cases.

${ }^{71}$ They continue: "Woman abuse is a societal problem, which manifests itself as a man's belief he has the right to have power and control over his partner," and "The goal of intervention is to empower women...." This one-sizefits-all theory is reiterated and expanded upon at pp. 7-8 ("Dynamics of Abuse"). The manipulative tactic employed by the authors of the manual is to present only the most dire scenarios to engage the sympathies of the reader scenarios that are reflective of at most $1 \%$ of cases - and then claim that domestic abuse is pervasive based on studies which include "all acts" of abuse, including very minor and isolated ones. The reader is left to infer that the problem is both as pervasive as the latter statistics indicate, and as serious as the former scenarios suggest. An astute reader will notice that, although "research" of this and "knowledge" of that is alluded to throughout the manual, no actual studies are ever cited. It is evidently intended as a training manual, not an academic treatise; but that hardly excuses the making of alarmist claims without any empirical support whatsoever.
} 
cases. Indeed, men probably resort to violence just as often as a means of regaining control in a relationship in which they feel emotionally manipulated or harassed by their partners. Another myth that is promoted in the quoted passage is that domestic violence, being male, is frequently sexual in nature. It simply is not. The general point, though, is that motives cannot be reduced to a simple formula in this, as in nearly all human relationships and interactions.

Likewise, the Domestic Violence Action Team takes as its premise that "a woman is not responsible for her partner's behaviour" (p. 5). This is facile. Human interaction is precisely that: an interaction, often involving perfectly predictable responses when an unwelcome initiative is taken. Even when provocation does not meet the legal standard of an outright excuse or a mitigating circumstance, it may still be highly imprudent. To suggest that women never provoke abuse, or when they do they should never be criticized for it, is to treat women like children.

With respect to intervention, agencies are directed to "believe her experience and respect her as an expert on her own experience," and to "value and help her to value whatever she has done or felt has allowed her to survive" (p. 6). In other words, police officers and others involved in the aftermath of an abuse incident are not to question the veracity of anything a female complainant says about it; nor are they to lay charges against her when she has participated in a fight if retaliation or even a pre-emptive strike is what she "felt" she had to do to "survive." This is not only blatantly sexist procedure; it is counter-productive. Any competent defence lawyer who is aware of police and other agencies following these procedures will have a field day discrediting the "evidence" so obtained. Police and others must maintain objectivity; they must not take sides, especially not based on ideological and sexist myths and stereotypes promoted by training manuals such as this one.

Contradicting what was said previously about believing her experience and respecting her as an expert on her own experience, the Domestic Violence Action Team later warns police: "At times the woman may be extremely fearful, withdrawn, defiant or supporting the abuser. This should not be interpreted as a lack of co-operation by the woman, but rather as indicators that she is extremely fearful about her safety" (p. 15). In other words, only believe the woman when she is alleging to have been the victim; never believe her when she suggests otherwise. The Domestic Violence Action Team is evidently of the view that men are to be presumed guilty until proven otherwise. If that sounds like an exaggeration, consider the recommendation on the following page: "It is often in the women and children's best interest to remain in the security of their home, if this can be achieved safely. The most effective means of achieving this is through removing the offender, as he is the one responsible for the assault." There's not even a pretence of innocence until proven guilty - the word "alleged" isn't in the vocabulary of the Domestic Violence Action Team.

It is beyond the scope of this report to critique the Domestic Violence Action Team's manual exhaustively. Suffice it to say that it continues in the same naïve, ideological, selfdefeating, and blatantly sexist manner for another 90 pages. One should not lose sight of the fact that this document was produced with the support of two separate divisions of Alberta Justice, the City of Lethbridge, Lethbridge Police Services, Lethbridge Family Services, and the Chinook Health Region. These governmental agencies should be embarrassed and ashamed. 


\section{References}

Archer, John (2000). "Sex differences in aggression between heterosexual partners: A metaanalytic review,"Psychological Bulletin, vol. 126, no. 5, pp. 651-680.

Uabry, Jack (2002). "Canadians say custody laws biased: Legal system tilted against fathers in divorce settlements, poll respondents say," Ottawa Citizen, 9 August. (Reprinted in the Edmonton Journal, p. A16.)

Bachman, Ronet and Linda Saltzman (1995). "Violence against women: Estimates from the redesigned survey," Bureau of Justice Statistics Special Report, U.S. Department of Justice.

Bland, Roger, and Helene Orn (1986). "Family violence and psychiatric disorder," Canadian Journal of Psychiatry, vol. 31, pp. 129-137.

Blumner, Robyn (1999). "Domestic abuse law stereotypes men as brutes and women as victims," St. Petersburg Times, Dec. 10.

Brinkerhoff, M., and E. Lupri (1988). "Interspousal violence," Canadian Journal of Sociology, vol. 13 , issue 4, pp. 407-434.

Brown, Grant A. (2000). "Is Justice Blind? Sex as a factor in sentencing," unpublished term paper produced for Justice Jack Watson in a course on criminal sentencing, Faculty of Law, University of Alberta.

Brown, Mareva (1997). "Arrests of women soar in domestic violence cases," Sacramento Bee, Dec. 7.

Browning, J., and D. Dutton (1986). "Assessment of wife assault with the Conflict Tactics Scale: Using couple data to quantify the differential reporting effect," Journal of Marriage and the Family, vol. 48, pp. 375-379.

Buzawa, Eve, and Thomas Austin (1993). "Determining police response to domestic violence victims," American Behavioral Scientist, May.

Daisley, Brad (1999). “Assault prosecutors fear interest groups," The Lawyer's Weekly, February 19.

DeKeseredy, Walter S. et al. (1997). "The meanings and motives for women's use of violence in Canadian college dating relationships: results from a national survey," Sociological Spectrum, vol. 17, pp. 199-222.

Fallen, David L. (1987). "Sentencing Practices under the Sentencing Reform Act," Sentencing Guidelines Commission for Olympia, Washington.

Farrell, Warren (1993). The Myth of Male Power, Simon \& Schuster. 
Fekete, John (1994). Moral Panic: Biopolitics Rising, Robert Davies.

Fiebert, Martin (1997). "References examining assaults by women and their spouses/partners," Sexuality and Culture, vol. 1, Transaction Publishers, pp. 273-286.

Follingstad, Diane R. et al. (1991): "Sex Differences in Motivations and Effects in Dating Violence," Family Relations 40, January, pp. 51-57.

Gelles, Richard J., and Murray A. Straus (1988). Intimate Violence, Simon and Schuster.

Glaeser, Edward L. and Bruce Sacerdote (2000). "The determinants of punishment: Deterrence, incapacitation and vengeance," Working Paper 7676, National Bureau of Economic Research, Cambridge, MA.

Goldberg, Carey (1999). "Spouse abuse crackdown, surprisingly, nets many women," New York Times, Nov. 23.

Gregorash, Leslie (1990). Family violence: An exploratory study of men who have been abused by their wives, unpublished M.A. thesis, University of Calgary.

Grandin, E., and E. Lupri (1997). "Intimate violence in Canada and the United States: a crossnational comparison," Journal of Family Violence, vol. 12, issue 4, pp. 417-443.

Johnson, M.P. (1995) "Patriarchal terrorism and common couple violence: Two forms of violence against women," Journal of Marriage and the Family, vol. 57, pp. 283-294.

Julian, Frank H. (1993). "Gender and crime: Different sex, different treatment?" in Female Criminality: The State of the Art, Concetta C. Culliver, ed., Garland.

Kent, Gordon (2002). "Nasty drunk' didn't want dog licking blood of man she killed," Edmonton Journal, 6 December 2002, B3.

McLeod, Maureen (1984). "Women against men: An examination of domestic violence based on an analysis of official data and national victimization data," Justice Quarterly, vol. 1, pp. 171-193.

Minister of Industry, (1999). Canadian Crime Statistics 2000, Statistics Canada catalogue no. $85-205$.

Minister of Industry, (2001). Canadian Crime Statistics 2000, Statistics Canada catalogue no. 85-205.

Ministry of the Attorney General (1996). Survey of Spousal Assaults Reported to Police in 1993-94 in British Columbia, Public Safety and regulatory Branch, Police Services Division, December. 
Ministry of the Attorney General (1999). Survey of Spousal Assaults Reported to Police in 1995 in British Columbia, Public Safety and regulatory Branch, Police Services Division, April.

Mirrlees-Black, C. (1999). "Findings from a new British Crime Survey self-completion questionaire," Home Office, London.

Morton, F.L and Rainer Knopff (2000). The Charter Revolution and the Court Party, (Broadview Press).

Ogrodnik, Lucy, and Catherine Trainor (1997). An Overview of the Differences between PoliceReported and Victim-reported Crimes, Statistics Canada catalogue no. 85-544-XPE, Minister of Industry Canada.

Paciocco, David M. (1999). Getting Away with Murder, Irwin Law.

Pottie Bunge, Valerie, and Daisy Locke, eds. (2000). Family Violence in Canada: A Statistical Profile, Statistics Canada catalogue no. 85-224-XIE, Minister of Industry Canada.

Selick, Karen (2001). “The Guidelines: Myth and F.A.C.T.,” Canadian Lawyer, January.

Shupe, Anson et al. (1994). The Violent Couple, Praeger.

Sommer, Reena (1994). Male and Female Partner Abuse: Testing a Diathesis-Stress Model, unpublished PhD Dissertation, University of Manitoba.

Sommer, Reena, G.E. Barnes, and R.P. Murray, (1992). "Alcohol consumption, alcohol abuse, and female perpetrated spouse abuse," Personality and Individual Differences, vol. 13, issue 12 , pp. 1315-1323.

Staples, David (2002). "Husband abuse: The flip side," Edmonton Journal, 13 October, pp. D3 $+\mathrm{D} 8$.

Straus, Murray (1993). "Physical assaults by wives: A major social problem", Current Controversies on Family Violence, Richard J. Gelles and Donileen R. Loseke, eds. (Sage Publishers), pp. 67-87

Straus, Murray (1999). "The Controversy Over Domestic Violence by Women," in X.B. Arriaga \& S. Oskamp, eds., Violence in Intimate Relationships, (Sage), pp. 17-44.

Straus, Murray, and Richard Gelles, (1989). Physical Violence in American Families: Risk Factors and Adaptations to Violence, Transaction Books.

Szinovacz, M.E., and L.C. Egley (1995). "Comparing one-partner and couple data on sensitive marital behaviours: The case of marital violence," Journal of Marriage and the Family, vol. 57, pp. 995-1010. 
Trainor, Catherine, ed. (2002). Family Violence in Canada: A Statistical Profile, Statistics Canada catalogue no. 85-224-XIE, Minister of Industry Canada.

Trainor, Catherine, and Karen Mihoran, eds. (2001). Family Violence in Canada: A Statistical Profile, Statistics Canada catalogue no. 85-224-XIE, Minister of Industry Canada.

Trickey, Mike (2002). "Women unsuited to combat duty, U.K. Study argues," Edmonton Journal, 5 August, pp. A1 + A3.

Tutty, Leslie (1999). Husband abuse: An overview of research and perspectives. (National Clearinghouse on Family Violence).

Verburg, Peter (1996). “Equal rights in Winnipeg,” Alberta Report, Feb. 12, pp. 22-23.

Walker, Lenore (1979). The Battered Woman (Harper Collins).

Warwaruk, Jody (2002). "The first year free is a time of danger for abused women," Edmonton Journal, 11 May, p. B3

Young, Cathy (1999). Ceasefire!, Free Press. 


\section{Acknowledgements}

This study derives from an Independent Research Project which was prepared in fulfilment of course requirements for the Faculty of Law, University of Alberta, under the academic supervision of Professor Wayne Renke. He deserves thanks for accepting such a "politically incorrect" project proposal as this. In addition, the Edmonton Crown Prosecutor's Office deserves kudos for boldly and enthusiastically opening its doors - and its files - to a curious academic. The cordial co-operation of prosecutor Dave Hill, under whose supervision the researcher collected the data for this study, was especially appreciated. He was able to clarify many details about the workings of the criminal-justice system that otherwise would have remained mysterious to a third-year law student. Cheryl Gillan, Public Assistance Co-ordinator in the Crown Prosecutor's Office, was invaluable in tracking down missing data and hard-toidentify Court of Queen's Bench files relating to partner violence - without which this study would have been more limited than it ended up being. Finally, Professor Terry Elrod provided indispensable advice in relation to the statistical analysis contained in this study.

A special note of thanks must go to Professor Emeritus Ferrel Christensen, President of both the Movement for the Establishment of Real Gender Equality (MERGE) and the Gender Issues Education Foundation (GIEF) of Edmonton. Professor Christensen acquired and made available to me the EPS data-set which was the subject of analysis in Part $A$ of the Results. His vast knowledge of and experience with this area saved the researcher a great deal of time tracking down useful information and bibliographical sources. Through many discussions over the years, he has also helped me to understand what data needed to be collected and analysed in this study. Perhaps most importantly, Professor Christensen has provided invaluable and continuous moral support throughout the 2-year process from conception to birth of this project.

\section{About the Author}

Grant A. Brown holds a B.A. (Honours) and an M.A. in Philosophy from the University of Waterloo, a D.Phil. in Philosophy from Oxford University, and an LL.B. from the University of Alberta. He taught applied and theoretical ethics and political philosophy in the Faculty of Management and in the Philosophy Department at the University of Lethbridge, Alberta, from 1990 to 1999 . He is currently a student-at-law in Alberta.

Dr. Brown has researched, written, and published extensively on the ethical and legal aspects of gender issues, particularly on the topics of employment equity and family matters. Although he has never been married and has no children, he does have 2 brothers, 4 sisters, 13 nieces and nephews, and his parents celebrated their $50^{\text {th }}$ wedding anniversary in 2002.

Grant A. Brown, D.Phil. (Oxon), LL.B.

Edmonton, Alberta.

Canada.

(780) 433-1505

grant.brown@shaw.ca 